Portland State University

PDXScholar

5-5-1989

\title{
Chinese Voices: Towards an Ethnography of English as a Second Language
}

Diane Niblack Fox

Portland State University

Follow this and additional works at: https://pdxscholar.library.pdx.edu/open_access_etds

Part of the Applied Linguistics Commons, and the Bilingual, Multilingual, and Multicultural Education Commons

Let us know how access to this document benefits you.

\section{Recommended Citation}

Fox, Diane Niblack, "Chinese Voices: Towards an Ethnography of English as a Second Language" (1989). Dissertations and Theses. Paper 3896.

https://doi.org/10.15760/etd.5780

This Thesis is brought to you for free and open access. It has been accepted for inclusion in Dissertations and Theses by an authorized administrator of PDXScholar. Please contact us if we can make this document more accessible: pdxscholar@pdx.edu. 
AN ABSTRACT OF THE THESIS OF Diane Niblack Fox for the Master of Arts in Teaching English as a Second Language presented May 5, 1989.

Title: Chinese Voices: Towards an Ethnography of English As a second Language.

APPROVED BY THE MEMBERS OF THE THESIS COMMITTEE:
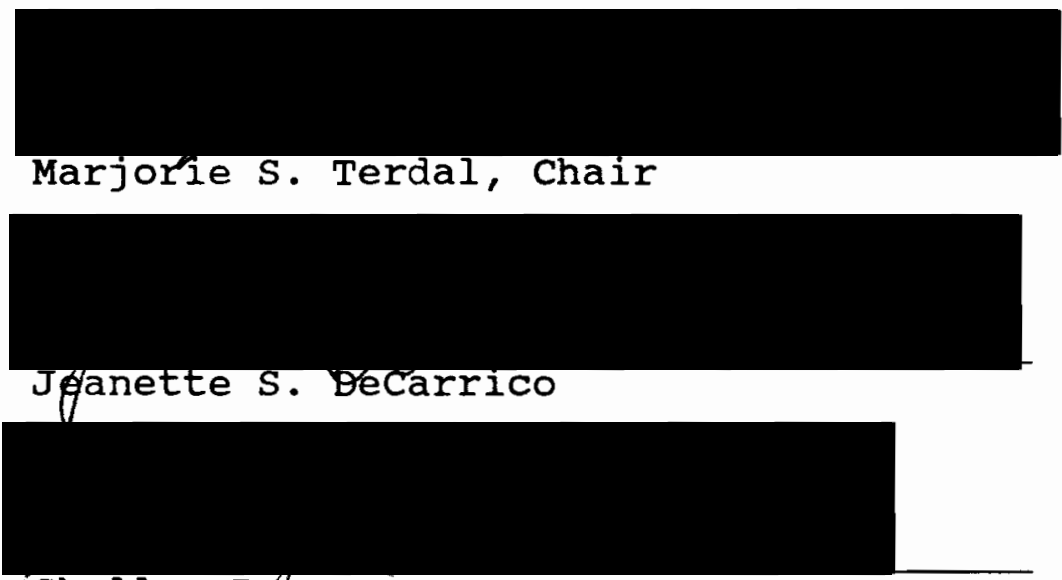

Shelley Røece

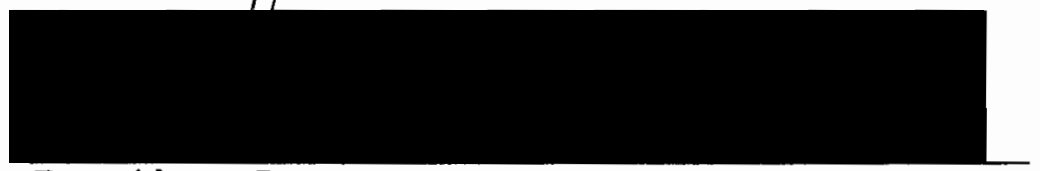

Jonathan Pease

This study draws on ethnographic methods to provide background information for the English as a second Language teacher who looks out at the classroom and asks, "Who are these Chinese students?" The goal is to let Chinese students describe for themselves their experiences learning English, both in China and in the United states. 
open-ended interviews are the heart of the study. seventy-four hours of formal interviews were conducted with 22 students and scholars. Two of the students who had recently arrived in the United States at the start of the study participated in a six-month case study that included extended interviewing and collection of their work in writing class.

Two questionnaires were developed from these interviews. The first dealt with the students' backgrounds: language, occupation, education, English, writing. The second focused on ESL programs in the United states. A third questionnaire transposed the questions asked the students in the ESL questionnaire into related questions for their teachers, and was given to ten ESL teachers at the site where the students were enrolled.

The results show a great diversity of experiences and attitudes. The one constant, a feeling of great pressure, is itself described with variable intensity. The study provides a framework of description the classroom teacher can use to move beyond generalization into an expansion of understanding of and discussion with students. 


\section{CHINESE VOICES:}

TOWARDS AN ETHNOGRAPHY OF ENGLISH AS A SECOND LANGUAGE

by

DIANE NIBLACK FOX

A thesis submitted in partial fulfillment of the requirements for the degree of

MASTER OF ARTS

in

TEACHING ENGLISH to SPEAKERS Of OTHER LANGUAGES

Portland State University

1989 
TO THE OFFICE OF GRADUATE STUDIES:

The members of the committee approve the thesis of Diane Niblack Fox presented May 5, 1989.

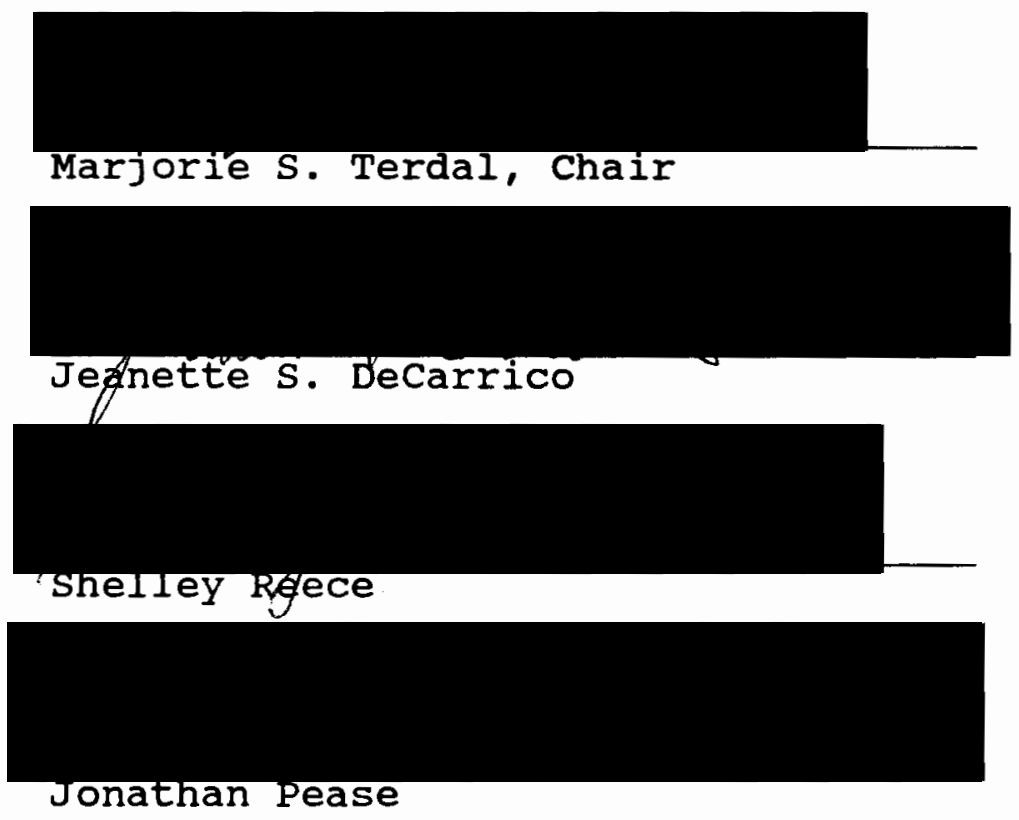

APPROVED :

James R. Nattinger, vchalr, Department of Applied

Linguistics )

Bernard Ross, Vice Provost for Graduate studies 
FOR MY KIDS, RACHEL AND CHRIS

May they keep the magic without the hocus-pocus. 


\section{PREFACE AND ACKNOWLEDGEMENTS}

I first became interested in studying Chinese history, politics, and culture in an effort to make sense of the war in viet Nam. After getting a B.A. in history, I taught English for one year to Chinese students at the Chinese University of Hong Kong. It was 1967-68, near the start of the Cultural Revolution. The Hong Kong government building that housed the headquarters of British colonial rule were barricaded with sandbags and and barbed wire, and bomb scares were daily occurrences.

Newspapers were filled with contradictory accounts from what was called "the mainland." It was difficult to find an objective language to describe what was happening: the words found in public discourse all had their roots in one sharply partisan view or another. Were the closing of Chinese schools and the attacks on members of the privileged classes signs of the spread of democracy in China, or deplorable acts of violence? Was Hong Kong being exploited under British rule or was it prospering? Were the bodies found on Hong Kong beaches washed down the river from fighting in China, or victims of local Hong Kong crime? Were Americans "paper tigers and running dogs," or were they "making the world safe for democracy"? Would the 
"workers, soldiers, and peasants" of the United States really unite to overthrow the imperialist government in Washington, or were these same classes the backbone of American intervention in Viet Nam? The answers depended on whether you believed the Chinese communist Ta Kung Pao, or the British colonial South China Morning Post.

For ten years after returning to the "States," a part of my life seemed to be on hold as I failed to find a language large enough to encompass the reality of those years, the dreams and the nightmares of those years--the years of the Cultural Revolution, the years of Viet Nam.

In the early 1980's I went back to school and began meeting students and scholars from China. Warily in the first years, then more and more openly and vehemently, they talked about the cultural Revolution as a colossal mistake in the increasingly distant past. Some also remembered with longing the vision: serve the people. The silence was broken, a language emerging.

This thesis was written thinking of all that those and later students have taught me, with love for the awkward, painstaking, heroic, and sometimes hilarious effort they are engaging, crossing from one language to another, from one way of structuring the world to another.

There are many people to thank. Zhou Xian Tao, a visiting scholar who opened the first doors for me. Ling Xia Li, a linguisitics student who delighted in her 
discovery of the link between T.S. Eliot and the Heisenberg principle. Jane Leung Larson and Katrina Chan Wai Ping Larson, who show the grace of living by translation. Cai Yuyu and Nancy Dollahite, for their love of education and of China. Wendy Larson for first showing me the incredible beauty of Chinese literature. Professors Zheng Xianda, Ning Zhishou, and Pan Chuanfa for their insights into English and the stories they have shared. Zhou Minglang and Changhua wang for lessons in reading and writing. 1 Lina Lu, who encouraged my first hesitant steps.

There are also many people to thank for taking time from intensely busy lives to read drafts and make suggestions. My wonderfully supportive committee: Jeanette DeCarrico, Shelley Reece, and Jonathan Pease. My husband, Richard Fox. Friends and colleagues: Elizabeth Beverly, Robert Whittemore, and Steve Kosokoff, who also contributed many stories and insights from his years of experience in China. And there is the energetically helpful librarian, Rosalind wang.

And then there is my advisor, Marge Terdal, woman warrior, TESL revolutionary--although she is perhaps too much of a lady, in the old, proud, quietly powerful sense

1 See Changhua Wang's A Comparative Study of Chinese Reading Instruction and American Reading Instruction, and Zhou Minglang's Script Effects and Reading Strategies: Ideographic Language Readers vs. Alphabetic Language Readers in ESL. Both studies were done as Masters' theses at Portland State University in 1988. 
of that now much-abused term, to see herself as such. Still she should know how much her students appreciate her strength, her seriousness, and her generous encouragement of their timid beginnings.

Above all, my thanks go to the many students and scholars from china, nameless here only because they were promised anonymity, who have made this study possible by generously sharing their time and experiences. It has been a great pleasure to work with them. 
TABLE OF CONTENTS

PAGE

PREFACE AND ACKNOWLEDGEMENTS . . . . . . . . . . . . . iii

LIST OF TABLES . . • . . . . . . . . . . . . . . . . . $\mathrm{xi}$

CHAPTER

I INTRODUCTION . . . . . . . . . . . . . . I

Questions. . . . . . . . . . . . 1

The Approach of this study . . . . . . 5

The Quantitative vs. Qualitative Debate

The Ethnographic Approach

The Scope of This Study

II REVIEW OF THE LITERATURE . . . . . . . . . . 19

Context: A Brief Look at History

and Statistics........... . 19

Education. . . . . . . . . . . 27

Education during the cultural

Revolution

After the Cultural Revolution

English Teaching at Chinese

Universities

Written Language Contrasts: Syntax

Vocabulary, Topics, Rhetoric,

and Voice. . . . . . . . . . . 41

Syntactic Contrasts

Cohesive Devices

Vocabulary

Thematic Contrasts

Rhetorical Contrasts

Voice: Devil or Angel or Mute? 
The Chinese in Intercultural Communication Theory . . . . . . 66

III METHODS. . . . . . . . . . . . 76

subjects . . . . . . . . . . 76

Instruments. . . . . . . . . . 80

Case study students

Questionnaire subjects

Interview Subjects

ESL Teachers

Instruments . . . . . . . . . . 80

Interviews

Questionnaires

IV CHINESE VOICES . . . . . . . . . . 85

Leung Wai Ping . . . . . . . . . 85

Educational Background

ESL Experience

"Breakdowns"

Li Xian Tao . . . . . . . . . . . 101

Educational Background

ESL Experience

"Breakdowns"

Interviews . . . . . . . . . . . 111

Life in America

Classroom and School Life

Differences

English in China

ways of Writing

Language Use and Translation

ESL Programs

V QUESTIONNAIRE RESULTS. . . . . . . . . . 139

Chinese students at a University

in the Northwest... . . . . . 139 
First Questionnaire. . . . . . . . . . 142

\section{Languages}

Work Experience

Education

Experience in ESL

Second Questionnaire . . . . . . . . 154

Questionnaire for ESL Teachers . . . . . 157

VI "A DAY ON THE GRAND CANAL WITH THE EMPEROR

OF CHINA OR SURFACE IS ILLUSION BUT SO IS

DEPTH" • . . . . . . . . . . . . . . 164

VII EPILOGUE • • • . . . . . . . . . . . . 173

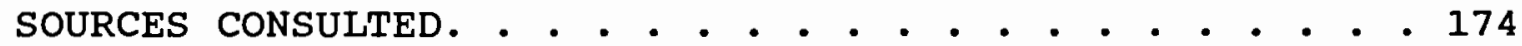
APPENDICES

A CONTRASTING MODELS OF CHINESE EDUCATION

SINCE 1949 . . . . . . . . . . . . . 182

B QUESTIONNAIRES . . . . . . . . . . . . . 184

C CORRESPONDENCE TO TEACHERS . . . . . . . . 173 


\section{LIST OF TABLES}

TABLE

PAGE

I Selected contrasts for $\mathrm{F}-1$ and $\mathrm{J}-1$

Scholars . . . . . . . . . . . 24

II Correlation of student Age and the Years of

the Cultural Revolution and Russian

Dominance of Education . . . . . . 39

II syntactic contrasts of Chinese and

English . . . . . . . . . . . . 51

IV First Questionnaire: Selected Results . . 151 
CHAPTER I

INTRODUCTION

QUESTIONS

"Why can't we work with beautiful language?" a Chinese student asked at the end of an ESI grammar class. He had come to the United States with great expectations, having been sent off with pomp and ceremony from the prestigious Chinese university where he worked. His coming was a sacrifice: he sorely missed his family, and his university sorely missed the contribution of one of its most skilled teachers and researchers. But he was here on an important mission which was worth the hardship: to learn all he could as quickly as he could in the United states, then return home to help China modernize.

He was prepared to concentrate intently on the fine points of English grammar, prepared to labor for hours to make a composition perfect, prepared to wrestle with thorny problems and master them under the intelligent guidance of a skillful teacher. He had lived through the Great Leap Forward and the Cultural Revolution: he was prepared to talk about serious, difficult topics. 
He was not prepared for the unchallenging and superficially treated subjects discussed in the ESL class where he was placed on the basis of his listening and speaking abilities. After a lesson on the supermarket, for instance, he said that he could not afford the luxury of learning the names of things he could easily point to or pick off the shelf: his time and money were too limited.

Nor was he prepared for the feeling of being stripped of his intelligence. "The teachers find we don't know simple words that every child here knows--apple, or banana, for example, or names for common things outside our culture, like fork--and they assume that means we don't know anything."I

Later, other Chinese students told me they felt it was the American teachers who didn't know enough: otherwise the material presented, especially the grammar, would be more complex. A few suggested another explanation: perhaps some of the teachers were just lazy.

Were these perceptions representative of Chinese students or idiosyncratic, I wondered. Out of that wondering came both the content and the form of this thesis.

I It is, of course, not just chinese students who face this problem. An American student in Greece made a similar remark: she had found herself in Athens equipped to write poems in classical Greek about the beautiful blue Aegean but unable to ask for a glass of water. 
The basic content question of my research is this: "Who are these Chinese students in our ESL classes?" What expectations do they have of language learning? What background in English do they bring with them that may not be apparent at first glance? A related question, to be treated more tangentially, is how their backgrounds and expectations are perceived and met by the ESL teachers they encounter in the U.S.

The form of this study--descriptive, based in part on an ethnographic approach to research--poses another question: what research tools are appropriate for our field? Will this study, based on interviews and questionnaires, contribute to our knowledge of language learning and teaching? How will we know if it does? Is it possible--and not only possible but better--for us, too, as researchers, to work with beautiful language? These questions cannot be answered definitively: the answers can only be provisional and must be tested by the reader's own experience.

Who are these students? This question likewise has no definitive answer. The complexity required for even partial answers may perhaps best be understood through the work of contemporary Chinese writers. In the novel Mimosa (Zhang 1985) for example, the hero zhang Yonglin creates his life in a world of contradiction, odd juxtapositions, and sudden reversals. He is an intellectual and a farm 
hand. He knows Marx and the Bible, Descartes and the Quran, Shakespeare and Neruda, the Tang poetry of Li Bai and the cart songs of the village mule drivers. He can shovel manure faster than anyone else on his work team; he can build an adobe stove that will keep a house warm in the cold winter of the north China loess plateau; he can cook and sew and analyze politics. Born into a "bourgeoiscapitalist" family in Beijing, he lost his home and most of his family to Japanese shelling. Trained as a poetry teacher, he lost his job during the Great Leap Forward, when he was condemned as a bourgeois rightist. He is imprisoned; he is released to do forced labor in a village; when he is about to be freed, he is condemned again through the jealousy of a fellow prisoner. Yet political fortunes shift again, and he is back in favor, turning his years in the village into a film and discussing affairs of state at important conferences in the Great Hall of the People. Through it all he endures, endures what he calls the inevitability of history.

Zhang's tale is not a metaphor for, but an actual description of the experience of many students who currently find themselves in ESL. Their life experiences are extraordinarily complex. The challenge of this study is to describe them in their fullness and provoke further questions that ESL teachers must confront in meeting the needs of these students. 
THE APPROACH OF THIS STUDY

The Quantitative vs. Qualitative Debate

"It doesn't matter if a cat is black or white, as long as it catches mice."

--Deng Xiao Ping, during the debate over the

criteria for truth that followed the over-

throw of the Gang of Four.

on another level this thesis is about ways of

knowing: ESL researchers' ways of knowing and Chinese students' ways of knowing. A brief discussion of the ongoing, sometimes tiresome, sometimes ill-phrased debate over quantitative and qualitative research methods will explore the assumptions on which this present study is based. Chinese students' approaches to knowledge are discussed in the sections on chinese education and in the findings of the study.

Although one of Deng's cats may be named qualitative research and the other cat named quantitative, there is a problem with applying his metaphor to the methods controversy: the cats may be chasing different kinds of mice, or different parts of the same mouse. Yet the metaphor can still serve if both kinds of mice, or both parts of the mouse, increase our knowledge of language learning and teaching.

"Contrast" and "irony" are the words Van Maanen (in Agar 1986:5) uses to introduce a series of scholarly essays on quantitative and qualitative methodology: "contrast" because of the differences between the two, "irony" 
because, he claims, the contrast between the two is "so often misleading, if not downright false."

Perhaps part of the problem can be explained by a Whorfian analysis of European languages, which have a penchant for "either-or" dichotomies: logic or intuition, science or art, realism (positivism, empiricism) or idealism, behaviorism or mentalism, right brain or left brain, -emic or -etic.... The last two pairings suggest the difficulty of drawing such clear lines, however: a brain is made up of both halves, a language is both -emic and -etic.

Nonetheless, there is some meaning to the differences, though they may not be as stark as extreme partisans of each position might like to think. One way of getting at those differences is by comparing the answers qualitative and quantitative researchers give to three questions smith (1983) suggests lie beneath the rhetoric: what is the goal of research, what is the relationship of the researcher to what is being investigated, and can research be objective in the sense of value-neutral?

To understand the different answers given, it is helpful to call to mind the different claims about "reality" made by what may roughly be termed the realist and idealist schools of philosophy. In drastically oversimplified form, the differences between these schools may be found in their differing answers to this question: 
Is there a reality out there that exists independently of the observers and their understandings of it? "Yes," say the realists, who favor quantitative methods; "No," say the idealists, who prefer qualitative. "Yes and no," is the no-longer surprising current position of the so-called "hard sciences," the disciplines which have set the not always appropriate quantitative standard for the less selfconfident social sciences.

Indeed, twentieth century work in the physical sciences suggests that the whole framework for making the quantitative/ qualitative distinction may be askew, based as it is on the relationships described by Newtonian physics, relationships which quantum and particle physicists since Heisenberg have found only partially adequate; now even natural scientists assume that the act of observation alters what is observed, at least in certain realms (Zukav 1979).

Though it can be both pretentious and dangerous to borrow convenient theories from distant disciplines, it should be recognized that, historically, that is what the social sciences have done in adopting the quantitative methods of the physical sciences. It is important to consider that the discipline of ESL is in the infancy of its development as a discourse, important to keep asking what goals, relationships, and tools are best suited to our field. 
Since the question of preferred methodology can never be definitively decided, many authors have reasonably suggested a "two-cat policy": both the black and the white cats, quantitative and qualitative as complements to each other. [See Wolcott (1983) and Crano (1981) on triangulation; Schumann on Art and Science in Second Language Aquisition studies (1983); and Stevick (1981) on the reciprocity of intuition and statistical research.]

However much this "walk on two legs" approach (to borrow out of context a quote from Mao) seems intuitively satisfying, given the uncertainty in which we work, it is possible to argue that qualitative methods are more congruent with the content and relationships of our field, and therefore more appropriate to it. Since the field still seems, at times, to cling inappropriately to the quantitative approach without acknowledging its limitations, it is perhaps useful to point out the strengths of qualitative methods for ESL research. [See Rosansky (1976) for a study of the limits of quantitative research.] ${ }^{2}$ The following argument is not meant to deny

2 Vivian Zamel (1983) uses an old Sufi story to illustrate the inappropriateness of appropriating quantitative methods wholesale to ESL research. One day a man saw his neighbor down on his hands and knees in front of his house, obviously searching for something. "What are you looking for?" he asked. The old man replied, "I've lost my key." "Tell me where you think you dropped it, and I'll help you look," the neighbor offered. "Inside my house," the old man answered. "What!" exclaimed the neighbor. "Then why are you looking out here?" "There's more light out here," was the reply. 
the value of quantitative methodology, since its value is widely accepted. Rather, the intent here is to show the usefulness of qualitative research.

The strengths of qualitative methodology for ESL, it may be argued, lie in the relationship of the assumptions on which ESL teaching is based to the assumptions on which qualitative research is based. These assumptions may be clarified by looking at the answers qualitative researchers give to the three questions mentioned earlier, questions of goals, relationships, and objectivity.

The quantitative researcher's goal may be characterized as a search for universal laws; in contrast, the goal of qualitative research is often expressed as some variation of Weber's goal of verstehen, of understanding the meaning that others give to their own situations by researchers' attempting to put themselves in the place of others. To the extent that good teaching is learner based, it can be improved by increasing appreciation for the way particular students in particular situations understand their worlds. It is qualitative research, not quantitative, that can provide such understanding and appreciation.

The goal of understanding seems further suited to the discipline of TESOL because meaning and communication, along with the attitudes, motives, and goals of learners are all critical to that discipline. Meanings are messy to 
deal with in quantitative research, but language study stripped of meaning is hollow, inadequate: an old cat finding only pawprints of mice.

The qualitative approach also seems suited to ESL research in the relationship it posits between the investigator and what is being investigated. While in traditional quantitative research this relationship is defined as subject-object, with the object of the investigation having a separate existence independent of the researcher, in qualitative research the relationship is thought of as subject-subject: the findings are in part influenced by the interactions of the subjects. To the extent that both teaching and learning are influenced by the relationship between teacher and learner, the qualitative approach again seems to be more appropriate to our discipline.

Finally: the question of objectivity, or the relation of facts to values. Are we, as observers of an independent reality, able to produce a value-free, valueneutral environment in which to conduct our research, allowing independent replication and verification? or does our observation alter that reality, implying that our work should rather be judged as an act of creation, perhaps on ethical or aesthetic grounds (Schumann)? Is our research context-bound or context-free? Both? To what extent? 
In fact, the point is not so much to answer these questions as to set about refining and sophisticating the tools of both approaches, qualitative and quantitative, to understand the strengths of each and use each where appropriate.

The limitations of objective methods, and the ability of qualitative research to make important distinctions that cannot be detected by quantitative methods, is nicely illustrated by Clifford Geertz' well-known example of the difference between a twitch, a wink, and a parody of a wink $(1973: 6)$. While the observable, measurable characteristics of the three actions may be exactly the same, their meaning clearly is not, and a research tool that confounds them is less useful to our discipline than one that can distinguish among them. Tools that can distinguish among various motivations for student silence, or for student success in a task are useful adjuncts to tools that measure silence and achievement.

The Ethnographic Approach

Ethnography is one kind of qualitative research often named as a supplement to quantitative research, but what is ethnography ${ }^{3}$ The word refers to both a written text that

3 "Ethno-" terms abound, and some seem to overlap. Below are some definitions from the oxford English Dictionary.

1) Ethnology: The science which treats of races and peoples and of their relations to one another, their distinctive physical and other characteristics. 
is a description of a way of life, and to the approach of disciplined observation that provides the data for such a written text. It may perhaps better be characterized as what spindler calls a world view than as a body of techniques, although some attempts have been made to provide systematic accounts of ethnographic procedures. (See, for example, spradley.)

Spindler (1982) names five features of the ethnographic world view. First, the researcher deals with the people who provide the information for the study not as "subjects" or "informants" but as "experts" who must be treated with respect and in good faith. The second point puts that expertise in perspective: all knowledge is considered as partial, ambiguous, having hidden dimensions which the

2) Ethnography: The scientific description of nations or races of men, with their customs, habits, and points of difference.

In 1876, according to the O.E.D., "ethnology" was used to refer to the rational exposition of a culture, "ethnography" to refer to descriptive details. spindler (1982) echoes this distinction, labeling as ethnography the collection of data in the field through observation and interviews, and as ethnology the interpretation of that data.

3) Ethnoscience: the study of races or cultures; ethnography (O.E.D.). The study of the way people try to determine the logic for the way things are (Whittemore). This seems to be a newer term, dated in the O.E.D. from 1964 .

4) Ethnomethodology: A subfield of sociology aimed at finding what principles need to be understood in order to interpret sociological surveys (Agar 1980); a field dealing with values and beliefs, trying to look at the ways in which lives are understood and the world is given meaning (Whittemore). 
ethnographer seeks to ferret out--at the risk of substituting invention for observation.

The third feature of this world view is the understanding that all behaviors occur in contexts which are always changing, and people change with the contexts. Related to this is the point that any context being studied is only one of many layers. A classroom, for example, is part of a school, which is part of a community, a region, a nation, and the world. Ethnographers speak of being "thrice-born": into their culture of birth, into the culture they study, and then again into their first culture when they return as they refamiliarize themselves with what was once known but has become exotic.

Finally, spindler mentions a feature of the ethnographic world view directly related to schooling. The function of schooling is thought to be the transmission of culture as it is, not as it should be. Each student in the school is part of that culture and has cultural knowledge that influences the educational outcome. 4

4 Agar (1980), when discussing the differences of ethnography from other research methodology, focuses on a difference in relationships. In ethnography, he says, there is direct, personal involvement in the community being studied, occasioning the development of long-term, diffuse relationships. The metaphor he uses for the ethnographer's initial role is that of a child or a student: in his words, the researcher is not "one-up," but "one-down." He says ethnography can be translated as a process of becoming a member of a group, and suggests that the goal of ethnography can be described as being able to give accounts of what is going on that group members recognize as possible accounts. 
In addition to defining ethnography as a world view, Spindler gives eleven "Criteria for a Good Ethnography of Schooling." 1) Observations are contextualized.

2) Hypotheses and study questions emerge from initial observations. 3) Observations are prolonged and repeated. 4) The view of reality of the people being observed is brought out by inferences from observations, by interviews, and by other instruments, including, cautiously, surveys. 5) An important part of the task is to understand what sociocultural knowledge participants bring to a setting. 6) Instruments are generated in the field as a result of initial study. 7) Tacit and implicit knowledge of the informants and participants is made explicit. 8) cultural variation over time is considered natural. 9) Inquiry must be the least disruptive possible. 10) The ethnographer must try to let the informant shape the unfolding of cultural knowledge by avoiding questions that predetermine responses. 11) Technical devices--cameras, tapes--are used to help collect live data.

Ethnographic research is typically hypothesisgenerating, not hypothesis-testing. While it has great validity, it is weaker in reliability and generalizability. In addition, in some contexts its lengthy and diffuse procedures make it impractical as a research instrument. The goal of this study of Chinese students in ESL is not a full-fledged ethnographic account. The shape of such 
full studies may be inferred from spindler's crieteria, or understood from the goals defined by other writers: the ability "to define the world through the other's categories" (Spradley 1979:5), or the gaining of the understanding necessary to act appropriately in another culture (Goodenough's classic definition given in 1957, and quoted in Agar 1986:54).

The goal of this study is limited to a preliminary step, to a rendering of some of the voices and perceptions of Chinese students learning English. The thick, mediating lens of the observer is ever present. The theorizing that would unite the disparate voices into a coherent world view is left for another study. For the moment, it seems more important to break down too-easy generalization.

This study does, however, draw heavily on ethnographic techniques and attitudes. Some of the ethnographic techniques used here include open-ended interviews; copious note-taking; formulation, testing, and reformulation of questions; a search for breakdowns in coherence and understanding; and a search for repeated themes and categories of themes (Spradley 1979; Wolcott 1981; Miles 1983).

More importantly, it adopts certain of the ethnographic attitudes mentioned above in relation to the work of Spindler and Agar, and repeated here by others: treatment of the subjects of the study as collaborators and 
correspondents (Hymes 1981); emphasis on learning from people, not studying people (Spradley 1979); a commitment to self-examination by researchers (Sanday 1983; Pratt 1986); a willingness to be tentative, to flounder about a bit, to start the research without ready-made assumptions and instruments (Wilcox 1982). 5

In addition, this study shares Agar's desire for greater complexity in qualitative research, and his assumption that an attitude he calls "anti-coherence"--an attitude of looking for evidence that does not fit coherently into the researcher's current understanding--will deepen understanding by leading towards more complex theories $(1986: 49) .6$

This study also, however, shares a concern expressed by Spindler (1982) and Said (1978) that focussing on the strange, on what challenges the researcher's understanding, may lead to a lopsided view that risks dehumanizing

5 Other work in ESL that draws on ethnographic method includes Zamel's "The Composing Processes of Advanced ESL Students: Six Case Studies," Allwright's "Understanding Classroom Language Learning: A Case Study Approach," Christison and Krahnke's "Student Perceptions of Academic Language Study," Frolich's "Case Studies of Second Language Learners," and Rubin's "What the Good Language Learner Can Teach Us."

6 Wolcott (1981:254-56) phrases this attitude in terms of looking for paradoxes, key problems, and "bumps" that stand out against a flat background. Kidder (1981:241) calls it "negative case analysis." Agar relates all these terms to Heiddeger's earlier concept of "breakdowns" (1986:20). 
subjects by overlooking what they have in common with the researcher's own world. The goal here is to see both common ground and difference, both coherence and conflict.

The Scope of This study

Within a framework of openness to discovery and willingness to change direction, three general categories of research questions guided this study:

1) What is the educational background of chinese students enrolling in an ESL program in a commuter university in the Northwest? Specific points of interest in that background include training in English, and in writing in both Chinese and English. I looked for information as broad as a picture of life at a chinese university, and as specific as writing topics and lists of vocabulary words graduating seniors are assumed to know.

2) How do chinese students describe their experiences in learning to write English in this ESL program? What questions do they have? What do they find useful, what confusing, what useless? What changes would they make?

3) How do ESL teachers in the program describe and explain the problems of their Chinese students? What knowledge do they have of their students' backgrounds?

Answers to these questions were sought in three ways: 1) two six-month case studies, 2) interviews, and 3) questionnaires. The case studies consisted of 21 hours of formal and informal interviews, in addition to 
questionnaires, and collection of writing samples. To provide a context for understanding the uniqueness or generalizability of the two students' experiences, 53 hours were spent interviewing fourteen other students and scholars; another twelve filled out questionnaires. Ten American ESL college teachers from the same institution responded to a questionnaire about their chinese students. The collection of information will be discussed more fully in Chapter III, "Methods."

This chapter began with a look at questions chinese students have about ESL and questions ESL teachers have about chinese students. The basic question of the study, "Who are these Chinese students," was raised. A secondary question was also posed: "How can we best find an answer to this question? What ways of knowing are most appropriate to ESL research?" These questions led to a discussion of the controversy over qualitative vs. quantitative methodology, including a brief look at ethnography. The first step towards answering these questions is to look at background information on Chinese students in the United States, changes in education in China, and linguistic and cultural contrasts facing Chinese students in ESL These topics will be addressed in the following chapter. 


\section{CHAPTER II}

REVIEW OF THE LITERATURE

A library search is one way to begin to answer the question, "Who are the chinese students in our ESL classes?" The literature considered here will be divided into four parts: a brief historical and statistical overview; a linguistic contrast of Chinese and English; a description of education in China; and a brief statement of cultural differences as they are currently formulated in the intercultural communications component of one training program for ESL teachers. The literature on methodology is discussed in the introduction and in the methods chapter.

\section{CONTEXT: A BRIEF LOOK AT HISTORY AND STATISTICS}

The approximately 20,000 Chinese students and scholars in the United States in 1988 are part of an onagain, off-again pattern of exchange that dates back to 1854. Such exchanges have included many who have played significant roles in China's public life, most notably the man who is commonly called the father of the 1911 revolution, sun Yat-Sen.

Those roles have never been simply accepted without conflict, however, and ambivalence has accompanied the 
exchanges on both sides of the Pacific from their start to the present. The conflict has been twofold: individuals have struggled to reconcile conflicting sides of themselves drawn out in Western and Chinese contexts, 7 and China has alternately appealed to scholars to come home to help build new China, and denounced them as carriers of western capitalist contagion.

The first formal educational mission to the U.S., arranged through China's prestigious Hanlin academy, lasted just nine years before being discontinued in 1891, on the eve of the passage of the first oriental Exclusion Act (Fairbank 1965:363-4). More recently, the cold war and Cultural Revolution interrupted exchanges. The number of visas granted for Chinese students to go abroad continues to fluctuate year by year with the debates over the need to keep skilled people home to help with modernization goals, and fears of foreign influence (Butterfield 1988). Despite this ambivalence, the current exchange has grown rapidly, from the first group of 50 who arrived in the U.S. in late 1978 , to the roughly 20,000 in $1986 / 87$ (Lampton 1986:30; Zikopoulos 1987:20).8 starting from

7 For an example of the literature dealing with this conflict, see Lao she's short story, "The Returned student."

8 The caution always advised in looking at statistics should be exercised with the statistics in this section. While they are based on the best sources currently available, their quality is uneven. First of all, it should be noted they refer to all chinese students and 
zero, in ten years china has leaped to third place in its share of the total U.S. international student population. At $5.7 \%$, it is close behind Malaysia (6.2\%) and Taiwan (7.3\%), and shows a far higher growth rate from 1985/861986/87 than any other country: $43.3 \%$. The next highest is singapore, with 15\% (zikopoulos:19-20). The rate of growth for Chinese students in intensive English programs during the same period is lower, $29.4 \%$, but second only to the $36.9 \%$ growth in Japanese students (zikopoulos:77). China currently sends half of all its overseas students to the U.S., although not infrequently proposals are made to diversify and send more elsewhere (Lampton:2).

What are the characteristics of these students? What is their age, gender, and marital status? What part of China are they from? How long do they intend to stay? What is their background in work? in English?

Age, like many other characteristics, varies depending on whether the student is privately funded (is among the $37 \%$ of students who have $\mathrm{F}-1$ visas) or is government sponsored (is among the $63 \%$ with $\mathrm{J}-1$ visas)

scholars in the U.S., not just specifically to those in E.S.L. In addition, the significance and scope of the available numbers varies: sometimes research scholars and other students are lumped together, sometimes they are separated; sometimes $\mathrm{F}-1$ and $\mathrm{J}-1$ visa-holders are lumped together, sometimes they are separated; often the statistics quoted are from 1983, without explanation of how that year compares to other years. Still, the statistics may serve as a starting point. 
(Lampton:32).9 The government scholars tend to be older and doing more advanced study; the privately funded students tend to be younger, and working on less advanced degrees (Lampton:252). In 1983, for example, $44 \%$ of the $\mathrm{J}-1$

scholars were older than $40,22 \%$ were $30-39$, and $31 \%$ were under 30 . On the other hand, $58 \%$ of the F-1 scholars were under 30 years old, with another $33 \%$ between 30 and 39 (Lampton: 45).

Most of the students are men, although there are twice as many women among the F-1 scholars as among the J-1's. Most are married, although again this varies with visa status: $73 \%$ of $\mathrm{J}-1$ 's are married, $30 \%$ of $\mathrm{F}-1$ 's. In $1983,77 \%$ of the scholars were men, and $63 \%$ were married (Lampton: 46).

Not surprisingly, most students come from the big cities: Beijing ranks first, Shanghai, second, for $\mathrm{J}-1$ students, and the ranking for $F-1$ students is Beijing, Shanghai, Guangzhou (Lampton:46).

The intended length of stay varies with visa status. J-1 visa holders plan shorter stays than F-1's: in 1983, for example, $75 \%$ of the J-1's planned to stay two years or less; $74 \%$ of the F-1's planned to stay longer than 2 years (Lampton: 46).

9 This high percentage of government sponsorship distinguishes Chinese students from the majority of international students in the U.S., among whom visas are divided into $11 \% \mathrm{~J}-1$ 's, $81 \% \mathrm{~F}-1$ 's (Zikopoulos:34) 
Students $(26 \%)$, teachers (16\% from higher education, $8 \%$ from high school or lower), and engineers (15\%) made up $65 \%$ of the total in 1983. Among J-1's, those from academia made up nearly $80 \%$; although the F-1 group was more diverse, including more technicians, farmers, and clerical and factory workers, again the largest single group, 53\%, was from academia (Lampton: 43-4).

What these students come to the U.S. to study also varies with visa status. Both $\mathrm{J}-1$ and $\mathrm{F}-1$ have high percentages of students in engineering and the physical sciences, but health sciences are studied by a greater percentage of $\mathrm{J}-1$ than $\mathrm{F}-1$ scholars, while business, computers, and the humanities are studied by a greater percentage of $F-I^{\prime} S$ than $J-I^{\prime} S$ (Lampton:38-9). Compared to the international student population as a whole, Chinese J-I students are less likely to major in business but more likely to major in health sciences, and both $\mathrm{F}-1$ and $\mathrm{J}-1$ students are more likely to major in physical sciences (2ikopoulos:23).

Table I gives some of the contrasts between F-1 and J-1 scholars for selected years.

It is important for ESL teachers to realize that $\mathrm{F}-1$ visa-holders are disproportionately represented in intensive English programs: only $2 \%$ of J-1 students come expecting to study English, while $25 \%$ of the F-1 students do. While information on the average TOEFL scores of 
TABLE I

SELECTED CONTRASTS FOR F-1 AND J-1 STUDENTS

$$
\text { F-1 }
$$

$$
J-1
$$

age

$$
\begin{array}{ll}
9 \%-40+(1983) & 44 \%-401(1983) \\
91 \% \text { - under } 40 & 56 \% \text { - under } 40 \\
58 \% \text { - under } 30 & 31 \% \text { - under } 30
\end{array}
$$

marital status

$30 \%$ married

73\% married

region of China

Beijing, Shanghai, Guangzhou

Beijing, Shanghai

intended length

of stay

$$
\begin{aligned}
& 74 \% \text { - longer than } \\
& \text { two years }
\end{aligned}
$$

$25 \%$ - longer than two years

work background

academics - 53\% (more technicians, farmers, clerical, and farm workers)

study objectives in U.S.

engineering physical sciences business computers

humanities engineering physical sciences health sciences

expectations of studying ESL on arrival

funding

$$
\begin{aligned}
& 75 \% \text { - their } \\
& \text { families, or } \\
& \text { individual U.S. } \\
& \text { sponsors }
\end{aligned}
$$

85-90\% government or foundation 
Chinese students in the U.S. is unavailable, Lampton's figures show that the mean test scores of chinese students in general has been improving, from 473 in 1980-82 to 491 in 1982-84 (p. 127-8).

Where do these students go to study? More than $97 \%$ of all chinese students go to four-year institutions, with only 2-2.6\% in two-year schools. Roughly $70 \%$ enroll in public schools, 30\% in private (Zikopoulos:48, 56).

While PRC students are enrolled in at least 390 colleges and universities in all fifty states, the geographic areas which drew the most scholars in the mid1980's were the mid-Atlantic, the east north-central, and the Pacific states (Lampton:201, 199).

Although $85-95 \%$ of $\mathrm{J}-1$ scholars receive government or foundation funding for their first year of study, they are then under pressure to prove themselves competent enough in their fields by the end of that year to qualify for funding from their universities. Students, as opposed to research scholars, are generally granted two years in which to get funding (1986:108-9).

The average government stipend in the mid-1980's was $\$ 460$ per month. Students who earned more than that were required to remit a large portion (as high as $85 \%$ ) of the surplus to their work units in China, which frequently continue to pay their salaries or to provide benefits to their families (Lampton:107). 
F-1 scholars face different pressures. $75 \%$ of these students are supported by family or other individuals in the U.S., with terms ranging from full coverage of all expenses to coverage of transportation here, to be repaid as soon as possible, and the expectation that once here the student will work to pay his or her way.

Inadequacy of health care coverage is a concern many American administrators have expressed for both categories of student (Lampton:106).

It is interesting to note that sponsorship by U.S. universities increased during the period covered by Lampton's statistics. He gives four explanations. First, for foreign students in general, U.S. universities usually pay half the bill. Secondly, Chinese students are able to compete favorably with other foreign and American students. Third, American research benefits from Chinese expertise. "In one sense," Lampton says, "Chinese support for their students and scholars [provides] subsidies to U.S. programs." (p. 52) That is, the U.S. research centers that hire chinese researchers may be able to do so at a lower cost because of Beijing's support of overseas scholars. Finally, the U.S. government thinks it is in the U.S. interest to help China's drive for modernization. Once here, these students face contrasts of language, educational style, and culture, contrasts which will be addressed in the following sections of this chapter. 


\section{EDUCATION}

George and Louise spindler, pioneers in the field of the ethnography of schooling, stress the importance of seeing education "as it is--embedded in the culture of which it is an integral part and which it serves" (in Sanday 1983:26). The link of education to culture is impossible to miss in China.

Because of the engagement of education in the struggle to create a new, post-1949 China, all but the very youngest Chinese students in the U.S. today have lived through dramatic, sometimes exhilarating, sometimes painful shifts and reversals. Some of these shifts have been described as another kind of holocaust, or as a time when the world was turned upside down, inside out, when false became true and true, false. (One of many examples to be found in literature and biography is Gu Hua's short novel, Pagoda Ridge.)

That is one way of putting it. Another way to express the educational experience of today's students is to say that they have lived through a period of historic transformation, in which the people of China were throwing off the bonds of two thousand years of feudalism. In that transformation, because the twin goals of modernization and democracy had to compete for scarce resources, education was at times pulled more towards serving democracy, at times more towards serving modernization. (The inevitable 
entanglement of historic movements with personal political ambitions adds layers of complexity side-stepped here.) Whether they call it the holocaust or the inevitability of history or something else, students twenty-five and older have directly experienced one of the most dramatic of these shifts: from the push for democracy 10 during the cultural Revolution to the push for the "Four Modernizations" (agriculture, science, industry, and national defense), students have been alternately treated as the devils and the saviors of Chinese society. In the midst of--perhaps because of, perhaps in spite of--these political shifts and struggles, China has made great strides in education, as students now in their late forties or older can remember. What follows is a brief description of the changes in education in postrevolutionary China.

10 Democracy? Another language difficulty for ESL students is suggested in the ambiguity and noncorrespondence of terms such as this one, not only between Chinese and English, but also between one period and the next within China's public discourse. For example, I have written "democracy." Some Chinese writers would agree. others would call it feudalism disguised in the verbal trappings of democracy. That is one level of the problem of translation. On another level, even if the fit of the situation to the term, here, democracy, is agreed on in Chinese, it is still but very imprecisely the equivalent of the American word "democracy." An additional complication is that the meaning of this word, on each side of the Pacific, is an issue for continuing debate: the meanings are not fixed. Even had I used the somewhat more accurate term "socialist democracy," the above ambiguities would have been but modified, not resolved. 
The task the new regime inherited in 1949 was sizeable: a population that was roughly $80 \%$ illiterate, 20\% scholarized (F. Kaplan 1979:228). Literacy--in the schools, in the work place, in evening classes, in "each one teach one" campaigns--was the first major educational goal.

The schools the new regime inherited were multilayered. There was the layer of traditional Confucian classical education, with its goal of producing scholarofficials unsullied by menial labor who would help run the imperial system--a system admired by Europeans like Voltaire and Rousseau as the best model of human government (Hayhoe 1984).

With the end of empire and the establishment of the republic in 1912 came layers of European and American influence. Generally speaking, the European model corresponded to the Confucian model in its centralized, authoritarian power structure, its preference for "pure" knowledge (although the Chinese and European definitions of purity differed), and its conception of education as the passing on of a collected, canonized body of literature. The American model, favored by the Kuomintang, may be characterized in contrast as having a more decentralized power structure, giving greater interplay to the pure and applied sciences, and conceiving of education as a "rounding" of the individual, prior to specialization. In 
addition, the American model, with its night schools and adult education, offered greater structural diversity and served a more diverse population (Hayhoe n.d. and Hayhoe $1984)$

This brief look at the history of education adds another dimension to the tensions in Chinese education: not only were they inherent in the twin goals of the new state, but they had roots as well in the conflicting Western models of Europe and America.

One other form of education inherited by the 1949 government must not be overlooked: the missionary school. This type of school is important for ESL because it is not uncommon to find older students, especially women ${ }^{11}$, whose first education was in these schools--or younger students whose parents' was. Another way in which these schools are important to an understanding of the relationship of English to China is that English played a large part in some of these schools: sometimes English texts were used, and frequently English was an important course in the curriculum. Many returned missionaries are still active in working with Chinese students in the U.S.; others look at ESL as a way of renewing missionary contact with china.

11 At the time, Chinese schools were only for boys. For an interesting study of how one group of women, Americans, helped another group, Chinese, while simultaneously helping themselves, see Jane Hunter's The Gospel of Gentility. 
The first educational task "new China" (as it called itself) undertook was literacy. It was successful. By the mid-1960's the problem of illiteracy had become a problem of inadequate literacy (Price 1979).

At the same time, longer range educational goals and institutions were being established. In 1951, five levels of instruction were announced, pre-school through university. Additional programs in vocational, technical, political, and spare-time education were also created. The missionary schools were banned; English, tied to bitter memories of a semi-colonial past, went with them (zhuang $1984)$.

This was the period of Russian domination of the schools. There were Russian advisors in the universities, Russian inspectors in the lower levels. The texts were translated from Russian; the lessons were also translated from Russian, written verbatim on the blackboard by the teacher, copied word for word by the students, then memorized. The natural sciences were the core of the curriculum. In the city, some integration of schools and industry developed. Russian replaced English as the dominant foreign language ( F. Kaplan). Some visiting scholars currently in the U.S. were in elementary school during this period; many others were taught English by teachers who had received their training in Russian. 
Schools and innovations in education, in particular the half-work, half-study schools in the countryside, mushroomed with the Great Leap Forward(1958-59); $90 \%$ of these new schools also collapsed with the Great Leap's collapse.

The Great Leap had emphasized socialism; in contrast, in the period that followed, schools reduced their political activity and labor requirements, and the debate over "red or expert?" once again flourished. Mao stressed the importance of "turning intellectuals into laborers and revolutionaries"; Liu Shaoqi, focusing more on the goal of industrialization, wanted to set up a two-track system of education. One track was to be for industrial and agricultural workers, the other, a system of "key" schools (sometimes called "little treasure pagodas"), was to prepare students for university and professional careers (F. Kaplan). During this period, following the 1960 sino-soviet split, English once again became the major foreign language (Zhuang) •

\section{Education during the Cultural Revolution}

By the time of the Cultural Revolution, the educational needs of China were significantly different from those the new regime had faced in 1949. Primary school enrollment had risen from 28 to 115 million, general secondary from 1.5 to 11.7 million, and tertiary from 
207,000 to 664,000 (Price 1979:306; these figures are approximations) .

once again, changes in education mirrored changes in the larger society, this time with the students and schools at the center of the storm. The earlier patchwork of academic and political education was "purified" as politics were put, as the phrase had it, "in command." Schools were closed for reorganization and elimination of bourgeois "capitalist-roader" tendencies. Initially closed for six months, some, universities especially, remained closed for four years, causing disruptions in both the national economy and personal lives. Party directives called for implementation of what chen calls "the revolutionary model." (See Appendix A.)

Technology was considered unnecessary for the achievement of the highest national goal, socialist reorganization; indeed, it was denounced as a threat to socialism, since it created a skilled elite. Expertise was considered a form of mystification, a con-game (Unger 1982). This attitude was captured in the slogan, "When satellites rise to the skies, the red flag falls to the ground" (Chen 1981:135). The schools had to be purged of the elitist emphasis on specialized skill.

By the time the schools were re-opened, changes in their enrollment, examination system, curriculum, and teaching and administrative staffing had all been made. 
The goal was universal education with a uniform content. The amount of basic schooling advocated varied from time to time and in accordance with local means: seven, nine, or ten years.

University admission was based on the work-place, not the school. The university entrance exam was abolished in one of the first acts of the cultural Revolution. Students went to work for at least two years after high school, and then were recommended for further study by their fellow workers in order to meet the needs of their work unit. Class background, not academic performance, was the key. For a period of roughly ten years, students selected for the university were required to have a "good" class background, that is, to be from a family of one of the following groups: worker, peasant, army, or high party cadre. When Beijing University reopened, $90 \%$ of its students were from these backgrounds (Chen 1981:98). The goal was equality, and the redressing of old wrongs. The effect on educational content is intimated by the following: at ling Hua University (the Chinese equivalent to MIT), freshman math classes consisted of learning to add fractions (Unger 1982:201).

The new curriculum was shortened and restricted to five subjects: political theory and practice; language; mathematics; military training and physical education; and industrial and agricultural production. (F. Kaplan). 
Lessons in struggle became the core of instruction.

Workers in the cities and peasants in the countryside told students stories of the misery of the past, and of class exploitation and class struggle (Chen).

other subjects were not only minimized, but also altered to serve political ends, as the following example from a primary school text illustrates:

Chairman Mao is the reddest 'red sun' in our heart; it is most fortunate to be able to see Chairman Mao. In 1968, on the national birthday, there were 150 representatives of capital workers, Liberation Army, Maoist propaganda teams, and the poor, lower-middle class peasants to visit Chairman Mao; there were also 67 representatives of Red Guards and the revolutionary public. How many representatives in total were there to visit Chairman Mao? (F. Kaplan:224)

The teaching and administrative staff was also radically reshaped. "Worker Propaganda Teams" (also called "Mao Zedong Thought Propaganda Teams"), backed by the People's Liberation Army, were in charge of the reopened schools. Many former "rightist" teachers and administrators had been purged: some were killed, many more were intimidated or removed. Seventy per cent of the faculty of Beijing University, for instance, was sent to the countryside (Chen:98).

English teachers came under especially heavy attack as "worshippers of foreign capitalism," and "running dogs of imperialism," or as American spies; this in addition to the 
problem they shared with other teachers of being "bourgeois intellectuals." Even after the end of the cultural revolution, English teachers were often reluctant to show enthusiasm in their teaching for fear of being criticized again (Zhuang).

\section{After the Cultural Revolution}

Thirteen years have passed since the official end of the Cultural Revolution, a large part of the mature lives of students in their twenties. With the arrest of the "Gang of Four," which followed one month after Mao's death in september 1976, China's priorities rapidly shifted from socialism to Deng Xiaoping's "four modernizations," and the schools from "politics in command" to what one observer phrased "examinations in command" (Chen 1981:209).

The examination system was reinstated in 1977, and, trailing it, an academic model of education. At a national conference on education in 1978, Deng set the following goals for education: 1) to improve quality; 2) to create "revolutionary order and discipline"; 3) to keep pace with requirements for development; and finally, 4) to train teachers (Chen 1981:156).

Liu Shaoqi's "key" schools made a come-back, breaking the drive for a single universal standard in education. The elitism thus reintroduced went even beyond Liu's original idea for key schools: key departments and key classes were set up in non-key schools, and labor 
requirements were reduced or eliminated for key school students. Students in neighborhood schools were, for the first time, divided into fast, medium, and slow tracks. The best teachers and administrators were taken from the neighborhood schools to run the key schools. Budgets, which had at first seemed ample to support both the key schools and the neighborhood schools, favored the key schools when agricultural or industrial demands made cuts necessary (Unger 1982:209).

Urban and rural differences increased. The urban system of universal education through high school was converted wholesale to college preparation, leading to frustration, since only $2-3 \%$ of the students could expect to pass the exams. Rural education, on the other hand, returned in large part to the half-work, half-study selfsupporting system, for economic reasons. In a period when the dominant political slogan is "get rich," rural parents are challenging the equity of the system (Robinson $1986: 87)$.

Politics remained an important part of the curriculum, but the proportion was greatly decreased, in some cases from $30 \%$ of the curriculum to 2 hours a week. Although the army remained in some schools to maintain order, the focus was now on rapid development of technical and scientific skills to support the four modernizations. 
See Table II for the correlation of student age and educational experience. 
TABLE II

CORRELATION OF STUDENT AGE AND THE YEARS OF THE CULTURAL REVOLUTION AND RUSSIAN

DOMINANCE OF EDUCATION

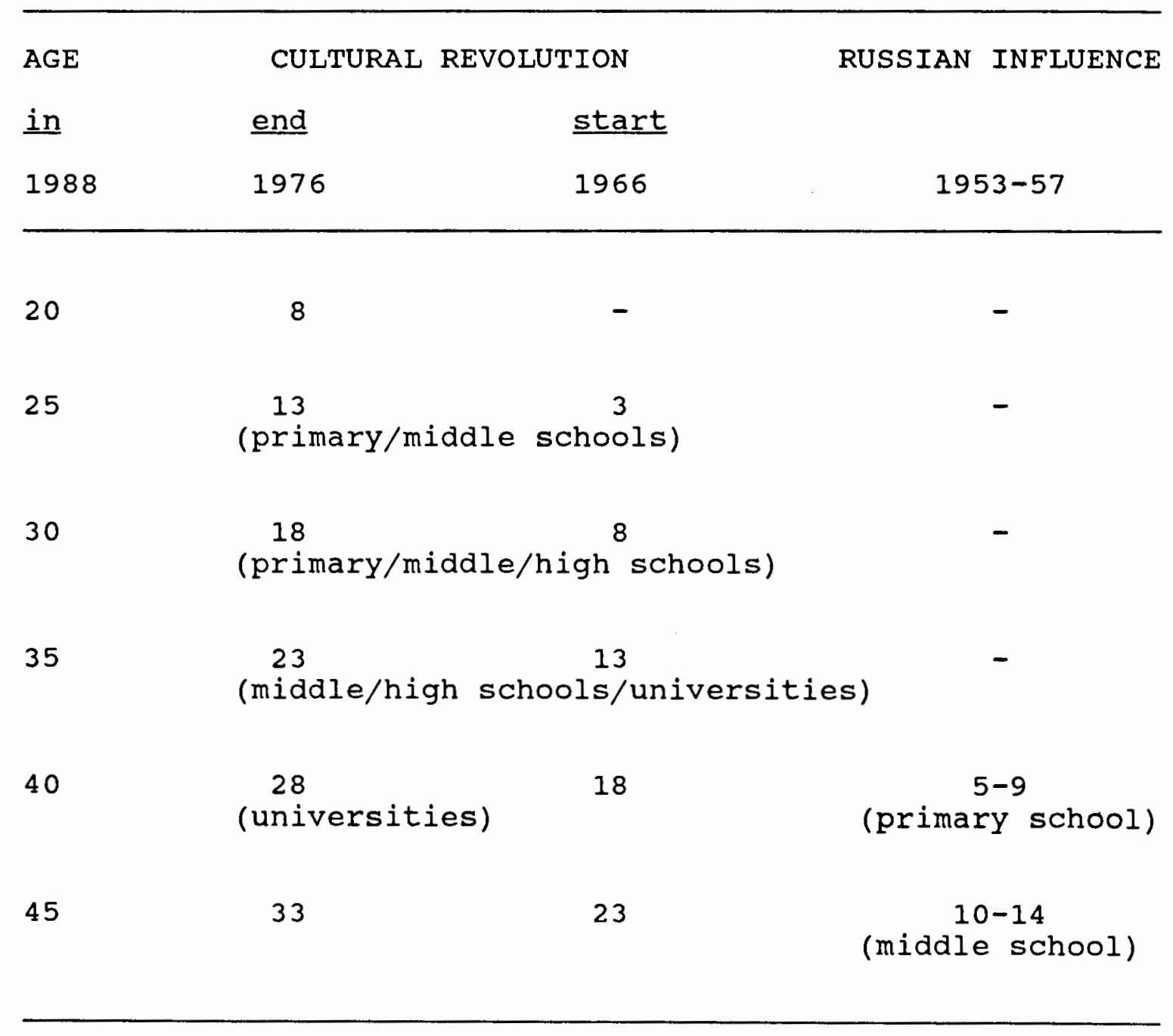


English Teaching at Chinese Universities

Since $85 \%$ of the information in international

information storage and retrieval networks is in English (Grabe and Mahon 1982:50), English has become an important subject throughout the university system.

Accounts of numerous teachers who have returned from teaching English in China, as well as descriptions by Chinese educators, depict university English teaching as heavily examination oriented, based on memorization and grammar translation, with "intensive reading" as the core course and basic methodological approach. [See, for example, Grabe and Mahon (1982), Van Naerssen (1984), Tinberg (1986), Turner-Gottschang (1987), Tang (1983), and Zhuang (1984).]

Another feature frequently mentioned by these authors is the teacher-centered classroom in which presentation of carefully prepared lectures, not discussion-leading, is the teacher's role. The extent to which this pattern in fact contrasts with the typical U.S. classroom, however, has been called into question by a UCLA research team's comparison of a small sample of science classes in both countries. The study found, for example, that while "teacher talking time" in the chinese sample ranged from 93.7\%-99.6\% of the time, the American sample revealed figures that were not far different: $88.1 \%-98.8 \%$. The study did find differences in the nature of in-class 
exchanges, in particular the presence of personal opinion and joking in the U.S. classroom, but noted that in China opinions are sometimes discussed with the teacher during the break that occurs at the midpoint of the typical 2-hour class (Van Naerssen 1984:4).

WRITTEN LANGUAGE CONTRASTS:

SYNTAX, VOCABULARY, TOPICS, RHETORIC, AND VOICE

In addition to contrasting educational systems, the Chinese student in an ESL writing class in the U.S. faces obvious contrasts of language: of graphic systems, syntax, word choice, and to an as yet ill-defined extent, of thematic content, rhetorical patterns of organization, and voice as well. The graphic contrasts will be left out of the following discussion, since all of the students in this study were able to write legible English.

The first thing to understand about the Chinese language is that it is more accurate to speak of languages. The differences between "putong hua" (Mandarin), the standard or common "dialect" found as a first language mainly in the north, and the eight other main "dialect" groups into which Chao (1976:21) divides what we call "Chinese," are as great as the differences between English and Dutch, or French and Italian (De Francis 1984:39).12

12 In 1984, De Francis (p.39) estimated that twothirds to three-fourths of all Chinese speak "putong hua." While government policy is to spread its use as the official language and language of instructions, there is 
While this variation is truer of the spoken language than of the written language that is the focus here, it has some ramifications in writing; for example, while the written text of a news report printed in a paper may be basically the same in Beijing and Guangdong (Canton), there will be variations due to the occasional insertion of dialect phrases for local color. This complexity is significant for the ESL writing teacher because it affects a student's understanding of the role of writing, and awareness of spoken and written language differences. Many Chinese students in America come from south of the Yangtze, from Shanghai, Guangdong, Sichuan and Hunan provinces (and from other provinces which vary from institution to institution, following the pattern of formal ties and exchanges). The linguistic complexity of this region prompts such comments as the following (in this case, about Fujian province): "People separated by a blade of grass could not understand each other" (Lehman 1975:49). This means that many of the Chinese students in ESL classrooms have developed a fair degree of linguistic sophistication through years of dealing with a variety of languages--sophistication, and sometimes surprising constructions of the linguistic world. One Chinese professor of English writing recalls that until she was seven she thought that the English her parents taught her

some resistance from speakers of other "dialects." 
in her home in Shanghai was just another dialect of Chinese, like the wu and Cantonese and other dialects her classmates spoke at home (Lu 1987:438).

The language contrasts dealt with in the rest of this chapter will be based on "putong hua," Mandarin.

\section{Syntactic contrasts}

Two general features of chinese lie beneath many of its syntactic differences with English. First, it is an isolating language, while English might be called residually inflective. An example of this difference is that tense, voice, mood, and number are all shown in Chinese by the addition of adverbs or other modifiers, or understood by logical inference. "I go yesterday," for instance, can only be an expression of past action; everyone knows that yesterday is past. If you talk about "two book" in Chinese, the meaning can only be plural.

Enough is enough, the Chinese language seems to imply. Why belabor a point and ask for trouble with a redundant marker like "-s"?

Topic/Comment. The second feature is that chinese is a "topic/comment" language, while English is "subject/verb" based. In a subject/verb language, the subject (or topic) of the sentence stands in grammatical relationship to the verb; in a topic/comment language, the subject (topic) is independent of the sentence. For 
example: That tree, the leaves are big. or: That house, the color is beautiful (Li, in Feng 1981:39).

This feature is linked to what English speakers see as a double nominative construction in Chinese. Instead of using double nominatives, English expresses the same concepts by adverbials, prepositional phrases, or relative clauses with "whose," as in the following example:

"Na haizi, baba si le, mama gai jia le, shezai kelian."

The child, father died, mother remarried, really pitiable. The child, whose father died and whose mother remarried, is really pitiable (Tsao 1983:107).

Binary scale. A third, perhaps less obvious contrast between the two languages is that Chinese seems to be based on a binary scale, while English is based on a sliding scale (Pease 1988). This binary scale produces positive/negative contrasts like the following: "Zuo tian shu fu, jin tian bu shu fu." That is, "Yesterday comfortable, today uncomfortable." While this construction is also possible in English, Pease points out a tendency of English to prefer qualifiers: "I don't feel as good today as I did yesterday." 13

Multiple, sliding scale distinctions are made by starting big and narrowing down, a feature that Pease finds recurrent in the language. For instance, where English can

13 This example incidentally illustrates another contrastive feature which often causes ESL students problems: the need for the copula in English where the adjective is sufficient in chinese. 
say, "I ate three of the ten cookies," in chinese it is practically impossible to say it in that order; one must say, "Those ten cookies, I ate three of them." Another example of this feature can be seen in the way envelopes are addressed. While an English address starts with the smallest unit, the individual person, and moves progressively larger, to the country, in chinese the reverse is true: the country comes first, the individual last.

Word order. While chinese may be described as having, like English, a subject/verb/object word order, it differs from English in several ways, including clefting, branching, and the positioning of relative clauses. 14 clefting functions in both English and Chinese to focus attention on new information and imply a contrast. The difference between the languages is that clefting serves this purpose in both spoken and written chinese, while in English it is more prominent in writing than in speaking, since stress and intonation perform the focussing functions in English speech (Tsao:103).

Chinese is left-branching, while English is rightbranching. This can be illustrated in the positioning of relative clauses before the noun they modify, as in the

14 While the contrasts referred to in this chapter are based on the "pu tong hua" or Mandarin form of Chinese, there is a significant contrast in word order for some other forms: "Pu tong hua" follows svo order, but some other "dialects" follow sov. (Chao, 1968: 13) 
following example: "My-father-gave-me-last-year-for-my birthday (particle) watch got lost" (Pease 1988).

Verbs. The most striking contrast in verb systems, the marking of tense in Chinese by adverbs, markers, or implication, has already been mentioned. Another important contrast is in the Chinese avoidance of the passive construction. In the past, chinese used the passive mainly to mark events that were unhappy or unfortunate for the subject; this is still largely true. In Chinese, the effect of the passive in English can be achieved by shifting the object to the front and making it the topic (Tsao:104).

Nouns and pronouns. In addition to showing plural through logic and added words, Chinese and English have several other differences in their treatment of nouns. Where English is apt to prefer a pronoun substitution, for example, Chinese will often prefer a repetition of the noun.

Definiteness is usually marked in Chinese through word order: if the noun comes before the verb it is definite; if it comes after, it is indefinite. Definiteness can also be shown through the use of "this," "that," or "one," plus a classifier plus the noun, but this is not often done. (Tsao:104)

All nouns in Chinese are treated as mass nouns are in English; that is, they must be preceded by numerals and classifiers to make them countable. This is similar to the 
destinction in English between "paper" and "three sheets of paper," where "sheets" is the classifier. Erbaugh (1988:18) points out that in conversation there is a distinction in classifier use: on the first mention of an object, its specific classifier is used; on second mention, a general classifier may be used.

Lexical nominalization is currently a topic of debate within the Peoples' Republic of China, since English is pushing the language to allow nominalization. (Tsao:108) In discussing this contrast, Tsao opens up the debate on the relationship of language to thought. The structural contrast between the two languages is this: in Chinese, any word may stand in subject or object position, but in English, as in other Indo-European languages, it is impossible to discuss a verb or an adjective as a topic unless it is made into a noun.

Tsao suggests that these different grammatical structures have arisen from, and perpetuate, different ways of thinking: in English, abstract nouns originating as verbs or adjectives are treated like entities, he claims, while in Chinese they are seen as metaphors. A sentence such as "I deeply feel his resistance," translated directly, becomes questionable in Chinese as "Wo shen shen juede ta de fankang," because "fankang" (resist, revolt) can not normally be treated as a noun, with the possessive "ta-de" (his) (p. 108). 
Cohesive Devices

a) Reference. In general, chinese is more tolerant of pronoun deletion than English; if either a pronoun or 0 can occur, Chinese tends to prefer 0 , while English prefers the pronoun. In addition, the pronouns that are used are not used in the same way as their English translations. The Chinese word for "it" ("ta"), for example, is not the equivalent of its English counterpart. Its use is much more limited in chinese, where "it" is used chiefly to refer to animals. Where English uses "it" in the subject/topic position, Chinese uses lexical repetition. In other positions, o pronoun is used.

b) Ellipsis. The deletion both of verbs after modals and of words in comparisons also contrasts with English. While both English and Chinese can delete verbs after modals, Chinese restricts the modals that may be followed by deletions to the following: can ("neng"), dare ("gan"), and will/can ("hui").

Tsao, like Pease, discusses the different ways comparisons are made in Chinese and English. While Pease discusses the difference in terms of a binary scale, Tsao discusses it in terms of ellipsis. He argues that, while both languages allow deletion in comparative statements, English is more concerned with making the logic explicit, and chinese with eliminating redundancy. He uses a similar example to Pease's: 
"Wo bi zuo tian shu fu."

I compared yesterday comfortable (word for word)

I am better than I was yesterday (idiomatic) ( $\mathrm{p}$. 101).

c) Connectors. Tsao makes three observations. First, Chinese tends to use parataxis (clauses following each other with no linking word), while English relies heavily on subordination. Second, English can in general, albeit with some overlap, distinguish three classes which are often indistinguishable in chinese: prepositions, conjunctions, and adverbial connectives. To Chinese students, therefore, these may all look alike.

The third contrast lies in the positioning of clausal conjunctions. While in English the conjunction can occur between the main and subordinate clauses, in Chinese most conjunctions cannot. On the other hand, Chinese has a group of "variable position connectives" that can occur either sentence initially or (unlike English) following the subject/topic:

"Ta suiran hen yunggong, haishi mei kao jige. "He although very work hard, still did not pass (Tsao: 102).

Teaching suggestions. Pease suggests the following as difficult points for Chinese students learning English: counterfactuals, the pluperfect, and comparisons of degree. 15 He adds that it may be helpful to composition teachers trying to understand their students' problems to

15 He takes pains to emphasize, however, that the difficulties are syntactic, not conceptual. 
think of Chinese writing more as a dialogue, and English writing more as a speech.

Feng (1981:53ff) suggests the following teaching points: coherence, subordination, affirmativeness, objectivity (no use of "I"), passives, double subject problems, and sentence boundaries.

Table III summarizes some of the major syntactic contrasts between Chinese and English. 
I. Inflections: Chinese relies on modifiers and logical inference to show tense and plural.

ex: These two letter I write yesterday. (literally)

II. Adjectives and prepositions can serve as predicates. ex: Ni hao? (literally, you good?)

III. Relative clauses come before the modified noun.

ex: My-father-gave-me-last-year-for-my-birthday (particle) watch got lost.

IV. Double nominative constructions in chinese become adverbials, prepositional phrases, or relative clauses in English.

ex: The child, father died, mother remarried, really pitiable.

The child, whose father died and mother remarried, is really pitiable.

v. Deletion differences

A. Chinese is more tolerant of pronoun deletion than English is.

ex: No matter do what, must from reality start.

B. While both Chinese and English can delete verbs after modals, Chinese restricts the modals which can be followed by deletions to can (neng), dare (gan), and will/can (hui).

C. In comparisons, Chinese seems to be more concerned with eliminating redundancy, English with making the logic explicit.

ex: I compared yesterday comfortable. (Chinese)

I am better than I was yesterday. (English) 
TABLE III

SYNTACTIC CONTRASTS OF

CHINESE AND ENGLISH

(continued)

VI. Connectors

A. Prepositions, conjunctions, and adverbial connectors, which are generally distinguishable in English, are often undistinguishable in Chinese.

B. The connector can sometimes be placed after the subject in Chinese, but usually not between clauses.

ex: He although very work hard, still didn't pass.

C. Chinese tends to prefer parataxis (clauses following each other with no connecting word), while English relies heavily on subordination.

VII. Cohesion: Chinese repeats the noun; English uses pronouns.

VIII. Word order: Chinese is topic/comment, with the verb or most important new information coming at the end. 
Vocabulary

Sun (1970:82) notes that Chinese students tend to think that the use of idioms marks them as fluent English speakers, adding that in reality their frequent and often mistaken use of idioms marks them as foreign.

Qiu discusses problems with denotation and connotation as well as with idioms. Chinese students new to English confront many words without equivalents in Chinese: hamburger, yippie, hippie, the "me generation," for example $(1983: 54,55)$. In addition, words they do know take on confusing connotations. "Authorities", for example, which is usually pejorative in Chinese, may be neutral or even positive in English; "indoctrinate", which is neutral in Chinese, is heavily pejorative in English; and calling a man a "wolf" in Chinese implies not that he is a womanizer, but that he is ferocious and aggressive (p. 55-56).

While a few idioms and proverbs translate well, others change meaning. If your hair stands on end in China, you are angry. If you lock the door after the horse is stolen, you are acting wisely, for it is never too late to take precautions (p. 56).

\section{Thematic contrasts}

Contrasts in themes and approaches to topics are at present much less clearly defined than syntactic contrasts; perhaps they are ultimately incapable of equally clear definition. Yet two studies are worth mentioning to 
illustrate both the potential and pitfalls of such contrasts. The first is Domino's (1985) analysis of 316 story-completions done by eighty $11-13$ year-olds in Beijing and eighty students of the same ages in Los Angeles. The second is McKay's (1986) comparison of story descriptions and interpretations given by Chinese students in Beijing and Xian with those given by foreign students in the U.S.

Domino discerned seven points of contrast. He perceived Chinese students as showing greater social orientation (more characters, more interaction, more teamwork, more public shame, fewer confrontations); more concern with authority; greater pre-occupation with moral and ethical rectitude; more affective elements; fewer rational or cognitive aspects and a stronger belief in chance, luck, or the influence of natural forces; less economic orientation; fewer instances of physical aggression.

The ease and attractiveness of such contrasts should be a warning of their potential to lead to absurdity, as is apparently the case with certain points in the McKay study. McKay's students were given this information: "You were standing in a long queue at a bus stop one evening. First, describe the scene, and then go on to say what happened when it began to rain heavily." The problem of cultural understanding enters immediately for, although westerners in 
China may wish for bus queues (Barlow and Lowe 1985:7), Iining up is not the custom there.

Two other limitations in McKay's interpretation further illustrate the importance of the background knowledge of the researcher. She suggests (p. 6-7) that giving a moral to the story, as "most" of the Chinese students did, may be linked to Mao's dictum that education must serve proletarian politics and the spirit of socialist morality. While this does show some cultural awareness, it does not go deep enough, and thereby risks skewing her reader's understanding by side-tracking it to politics, instead of showing that moralizing has been central to Chinese education for thousands of years.

The second point illustrates the limitations of conjecture. Several of the students in America spoke of weather predictions in their descriptions; none of the Chinese students did. From this McKay concludes: "...this is most likely due to their unfamiliarity with such an occurrence." Yet even non-Chinese-speaking visitors to China say they saw weather forecasts nightly on television, and Chinese students simply laughed and shook their heads at her statement. The moral here seems to be that, although thematic contrasts and interpretation are intriguing, they should be made, and read, with caution. 


\section{Rhetorical Contrasts}

Kaplan's Theory. The cautions raised about thematic contrasts apply to rhetorical contrasts as well. In this section the work of Robert Kaplan will be examined in some detail, since that work has become the obligatorily cited foundation of the field of contrastive rhetoric.

To be fair to Kaplan, it should be noted that his own theories have developed over time and his more recent writing urges caution in making comparisons, talks of some of the findings of his earlier work as naive and too strong (for example, see the addendum to his "Cultural Thought Patterns in Inter-Cultural Education," 1980:416). Yet in the process of developing a discipline by text building on text (see Edward Said's orientalism), a process in which later texts draw their justification from prior texts and prior texts become lenses that determine the way in which the world is seen, Kaplan's early writings are still to be reckoned with.

What, then, is the world of contrasting chinese and English rhetoric, according to Kaplan? It is a world in which the "indirection" and "negative development" of chinese rhetoric contrasts to the direct linearity of English (in croft, 1980:406). He symbolizes the organizational structure of chinese as a spiral (O) , in which a subject is developed by paragraphs which turn around it, showing a variety of tangential views without 
making a direct statement. He claims that often the subject may be developed in terms of what it is not, negatively.

Kaplan based his original characterization of chinese on a form which was the standard for writing from the fifteenth century to the beginning of the twentieth, the "eight-legged essay."16 Despite work showing Chinese students' ignorance of this essay form (see Feng), so much of the work of contrastive rhetoric has been based on this that a brief description will be included here.

The essay was called "eight-legged" because it consisted of eight clearly prescribed parts, which were bound by "elaborate parallelism" and "harmonious contrast" (Kaplan 1968:3). The length, too, was prescribed, varying between 350 and 700 words. The specified "legs" were as follows:

$\left.\begin{array}{l}\text { 1) p'o t'i--breaking open the topic } \\ \text { 2) ch'eng t'i--accepting the title }\end{array}\right\}$ parallel

3) ch'i chiang--embarking (introductory discourse)
4) ch'i ku--introductory corollary

$\left.\begin{array}{l}\text { 5) hsu ku--first middle leg } \\ \text { 6) chung ku--second middle leg }\end{array}\right\}$ parallel

7) hou ku--first final leg

8) chieh shu--tying the knot\} parallel

16 A good lesson in perspective is found in the different responses of two researchers, one American and one Chinese, to this 400 year dominance. While the American was impressed by the longevity of the form, the Chinese researcher observed, "The 8-legged essay lasted only 400 of China's 5000 years of literary history." (Feng, 1981:12) 
In the "p'ot'i," the topic was introduced; the "ch'eng t'i" gave a brief explanation of the writer's position on the topic. In the "ch'i chiang," the writer elaborated on the topic, demonstrating his scholarship; in the "ch'i ku," the center of the essay, he demonstrated his rhetorical skill. The "hsu ku" was brief, typically a rhetorical question followed by the "chung $\mathrm{ku}$," the answer to the rhetorical question. The "hou ku" would elaborate on that answer. The "chieh shu" was the exclamatory grand conclusion (Kaplan 1968:6).

The three particular rhetorical points in the eightlegged essay which ESL teachers may find most relevant are the use of rhetorical questions, the tendancy to rely on parallelism for coherence, and the exclamatory grand conclusion. The following conclusion from an intermediate ESL student's composition illustrates the last point: "The above three common situations are not good for society. May it be better."

Challenges to Kaplan. More recent work raises questions about Kaplan's analysis and offers other explanations for the differences between Chinese and English writing [see Feng (1981), Mohan and Lo (1985), and Houghton and Hoey (1983)]. Chinese student awareness of the eight-legged form was part of a study of sixty students at Fresno State University. Feng determined that none of the students knew what the eight sections were, although 
almost all recognized the name, and one-fourth of the students knew "more" than the name. (This is not meant as conclusive "proof"--or "disproof"--however; it is, of course, quite possible to use a pattern without being able to name it.)

Mohan and Lo's "Academic Writing and Chinese Students: Transfer and Developmental Factors" approached the contrastive rhetoric argument from several sides. In examining classical Chinese texts, they found "no support for claims that the organizational pattern of chinese writing differs markedly from that of English" (p. 515). Instead, they cited examples from Confucius and Mencius illustrating generalization and direct support on the one hand, and inductive development on the other. Further, they cite textbooks on modern chinese composition which urge students to be direct and concise; to have a thesis for the composition, a main idea for each paragraph, and unity and coherence for the whole. They conclude that similarities are more apparent than differences, and that problems in English writing were not conceptual but stemmed from a teaching emphasis on sentence level accuracy. 17 Houghton and Hoey challenge contrastive rhetoric on more theoretical grounds. They see it as based in

17 In a related study, yau (1983:i) found that the development of syntactic maturity in secondary Chinese students studying ESL followed the pattern of native English speaker development. 
ethnocentrism and as displaying a lack of awareness of nonIinear patterns of English organization (p. 9). They are especially critical of problems it poses for comparability: comparability of discourse, of student vs. published work, of native language vs. second language, of synchrony vs. diachrony, of over-narrow interpretation. They conclude, "One thing is certain: if French cheese is compared with English chalk we will learn little about the differences between the two countries' cuisines" (p. 13).

Another model. One way to develop contrastive rhetoric theory is to de-bunk false assumptions. Another is to try to formulate other, stronger models. Tsao (1983:110) presents the "chi-cheng-juan-he" as "the most famed principle of paragraph organization in Chinese." The four parts of this model may be described as follows:

chi (beginning or introduction of a topic) cheng (hook up, or elucidation of the topic) juan (turning to another viewpoint) he (coming together, summary, closing, or conclusion) Tsao emphasizes two points of contrast with the explicit, linear development found in English. The first is that the "chi," or introduction, is not the same as a topic sentence: it must be related to the theme, but it is not necessarily a statement of the theme. (In Kaplan's terms, it can approach the theme through indirection.) The second major point of contrast, according to Tsao, is that the "juan" involves a change of some kind: 
mood, place, time, point of view, tone, or grammatical subject.

It can be helpful to the ESL teacher to realize that what appears as a logical leap (some teachers might prefer to call it an "illogical leap") may not be based on a difference in logic, but rather on an attempt to produce a different effect, on a conscious effort to arrange the composition to provide a feeling of change. Reliance on the use of parallelism for coherence, mentioned above, may heighten this effect of leaping without tight, explicit connection from one idea to the next.

At the same time, contrastive rhetoric theory is pushed towards greater sophistication by a study referred to in Tsao (p. 110). This study found the "chi-cheng-juanhe" pattern applicable to the analysis of many English reading passages taken from the TOEFL and the GRE.

Rhetoric and cognition. There are some on both sides of the Pacific who think rhetorical contrasts have cognitive implications. While some Western psycholinguists extoll the particular fit of an alphabetized, linear language to the organization of the language-processing centers of the brain, Chinese psycholinguists write of the particular suitability of Chinese characters for developing the whole mind in balance, since they engage both the right and left hemispheres of the brain (zheng). 
There are other claims. The Chinese "lack a concept of time and history because their verbs do not mark tense"; the Chinese "rejected Christianity in part because chinese grammar does not distinguish between being and essence"; "Chinese philosophy has no concept of truth' and little impetus for abstract thought because they ${ }^{\circ}$ can rely on picturing or representing as the method of tying language to things without having to invent a detour through mental images'" (Erbaugh 1988:3-4). Erbaugh cites these claims only to argue against them. They are, she claims, based on a poor understanding of grammar and its relation to culture.

A brief description of the argument between Erbaugh and Bloom should raise the necessary cautionary questions about the validity of such speculation. The psychologist Alfred Bloom, in his book The Linguistic Shaping of Thought: A Study of the Impact of Language on Thinking in China and the West, claims that theoretical thinking in China is more restricted to the scientist than it is in the West, where it "can become a part of the speaker's everyday linguistic and cognitive activity" (1981:53).

He bases this claim on the results of a study he did on the different use in Chinese and English of counterfactuals, statements about events that could have happened but did not. Chinese and American students were given passages to read in their native language, and then 
asked to answer questions about whether or not the events actually took place. When the Americans answered the questions correctly and the Chinese did not, Bloom was led to speculate about the ability of the Chinese to think theoretically.

Erbaugh suggests that it is Bloom's ability to translate English into Chinese, and not the Chinese ability to think hypothetically, that should be questioned. She discusses two separate replications of Bloom's studies which showed that Chinese students did as well as or better than their English counterparts when Bloom's materials were translated into idiomatic Chinese. She also cites a study of the development of counterfactual language among children, showing the comparability of Chinese, Polish, and French two year-olds.

Caution, then, is urged in the consideration of the link of grammar to cognitive capacity.

Voice: devil or angel or mute

A discussion of the language difficulties Chinese 18

18 Not Chinese only. In Satanic Verses (1988), Salman Rushdie struggles with the disorientations of voice and being that accompany crossing cultural boundaries. Eric Sellin (1988), discussing Francophone Maghrebian (North African) writers, talks of both the terror and the liberation of the creativity engendered by such crossing. "Narrative frequently yields to verbal play," he writes, "reverberation between or among the languages which the bilingual or plurilingual writer knows and uses...." (p. 168). Sellin quotes from one of these writers, Abdelkebir Khatibi, a passage that is strongly reminiscent of a passage from another writer living between two languages, Maxine 
ESL students face cannot neglect problems of voice. Who is it that is speaking, writing? Which self? Who is the audience? How much of the student's world will that audience accept as real? What expectations does the audience have of the student speaker-writers? How has it pre-constructed them? Are they cast as inhuman, extrahuman, devils or angels?

Silence, and a struggle to end the silence, is one possible response to these questions. In her novel Woman Warrior (1975), Maxine Hong Kingston meditates on her own silence as she left the chinese world of her parents' home for the American world of the school playground. The book starts with an injunction not to reveal secrets; it ends with the high, clear sound of the exile singing.

In "From Silence to Words: Writing as Struggle," Min-zhan Lu writes a more scholarly account of a similar journey. Her two worlds were the Western humanist tradition of her English-speaking Shanghai family, and the Maoist version of Marxism that she met at school. Sometimes the meanings of words in the two worlds were compatible, reconcilable: the red of the flag in China and

Hong Kingston in The Woman Warrior. In Kingston's novel, the mythic-heroic woman warrior's parents carve words of grievance and revenge on her back. In his passage, Khatibi writes, "The other night I dreamt that my body was made of words." Sellin sees this notion "of not so much living one's language as being lived by it... or being born of it..." (p. 172) as a leitmotif in certain Maghrebian writers. A leitmotif rich in suggestiveness for understanding the experience of ESL students. 
the red of "MY love is like a red, red rose" seemed to reinforce each other (1987:439). Sometimes she could manage to shift in speaking and reading from one language code to another, one value structure to another, "in the same way I put on and took off my school clothes, to avoid being criticized for wearing Bourgeois clothes." At home she loved to read for the moments when characters experienced internal conflict. At school she read to discover moments when the hero showed revolutionary spirit, or ways the collective taught the individual a lesson. But these worlds would not stay separate, and switching between them became confusing, frustrating, painful. She became suspicious of herself and afraid she was losing her command of both languages. Writing became a "dreadful chore" (p. 443).

Reflecting on this experience, the mature Min-zhan Lu, writing as an English teacher in the United States, argues that the way out of the dilemma is to help students negotiate the different voices by teaching them to transform as well as preserve the discourses they are learning. "Don't teach them to 'survive' the whirlpool of crosscurrents by avoiding it," she urges. "Use the classroom to moderate the currents... but teach them from the beginning to struggle" (p. 447). 
THE CHINESE IN INTERCULTURAL COMMUNICATION THEORY

One way ESL teachers come to know their students is through required coursework in teacher training programs. At the site of this study, prospective ESL teachers were required to take nine credits in "cultural studies," which generally included courses in intercultural communication. This section of the review of the literature will focus on the information about the chinese presented in the basic intercultural communication courses, those courses ESL teachers are most likely to take.

It should be noted at the outset that these introductory courses do not pretend to teach any one culture in depth, so what is to be learned about china from them is no more substantial than a pastiche of the stories about China that various writers have used to illustrate this or that theory. For that very reason, since a little knowledge is a dangerous thing, it is instructive to see what sort of picture of China they create, and to point out some shortcomings.

In Cross-Cultural Encounters, Brislin refers to China five times. He uses the expression "Chinese puzzle" to illustrate the way everyday language imputes characteristics to ethnic groups (1981:32). He uses China as a contrasting culture in his discussion of the development of the value of rugged individualism in America; he cites a writer with a chinese surname who 
discusses the "fundamental contrast in cultural orientations" between America and China with respect to what he calls the "collectivist-individualist dimension" (p.39). 19

He next mentions the chinese in probing the difference between racism as dogma and racism in face-toface situations. His example is of a 1934 study done in the United states which found that a chinese couple accompanied by a white American was served at 250 different hotels and restaurants, although $90 \%$ of those same establishments, when contacted by letter, claimed they would refuse service ( $p$. $141-142)$.

His two final references to the chinese have to do with the re-opening of relations between China and the U.S. in the late 1970's. He uses the positive comments of the first Americans visiting China to illustrate the role of situations in determining attributions of national characteristics. The Americans were treated well, and (therefore, he implies) brought back extremely positive views of China (p. 163-4). Finally, he mentions in passing the media attention given to groups of students arriving from the PRC (p. 238).

19 This observation was published in 1979, not long after the end of the cultural Revolution. It would be inteesting to know whether the intervening years have modified his assessment. 
An ESL teacher reading Brislin, then, would have these pieces of a picture of chinese students: the common language depicts them as complicated, although we are supposed to challenge this language; they are more oriented towards collectivism than individualism; there has been racism towards chinese in the past, but the current attitude is approval and enthusiasm. Or, as a teacher of Chinese history phrases it, the Chinese are either demons or saints, the yellow peril or magicians who throw dough into the air and it comes down noodles (Lee 1984).

Another standard text, Intercultural Communication:

A Reader (Samovar and Porter, 1982), contains Chinese examples illustrating variations in gesture, proxemics, family structure, and food taboos; it also cites a study showing there was no difference between European children and Chinese children from Hong Kong in their ability to interpret Piaget's exercises manipulating volume and shape.

The reference to proxemics includes a statement that Chinese may prefer side-by-side rather than face-to-face contact (p. 42), and that "Chinese hate to be touched" (p. 282). The importance of the extended family is mentioned (p. 68), as is the "extensive" eating of pork (p. 65). Perhaps a single comment will be enough to point out the limits such limited statements place on the mind of the trusting reader. Teachers who "learn" from this that Chinese do not like to be touched will not have the 
framework they need to understand what is happening when they see same-sex touching. They also risk missing a potential for great emotional warmth if they assume "hate to be touched" is the equivalent of cold. Such an assumption could keep a writing teacher from helping students find their true center, their voice.

The most extended discussion of the Chinese is found excerpted in the Samovar and Porter reader from Beyond culture, by Edward T. Hall. It is a discussion which illustrates the need for extreme caution in relying on the insights of this field. Hall uses the chinese language and the cultural Revolution to illustrate a distinction he wants to make between cultures he labels "high context" and "low context." In high context cultures, according to Hall, much of the meaning is implicit, embedded in the shared knowledge of generations; in low context cultures, the message is made more explicit.

One of Hall's arguments for China's having a highcontext culture is based on its written language, a language which he claims ties together Chinese, Koreans, Japanese, and even some Vietnamese of Chinese origin (1977:91). The limits of his knowledge appear, and begin to undermine his credibility. Why did he exclude from his list all the other Chinese scattered throughout southeast Asia--or throughout the world, for that matter? But more importantly, how is it meaningful to claim that these 
diverse groups are tied together by this language? surely it is no more meaningful than it is to say the English, the French, the Germans, and the Italians are tied together by a common script; in some ways, it is even less meaningful, since the Koreans, Japanese, and Vietnamese all have other scripts as well. What Hall is writing seems embarrassingly close to the "all orientals look alike" he presumably would eschew. 20

Unfortunately, that is just the beginning. Hall goes on to rest his case for chinese as a "high context" culture on an inadequate understanding of the Chinese language. He makes four claims, each of which is doubtful (p. 91-2). He says it is necessary to know the significance of 214 radicals (one part of a chinese character) in order to use a Chinese dictionary; in fact, it is only necessary to be able to recognize the character. He claims it is necessary to be conversant with Chinese history to be literate in Chinese; that is profoundly true for any language. He claims that writing chinese is an art form, and claims not to know of any "low context" culture in which writing is an art form; perhaps this is open to interpretation, but Western calligraphers exist and practice writing as an art.

He claims, finally, that unlike European language, it is necessary to be able to pronounce chinese in order to

20 Again, Edward Said's orientalism is called to mind as an antidote to this kind of thinking. 
read it, because each word can have four or more meanings depending on the inflection given it. This is partly true. Many "words" (identical configurations of vowels and consonants) do have four meanings that vary in the spoken language based on tone. The most common example is "ma," which can mean "mother," "horse," "scold," or can indicate a question, depending on tone. But this is irrelevant to the written language, since there are four separate characters to represent those four meanings. At no point does his argument for a contrast based on an inherent difference in language scripts stand up to scrutiny.

Hall's treatment of the Cultural Revolution displays a similar willingness to make easy generalizations based on slim understanding. He introduces the Cultural Revolution into a discussion of the relative effects of activism in high and low context cultures. Activism, he claims, is "less predictable and more threatening" in low context cultures, more easily absorbed by high context cultures without those cultures being shaken to their roots. "Chinese friends with whom I have spoken about these riots took them much less seriously than I did," he writes. "I was, of course, looking at them from the point of view of one reared in a low-context culture, where such riots can have disastrous effects on the society at large" (p. 94). (William Westmoreland's chilling words about the Vietnamese come to mind: "They don't value human life as much as we 
do.") Hall was, of course, writing in 1975 or 1976, unable to see how the effects of activism in both countries would appear a decade later. But he should have understood that his Chinese friends might not have been expressing a difference in seriousness, but rather a caution in speaking at a time when speech and thoughts were often turned against the speaker or those the speaker loved, with painful results. 21 It is not fair to judge a field by its stray remarks, but it is also important to consider the information or mis-information conveyed.

Not included in the basic courses, but made available to those students in one advanced course who made a special request, are articles giving information keyed to specific cultures. Were the prospective ESL teachers to reach this point, as most do not, they would begin to find useful information.

The article on the chinese comes from the chinatown Resources Development Center in San Francisco (no date given). Its presentation of potential areas of cultural conflict is nicely couched in an insistence on the complexity of cultural influences and the individuality of the people involved. The writers emphasize that in talking about chinese people, they are talking about people first,

21 It seems fair to speculate that this same looseness and recklessness is a source of Hall's creativity as well as of his misinterpretations; his silent Language has opened the eyes and minds of generations of students. 
Chinese second (p. 138). Attention is called to the heterogeneity of the Chinese in the U.S. (p. 127).

The writers of this text raise the following points of possible misinterpretation. Because of the different tonal patterns, rhythms of sentences, and use of lead-in phrases, Chinese may sometimes appear to Americans as rude or blunt (p. 130, 136). Because of a cultural injunction against boastfulness, Chinese may sometimes appear to Westerners as lacking in self-confidence (p. 137). Because making eye contact is thought rude in certain situations, Chinese may find Americans consider them as dishonest or as lacking confidence (p. 135). Because memorization, not the asking of critical questions, has been the basis of chinese education, students may not be eager to engage in critical questioning. Further, they may always respond in the affirmative to someone in authority, so it could be useful to have students repeat information to show understanding, rather than expect them to admit lack of understanding ( $p$. 131-2, 135). There are different concepts of what is public, what private (p. 136). The writers suggest that a longer term perspective on life may produce a greater willingness to accept deferred gratification and lead to stereotypes of the hard-working, uncomplaining Chinese--in turn producing the risk of exploitation (p. 134).

The above are some points to consider, perhaps, in teaching, as long as the basic point is not overlooked: 
"Chan is missing." The writers of the article on Chinese and American contrasts use this title of a movie about Chinatown to close their article with an insistence on the diversity and conflict within the Chinese population, and an emphasis on the "individual personalities, which often differ independently of cultural influences" (p. 139). In the film, a spoof on 1940's detective movies, the missing hero chan is described by various characters in a series of conflicting stereotypes that never seem to fit. In the end, we never see him, but are left with the narrator musing on his inability to pin down the nature of Chan (p. 139). We are left with questions--a truer position than the too easy answers we started with. A good position for ESL teachers.

This study, too, is a search for the right questions. Chapter I posed broad questions about the nature of Chinese students and the nature of research. This chapter looked for some beginnings of answers in what has been written about Chinese students in America, about education in China, and about linguistic and cultural contrasts facing chinese students who enroll in American universities.

Chinese students in the United States are part of a bursting open to the west that has sent their numbers soaring from 50 in 1978 to 20,000 in 1988. Depending on their age and class background, they bring with them an educational history that has been more or less interrupted 
and shaped by the sweeping political and cultural campaigns China has experienced in their lifetimes.

They face language differences in graphic systems, syntax, vocabulary, choice of topic, rhetoric, and voice. Syntactic differences--in sentence structure, word order, and ways of marking tense and number, for example--are the most clearly defined contrasts. At the other extreme are contrasts in rhetorical organization, which, while useful to pursue cautiously, may lead the unwary to speculation that is more akin to racism than to scholarship. A similar danger is present in cultural contrasts, although such contrasts may also lead to greater understanding.

The next chapter will discuss the methodology for the major portion of this study, which was the gathering of information from the students themselves. 


\section{CHAPTER III}

\section{METHODS}

One way of learning about chinese students is by reading about them. Another is by talking to them. This chapter will describe the disciplined talking that is the basis of the rest of this thesis. For a discussion of the theory behind these methods, see the introductory section on the ethnographic approach.

\section{SUBJECTS}

There were four groups of subjects in the study. Two students participated in the case study; twelve additional students in a university English as a second Language (ESL) program filled out questionnaires; fourteen other people with experience of learning or teaching English in China were interviewed: Chinese students and teachers, and Americans who had taught Chinese students. (Six others who filled out questionnaires were also interviewed, bringing the total interviewed to 20 , or 22 counting the two case study students.) In addition, ten ESL teachers responded to a questionnaire. All the subjects were currently living in the same Northwestern 
city; all but two were teaching or studying at the same university.

\section{Case study students}

The two students in the case study were selected because they were newly arrived in the United States, newly enrolled in an ESL program with which the researcher was familiar, and willing to participate in the study.

Both students entered the ESL program in the fall of 1987. Both were placed in "Level 2," the second, lowerintermediate, level of a four-level college ESL program, a level that corresponds very roughly with a score of 50-60 on the Michigan Test of English Language Proficiency. Both were women. Each had had her high school and college education in China interrupted and redefined by the Cultural Revolution, and had begun serious study of English in her mid-twenties. Both were from south of the Yangtze River, and both held F-1 visas.

Li Xian Tao (a pseudonym) entered the university in China in the first class of students to be admitted when the examination system was restored in 1977 , at the end of the Cultural Revolution. After earning her degree in physics, she taught physics in a university until she came to the United States to earn a higher degree.

Leung Wai Ping (also a pseudonym) was sent to night school by her work place in order to learn English for her job in importing and exporting. Later, when she was sent 
to the university to study accounting, she also studied English. She is in the U.S. to earn a business degree.

Li Xian Tao began English in middle school, dropped it during the Cultural Revolution, then picked it up from conversation classes taught by Americans at the university where she was teaching. In fact, however, she feels she learned little from the classes, but much from befriending the American teachers, with whom she talked nearly every day.

Leung Wai Ping had a more standard education in English, based on grammar rules and exercises. She had little chance to talk in English, either inside or out of class, although she did use English in her work, on standardized business forms and TELEXes.

Both students were recruited near the beginning of the term. One was recruited on registration day by a visiting Chinese scholar familiar with the ESL department and this study. The second responded to a letter sent to all seven Chinese students in Level 2 that fall.

\section{Questionnaire Subiects}

In all, 14 students responded to the questionnaire: the two case study students and 12 others. The 12 subjects recruited to respond to the questionnaire were selected because they had all been students in ESL, for at least one term, within the last five years. Eight of the 12 were students at the time they completed the survey. They were 
recruited in two ways: through an announcement made at an orientation meeting at the start of the term, and through personal oral invitation, followed by a written explanation of the project.

Eight men and four women participated (making the balance eight men and six women, counting the case study students). Ten were recruited on the basis of their interest in being part of the study. I invited the two others to participate for balance: one because of having had a long, difficult experience with ESL, the other, because of having great facility with English and of having had a brief but useful and successful experience with ESL. other characteristics of these students will be discussed in the chapter on questionnaire results.

\section{Interview subjects}

Fourteen people who did not respond to the questionnaire were interviewed; in addition, six (or eight, including the case study students) who did respond to the questionnaire were also interviewed. Ten of the twenty interviewees were teachers; the other ten were then, or had earlier been, ESL students. The teachers included five Chinese teachers of university level English, one Chinese professor of comparative education, two Americans who had taught English at Chinese universities, one American who had taught history at a "key" chinese univsersity, and one American who had worked with Chinese students in the U.S. to 
develop a video-tape for prospective chinese students coming to the United States. They were selected on the basis of their ability to articulate contrasts between the two educational systems and of their willingness to be interviewed.

The students were selected on the basis of having had experience in ESL, and of their willingness to be interviewed. The four students who did not also complete the questionnaire were among the first students interviewed; their responses and questions helped shape the developing questionnaire. (Not counted as interviews, but influencing the shaping of questions and the understanding of answers were many informal conversations with students and teachers.)

\section{ESL Teachers}

Ten ESL teachers from the university the students attended were surveyed. Three of the teachers had one to two years experience; five had from five to ten years; two had more than ten. All the teaching staff was given the questionnaire; ten out of twelve responded.

\section{INSTRUMENTS}

The instruments used in the study were guided but open-ended interviews, and three different questionnaires. 


\section{Interviews}

Open-ended interviews were the heart of the study. The student interviews, with both the case study students and the other students, all started in much the same way. The principal difference was that with the case study students, I was able to follow the discussion further in the directions I thought they were leading.

The interviews were held at a place chosen by the student: my office, the student cafeteria, the business lounge, a classroom, a student's apartment. Several times a student, knowing $I$ was interested in Chinese students learning English, would come prepared with something he or she felt I should know, and would, without ceremony, begin to tell it to me as soon as we sat down to talk.

In most cases, however, I started with a general question about how that student had learned English in China, then pursued the ensuing conversation as long as it seemed fruitful. A second general question was about learning to write in Chinese; a third, about learning English--especially writing--in the U.S.; a fourth, about contrasts between Chinese and English writing. I would attempt to cover all four points during the course of a one-to-two-hour interview, trying to work the questions naturally into the developing conversation. Sometimes a student had more to say than two hours could hold, so we scheduled a second session. Interviews ranged in length 
from half an hour to eight hours (this latter, spread over five meetings).

Interviews with teachers were open-ended as well, frequently starting with the question, "What differences have you noticed between students and teaching in China and in the United states?"

Information from the interviews was recorded in notes, which were then categorized thematically. The themes were then analyzed for frequency, redundancy, and "breakdowns."

\section{Questionnaires}

Three questionnaires were used, two for ESI students and a third for ESL teachers. The first questionnaire for students was based on recurrent themes drawn from the first interviews with Chinese teachers and students, and from the model of a questionnaire used in Maria Frolich's case Studies of Second Lanquage Learners (1976:220-227), a study that was part of a Canadian government project.

The first questionnaire was five pages long, with thirty-three questions (of which three were open-ended), divided into four major parts: general information, English education in China, writing background in Chinese, and English education in the United states. It was accompanied by a cover letter. (See Appendix B for copies of all three questionnaires used.) 
Mid-way through the project, when it seemed not enough information about ESL was being generated, a second questionnaire was developed. It was much shorter: two pages, with a total of eight questions (two open-ended and six requiring rating, ranking, or checking the appropriate box) .

The two questionnaires were intended to be complementary to the interviews. The questionnaires provided information that could be tabulated and compared; the interviews allowed a check on the interpretation of responses to the questionnaires, and allowed those students who felt comfortable to lead the discussion and define the issues.

A third questionnaire used in this study, a survey of ESI teachers at the students' school, was developed on the bases of the second student questionnaire and a discussion of undergraduate research done at the Institute for the Study of American Language and Culture at Lewis and Clark College (Whittemore 1988). The purpose of the survey was the same as that of the Lewis and clark study: to sample the congruence or incompatability of students' and teachers' views of ESL.

Most of the questionnaires were completed at home. Two student questionnaires were filled out in the presence of the researcher. Students were guaranteed anonymity, and told they did not have to respond to any question they did 
not like. This variation from standard surveying practices seemed important for establishing trust, given the history of information collection during the cultural Revolution. It also seemed better to have no information than misinformation.

Responses to the questionnaires were tabulated to show frequency and range of response. Since the sample was neither large nor randomly selected, the purpose of such tabulation was not to provide a basis for generalizations, but rather, to raise questions that could lead to interesting hypotheses for future studies.

The results from the interviews and questionnaires will be found in chapters IV and V. 
CHAPTER IV

CHINESE VOICES

Interviews were the heart of the study. In this chapter, twenty-two Chinese students speak about learning English. The first two sections are accounts of the two case studies; the last section is based on shorter interviews with twenty other students.

\section{LEUNG WAI PING}

When I first saw Wai Ping she was laughing and talking animatedly in chinese with a group of ESL students who were filling out forms on registration day of fall term, 1987. A visiting scholar who had been in the ESL department for a year and had offered to help me find students for my project was part of the group; eventually she brought wai Ping to the desk at the front of the room where I was working with students, and introduced us. There was no time to talk then, but we agreed that we were glad to work together and that we would have our first meeting two days later.

At that meeting we began to discuss her background in English and made plans to meet twice a week, Tuesdays and Thursdays, for two terms (which would have made a total of 
roughly 35 meetings). We planned to discuss education in China and learning to write in English. But my first lesson in the practical reality faced by many chinese students intervened before we could meet again.

on Monday she came to see me after class (she was one of six Chinese in a class of twenty lower-intermediate students to whom I taught grammar). She told me she was sorry she couldn't meet me the next day, but she had to find a new place to live--immediately. I was surprised, since at our first meeting she had said what a good host family she had; I thought she might be having second thoughts about talking with me. I was also worried that something might be seriously wrong, since occasionally ESL students had stories of beatings or sexual harrassment by host families. At the same time I did not want to make things even more difficult for her by directly offering help she might have found unwelcome, so I sent her a note in an afternoon class, saying that if she felt in danger she could come stay with me until she found a new place. she came early that evening and stayed for a week.

our talks, then, did not proceed in the regular fashion envisaged at their start, but they were fruitful in providing understanding of some of the dimensions of ESL students' lives. Not only were individual talks sometimes missed because of practical needs--the chance to get a ride to do a distant errand, for example--but the original plan 
of following a student through six months (two terms) of ESL had to be refashioned as wai Ping decided to spend the second term in a TOEFL preparation center, working with tapes and workbooks, rather than to continue with ESL. Yet in making that decision she was not atypical of Chinese students in the program: four of the six students who started that fall eventually switched to a TOEFL program, three after one term in ESL, and a fourth after two terms. So once again, while our meetings did not follow my plan for my study to the letter, they followed the spirit, by helping me understand some of the choices and decisions of one chinese student.

I interviewed wai Ping formally nine times over a six-month period, for a total of eleven and a half hours. For the first three months, I also saw her nearly every day, five days a week for one hour a day, in grammar class; often we would talk briefly about the day's work during the class, and occasionally talk a minute or two before or after class. Towards the end of the term we frequently talked informally about her decision to leave ESL. I also saw her at our home for Christmas, at a chinese movie in late winter, and, of course, during the week she lived with us.

In addition to formal and informal interviews, the case study consisted of her responses to three questionnaires and a collection of writing for the six- 
month period. Originally I had planned to make videotapes to analyze for classroom interaction, but her leaving the program made that impossible.

The information from the study will be organized into four parts: educational background, ESL experience, and "breakdowns" (Agar: 1986).

\section{Educational Background}

All but the first three years of Wai Ping's primary and secondary school education fell during the period of the Cultural Revolution. On leaving high school she spent three years as a factory worker, then three years as a clerk. She began to study English in night school when her manager asked her to do so. She studied at night for two years before passing the college entrance exam in 1982. At the university, her accounting major included another three years of English. After finishing college she worked as an accountant for a trading company for two years, just before coming to the United states to work for an M.B.A. degree.

Classes in China. In China, classes were different, Wai Ping reported, "no like here." 22 In China, she said,

22 A typical learner error. "But 'no' can be both an adjective and adverb," another student told me. "How do you know when you can and can't use it?" Uncertainty about rule application is only a partial explanation for some learner errors, however. Schumann (1986:293) posits two general principles at work in learner ("Basilang") speech: 1) Keep target language output simple; 2) Maintain the native language to whatever extent possible (here, in form). Both these rules seem to apply to this bit of 
the teacher speaks and the students take notes. They do not ask questions during class, only afterwards. "It isn't necessary to understand at once what the teacher says," she explained: "just write down the words." The notebook is more important than the text because the test will be based on the notes, she added, giving a rough translation of a bit of Chinese students" doggerel: "In class we write down notes; after class we check over notes; before the exam we recite notes; after the exam we forget notes."

She spoke of the organization of English classes at the university. Entering college students were given a written exam and then divided into six proficiency levels in English, twenty students to a class. Wai Ping was assigned to Level 4, which studied two years of "Basic English," then a half year each of "Business English" and "Accounting English."

The texts used in her first two years of study were from the popular English series put out by the Beijing Foreign Languages Institute. One book was used per term. (Higher levels, Levels 1 and 2, used New Concept English.) There was no writing or speaking; emphasis was on grammar and vocabulary. The students were to read the book and learn the grammar; homework was mainly translation. Before the exam the teacher gave a sheet of vocabulary and grammar points to study.

learner speech. 
Ping distinguished the work in her third year of English from the other two by content, not method of presentation. The content of the first two years she described as general, short stories with no humor and no violence. This was due to the lingering influence of the Cultural Revolution, she explained, describing the stories as embodying these themes: "A farmer works hard, has many children; or, a poor man has a hard life."

Her one-semester class of "Business English," used a British text (British Enqlish Lanquage) that described life in the business world. For example, it told about the lives of various employees in a furniture factory: what the general manager does, what the department manager does, what the workshop manager does. In her semester of "Accounting English," a text of that same name, written by the professor who taught the course, was used.

classes were two hours long, with a break of ten minutes in the middle. She had four to six hours of English per week (two to three classes). During the first hour, the teacher would usually explain the meaning of the text. The second hour was generally for grammar and exercises: the teacher would write an example on the board, give an explanation in Chinese, have the students do some cloze exercises, and then work on translation.

students would participate when called on by the teacher to give an opinion or stand up and read, but Ping 
said, "All of us rather close the mouth." Why? Because their education from the beginning did not encourage them to speak in class, she said. [See Taborek and Adamowski (1984), "To Seal Up One's Mouth Three Times."] They did ask questions, however, but only after class, during the break, or during the teacher's office hours.

Learning to Write in Chinese. Wai Ping was not sure how she had been taught to write in Chinese, apart from remembering being given the advice, "The more books you read, the better you write." In elementary school she remembered looking at a picture and then writing about it. In high school, she wrote summaries, personal letters, scientific reports, poetry, and political essays.

Sometimes the teacher would give a title and the students would write. "In the Cultural Revolution we always write about--you know...." Ping trailed off. I assume she was referring to the political slogans we had discussed briefly earlier: "Serve the people"; "To die for the people is heavier than Mt. Tai"; "Imitate Chang Si De" (a soldier held up as a hero of the revolution); and the one that came first to her mind, but that she didn't know how to finish translating: "Across the long river to Nanjing, the Peoples' Liberation Army...."

At other times in high school she wrote about activities they had done as a class: planting a tree, 
going to the countryside to do work, working for a week in a factory.

Daily life in college. Wai Ping found the most striking contrast between university life in china and in the United States was the relationship to classmates. In China, students entering the university are divided into classes of roughly thirty. These students spend most of their time together: they have all their classes--with the exception of English, in which students are grouped by ability level--together; they eat in dining halls together; and, segregated by gender, they sleep together, most often eight to a room.

The routine of Wai Ping's college life began at seven, when she would get up and go to the dining hall for a breakfast of rice porridge and steamed bread. (students in some departments in the university got up earlier to do exercise, but those in her department didn't.) classes started at eight and went to 9:50, with a ten-minute break in the middle. A second class started at ten, and went to lunch time, 12:00. After a 15 to 30 minute lunch in the dining hall, students had one to two hours for a nap. At 2:00 or 2:30, depending on the season, classes would begin again for some departments, although not for all. After 4:00, students were free to do as they liked, which for many meant sports: volleyball, badminton, basketball, 
football (soccer), tai-chi, tennis, and something she translated as "use a knife."

\section{ESL Experience}

The major emphasis in this part of the study was to have been on Wai Ping's experience in learning to write in English through an ESI writing class. However, as mentioned earlier, events gave me both less and more than I was looking for, as the emphasis shifted towards the end of the first term to Wai Ping's decision to leave ESL for a TOEFL preparation center.

Before that decision we had had a chance to discuss four different assignments and her reactions to them, reactions which became increasingly negative as the term progressed.

Her first assignment was to write an article introducing herself, her family, or her house; she chose the latter. Although she had never written a composition in English before ("I haven't write like this--in China the teacher would give us chinese sentences to...transfer...no, no, no, I mean translate."), she did not think it was very hard. In her words, in her ESL class there was "no requirement to reach a certain level--you just write free."

Two weeks into the term, her writing class was working on "linking words" and summarizing. Each student was to get information about a service on campus--the bookstore, the library, the International student services 
office--that might be useful to students in the class. They were to write 8-10 questions, ask them, write a report, then tell the class what they found out and answer questions. Again, Ping found this not too difficult, and seemed to enjoy it.

The next assignment we discussed was on "Life in the U.S.A." The first day they brainstormed categories and then supporting details for each category. The second day they continued their earlier discussion of connecting words, and then did an in-class assignment, making sentences as quickly as they could about life in the U.S., using the connecting words. Wai ping commented that since there was no time to think, it was easier to write, but the result was not so good.

Shortly after mid-term time we had our longest discussion on writing. She liked writing compositions, she said, because "the teacher can correct and help me organize"; she didn't like journals because "the teacher not correct--I don't know what's right or wrong." After I attempted to explain to her the theoretical relationship between corrected and uncorrected writing, she told me, "We just want to pass the TOEFL--we don't want to be a writer." Nor did she want to work with a partner or in small groups. "Maybe they are wrong--we are the same," she explained. 
our discussion of her fourth assignment--a discussion which included her writing teacher for part of the time-raised a theme repeated by several other students: English writing was too simple, too straightforward. The assignment was in several parts. First students were to interview a classmate from another part of the world to learn about different non-verbal greetings, then write an essay comparing and contrasting those greetings to the ones found in their own countries. Next, they were to discuss their papers with the person they had interviewed, and finally, they were to take their papers home and "make them perfect."

Wai Ping came to me to ask for help in making it perfect. Not being sure what perfection was, I asked the writing teacher for help. She was, of course, dismayed to find her joke had been taken so seriously. With great care she went through the paper with Ping, pointing out places where her paper did not match the outline the teacher had given for comparison and contrast compositions. She pointed out parts she thought did not balance, sequences that were jumbled, and points that were omitted.

Wai Ping listened, then said that following the form "made it too long the same thing, repeating and repeating." She didn't want to do that.

The teacher thought she hadn't understood what to do, and explained again how to balance the piece. After the teacher left, Ping explained, "I don't like writing to be so 
that-that-that-that," gesturing with her hands to show a step-by-step pattern.

After Wai Ping left, the teacher commented that Ping "still didn't seem to get it." The remark about "perfect," she added, was half a joke, half a serious comment related to editing problems: on a subject-verb agreement level, their papers should be perfect.

Towards the end of the term, outside the formal interview times, wai Ping began to talk about whether or not she should leave ESL. Her biggest concern was to pass the TOEFL so she could begin work on her major. The most important question for her, therefore, was, "Which route will get me there fastest?"

Another consideration was cost. The ESL program cost roughly $\$ 1000$ per three-month term; the TOEFL preparation center, $\$ 900$ for six months. Logistics were also a problem. She was moving to yet another family, forty minutes from town by bus, and so the center's drop-in policy was more convenient than the fixed class times of ESL. (This point came up again later in a conversation with wai Ping and another student who left ESL for the center at the same time she did. She agreed with him that the ESL program was good, but that, as an adult, it was preferable to be able to manage your own time.)

One drawback to the center wai Ping discussed in advance was that there was no teacher available to give 
help. Another drawback was the one-dimensional nature of instruction: workbooks keyed to tapes. She would lose the chance to speak and write. However, she thought that living with a compatible American family would make up for some of what she lost in speech, for it meant that she was immersed in English as a living language many hours a day.

\section{"Breakdowns"}

As mentioned in the introduction, what Agar calls "breakdowns," or moments where unexpected answers or actions push researchers beyond their current frameworks of understanding, are critical in ethnographic work. The four points mentioned briefly here, while not strong examples of breakdowns, illustrate the fruits of keeping open to the unexpected, and indicate paths along which full-blown breakdowns might be discovered, given a clear theoretical framework to contravene.

The first had to do with cultural expectations. When Wai Ping was temporarily living at our house, she arranged an interview with a new "au pair" family; before the family arrived, she appeared dressed in pajamas and a robe. When I told her pajamas weren't appropriate, she quickly changed but kept the robe. When I told her, half-apologetically, that she should also take off the robe, she told me not to 
be sorry, that was one of the things she needed to learn.23 Through this episode I learned two unexpected things. The first was the extent of explanation necessary, and the way it was narrowly interpreted. Pajamas meant pajamas, not robe. I began to imagine the accumulation of the details of daily life that are called into question for ESI students. Nothing can be taken for granted. The second surprise was how willing Wai Ping was to accept suggestions. I was the one who was embarrassed; she was eager to adapt, wanted me to speak, to help her. That very eagerness to adapt raises ethical questions: to what extent should ESL teachers encourage changes? In what areas? Where is the line between adapting to the culture and bringing something new to it?

A second quasi-breakdown occurred when she explained that she often made mistakes with "she" and "he" because she had a great deal of trouble saying the "sh" sound, even in Chinese. Other students suggested this trouble was regional, and was present in Chinese as well as in English: in some dialects of Chinese there was no "sh" sound. What I had thought of as a problem of contrastive grammar--"he" and

23 For an excellent account by a journalist of the surprises and conflicts of culture he faced as a student in Chicago, see Liu Zongren's Two Years in the Melting Pot. 
"she" in spoken chinese are both "ta"--was now being redefined as a pronunciation problem. 24

Wai ping's taste in literature raised questions about the cultural difference theories currently popular in intercultural communication (Bennett:1985). Although educated primarily during the cultural Revolution, she held Maupassant, Chekov, Dickens, and Balzac more clearly in mind than I did. The problem in communication was not, then, her lack of knowledge of Western culture, but rather my lack of knowledge that we could communicate on that level.25 This experience highlights the inadequacy of a single-minded focus on difference.

Finally, wai ping gave me a lesson in the possibilities of memorization. Teachers often spoke of her as quiet and reserved in class, and for the most part, she

24 One of the Chinese teachers of English asked if I thought people from the south could learn English easier; she thought she had observed such a pattern, but was looking for confirmation. Her point was that there are certain sounds of English that appear in dialects and languages in southern china that are absent in the north. Although Ping's being from the south seems to contradict the pattern the teacher suggests, Ping confirms the premise of her analysis by stating that her problems in English pronunciation are related to sounds that people in her dialect are unable to pronounce, even when they appear in other chinese dialects.

25 Another one of the students who left for the the TOEFL center surprised me one day by humming the first bars of Beethoven's 5th symphony as I was passing back tests. When I looked at him he thought he needed to explain it was Beethoven. He was surprised and delighted when I said yes, fate knocking at the door. Neither of us had suspected this knowledge in the other, apparently. 
was so in my class too. Yet given "How Much wood could a Wood Chuck Chuck" to memorize, her animated face and strong voice filled in the gaps when the other, usually more vocal, students faltered. I was drawn into rethinking the value of memorization in a communicative curriculum.

The interviews with Wai Ping gave me an introduction to the practical constraints on Chinese students. Housing was one problem; during the six-month study she lived au pair with three different families. The cost of ESI was another problem, as was the seeming lack of concern in ESL for the TOEFL, mastery of which Wai Ping and other students saw as the first practical hurdle to overcome in their course of study here.

Wai Ping's discussion of study in college recalled to mind the teacher-centered, memory-based focus of Chinese education described in the literature. Her discussion of the political topics given in writing class gave life to the shifts in educational policy during the Cultural Revolution.

Wai Ping's comments on writing instruction in ESL showed that some students may have more trouble with what they perceive as the over-simplification of ESL than they do with its difficulty.

Some of these themes were repeated in the comments of the second case study student, Li Xian Tao: the pressure of cost, the urgent necessity to pass the TOEFL, and the contrast of the isolating U.S. campus and the protective 
Chinese university. While pressure was one of many themes in talking with wai Ping, however, in my talks with Xian Tao it became at times overwhelming.

\section{XIAN TAO}

The second student in the case study, Li Xian Tao, was part of the same grammar class as Leung Wai Ping. I met her first in class, where I was struck by her lively, accurate participation and her warmth towards her classmates. Others of her teachers that fall term of 1987 commented on how quick and articulate she was, a pleasure to have in class. The transformation of that liveliness into anxiety is one part of the story of Li Xian Tao's experience; another part is the dominance of the TOEFL; another is her reliance on memorization--with an attendant reliance on long lists of words out of context.

I had intended to follow the same format with both students in the case studies: interviews twice a week for two terms. But following the larger plan of my study, to try to gain a better understanding of ESL students from China in order to teach them more effectively, meant changing that format. With Leung wai Ping those changes had meant following her through her decision to leave ESL for a TOEFL preparation center. With Li Xian Tao, the major change in format was the near abandonment of formal 
interviewing because I thought it important to alleviate the pressures weighing on her.

This change in format reflects a major ethical problem confronting participant-observers, be they anthropologists, photographers, writers, or ESL researchers, a problem often posed in "either/or" terms: When you see someone in trouble, what do you do? The assumption is you face a choice: either to go on making a faithful record of the event, or to offer help. Yet this is a false distinction, based on the untenable notion of the observer's invisibility and lack of influence on the observed. The question, and the work that results from the way it is answered, require not so much an answer as a reformulation.

In the case of Xian Tao, for example, giving help by abandoning the formal interviews led to a closer relationship which made possible more understanding of her view of the world. Giving help was consonnant with, not in opposition to, the goals of the study.

There is a further question to ask. What kind of knowledge is it that can be divorced from the human impulse to help? To the extent the observer influences the observed, then to that same extent it is perhaps not only fair but important to speculate that observation stripped of human generosity and kindness is not neutral but, in its extreme form, pernicious, yielding knowledge of its subjects in dehumanized conditions as it participates in that 
dehumanization. The real question is how to keep knowledge and compassion integrated, how best to both give help and observe accurately.

Li Xian Tao and I had only two formal interviews arranged at my request, and a third formal conference which began with a discussion of a paper she had written for my class. We made plans for many more, but as with Leung Wai Ping, there were many obstacles. Nonetheless, we spoke a great deal: sometimes after class, sometimes by phone, sometimes in the halls at school, where exchanges lasted from a few minutes to nearly an hour. In all, not counting roughly eighty classroom hours and brief encounters after class, we talked for nine and a half hours during the period from late October 1987 to late June 1988 .

The information we discussed will be organized as for Leung wai Ping: educational background, ESL experience, and "breakdowns."

\section{Educational Background}

Like Wai Ping, Xian Tao completed her primary and secondary education during the time of the cultural Revolution. Unlike wai Ping, she did it in ten years, not twelve: five in primary school, three in middle school, and two in high school.26 one of her high school years was

26 At various times and in various parts of China, responding both to central planning and to the limits of local resources, attempts have been made to condense twelve years of study into ten. 
spent in the countryside, going to school in the morning and building houses in the afternoon. Another half-year of high school was spent working in a factory by day and going to school at night.

She graduated from high school in 1977, just as the examination system was being restored as the standard for college admission. She sat for the first exam, was admitted, and was assigned to study physics, although her preference was radio. After four years of university, she was sent to the countryside for two years, where, in her words, she "became a peasant." Then she came back to the city to teach college physics for three years, until coming to the U.S. Although she was undecided about the major she would pursue here, her over-all goal was clear: to learn something that would be useful to china and return home to her friends and her teaching as quickly as possible.

Her education in English in China was episodic. It began in middle school, with one or two 40-minute classes per week, for one or two semesters (she couldn't remember which). During this time the emphasis was on pronunciation and simple grammar. She next encountered English in her first year in college, when she had two 50-minute classes a week. In 1985, when her school began inviting American teachers, she began attending their evening classes for one hour, twice a week. The real chance for improvement came, though, she felt, the last year before she came to the 
United States. Three American women came to teach English at her school, and while she found their classes boring and not very useful, she enjoyed talking with them nearly every day, became their friend, and made a lot of progress. It seems reasonable to assume that Xian Tao's unusual facility with speaking and understanding come from her unusual, oral/aural approach to the language.

Before coming to the U.S., the writing she had done in English consisted of fill-in-the-blank exercises, writing sentences to illustrate vocabulary words and grammar points, giving short answers to questions, and writing letters to friends.

But she had had training in writing chinese, in high school, not at the university. (Only normal schools taught Chinese at the university level, she explained.) The topics for compositions she mentioned were similar to the ones Wai Ping described. One example she gave was the class' choosing a place to "do labor," and then coming back to write about it. Another assignment was to describe a classmate; a third, to describe a factory. Another was to prove a political point, through logic, example, or by imitating a model given in a book. She classified the kinds of writing she had done in Chinese as argument, description, narration, lab reports, poetry, and "free." For all except the latter, the teacher would give detailed instructions of what points to include. 


\section{ESL Experience}

The most striking feature of Xian Tao's ESL experience, seen from the outside, is her apparent turn from eagerness to anxiety, and the corresponding change in teachers' evaluations of her. The brightness of her presence in the classroom was, from the start, not unmixed with worry. Worry was present in our first talk: she wanted to pass the TOEFL in January; she worried what her friends at home would say if she were still studying English by the time summer came; she worried about being a burden on her American friends who were supporting her; she knew she spent too much time talking with Chinese friends at her dorm, but worried about refusing them, for they were lonely. Yet it is also true that the worry grew to a point where the brightness was, for a time, eclipsed, to a point where she couldn't catch her breath and went to the infirmary complaining of chest pains--pains which disappeared once she got there. Teachers who knew her only the second term thought her a lackadaisical student and complained of her absences, "excuses," and failure to do homework. Teachers who worked with her both terms talked of a big change.

The peak of the crisis came in mid-January, shortly after the start of winter term. Many things happened at once. Xian Tao registered almost a week late, so she was faced with a back-log of work. The level of English and 
amount of English required jumped dramatically: it made her dizzy, she said, and sometimes she couldn't understand in class. In addition, three of her five Chinese classmates had gone to TOEFL centers, and a fourth on to his major at another university. She was worried she had made a bad decision by staying in ESL.

There were more worries, large and small, piling on top of each other. She was worried about the health of her grandfather, because she had had no word from him for a very long time. She was worried because she read so slow; she would stop herself as she was reading to criticize herself. She was worried that she was too old to learn. She was worried because she had received a phone call from the friend whose parents were supporting her, saying they could only pay for one year of English, then she would have to be in her major. So she was looking for a job.

on top of all this, she was worried about her major. Because she wanted to switch to biophysics, she was reading biology in Chinese; other friends were encouraging her to switch to international relations.

Her daily schedule ran something like this: up at 6:00, reading until $8: 30$; class from 9 to 2 with an hour off for lunch; homework in the afternoon; dinner, then TOEFL until bed at midnight. Mid-way through the second term she complained that when she tried to do her homework she couldn't because she felt guilty for not working on the 
TOEFL; then when she tried to prepare for the TOEFL she felt guilty for not working on her homework.

At the end of that term, her second in ESL, one of the steps she took to resolve these worries was to leave the ESL program for the TOEFL program, a move which seemed reasonable to her since it saved money and allowed greater concentration of attention. After one term at the center, she left it and took a job "au pair," caring for children; at the same time whe went back to school to take two computer classes, having come to a decision about her major. She continued to take the TOEFL test every time it was offered. By May she had reached 503, with a 4 in writing. 27

Conversation about these worries, while adding another dimension to the study of the lives of ESL students, largely overshadowed talk of the ESL program. However, two comments she did make, one about what she liked, the other about what she didn't, tended to corroborate what is written about Chinese students' preferred--or perhaps only customary--learning styles (Taborek and Adamowski 1984; Turner-Gottschang and Reed 1987; Tinberg 1986; Mohan and Lo 1985).

She didn't like the way reading was taught, a way which dealt with skimming, scanning, predicting, and focus on the main idea. In her terms, she wasn't "learning"

27 Post-script: By July she had scored 537 on the TOEFL, enough to gain her provisional admission to a graduate program. 
anything in reading: "In class, the teacher doesn't do anything helpful--just assigns a certain amount, then asks questions on a quiz." Reading was hard, uninteresting, and not useful for the TOEFL, she said. She spoke of a friend who had read an assignment ten times, and still not been able to understand it.

She did like a vocabulary class, where she could prepare lists of words to memorize. She could see its usefulness for the TOEFL. It is worth noting that her reliance on memorization was not un-self-critical, however. At the same time as she talked of memorizing 50 words one day, she complained that the words were useless to her, good only for the TOEFL, and that she would forget them immediately after the test.

\section{"Breakdowns"}

Four areas emerged from our discussions that might loosely be called breakdowns; at the least, they opened up other directions for this or future studies. One question was how to evaluate the legacy of the Cultural Revolution. Many of the teachers in the program shared horror stories their students had written about experiences of hardship, separation, and unsettling reversals in the meaning assigned to thoughts and actions. Xian Tao, on the other hand, spoke not only of the difficulties, but also of what she had learned: survival 
skills, and an affection for the villagers among whom she lived.

A second point opened up questions of decisionmaking and responsibility, in the home and perhaps at school as well. At the moment when Xian Tao seemed to me the most overwhelmed with troubles, she told me one further problem: at home, when she had problems, she could ask her parents; here, she couldn't. "My parents always tell me what to do," she explained. When at one point she asked me to tell her what she should do, I felt the discomfort of being asked to play a role that was beyond my definition of what a good teacher should do. I was glad to talk with her to help her make up her own mind, but unwilling to take over the decision-making. Who plays this role for chinese students away from home? Do younger students feel a need for advice as much as older students, or is a new, more independent generation coming of age now? Is Xian Tao typical or atypical?

A third topic was the way Chinese students perceive other students in their ESI classes. "Muslims can't eat pork," Xian Tao told me, "because their ancestor was a pig." Other students and visiting scholars corroborated her story. One elaborated that she had heard the reason people believed this was that someone had looked inside a mosque and seen a picture of a woman and a pig. There are many questions to be asked here. What is meant by "ancestor?" 
What other effects of this ancestry do the chinese perceive? How widespread and how current is this belief? Are Chinese Muslims aware of this perception, and if so, how do they respond? What else is thought about Muslims? About other groups (e.g., Americans)?

Another experience with Xian Tao opened up possible variations in the meaning of silence. One day she came to see me for a paper conference. After we had discussed the paper she made no move to go, so I kept raising questions, trying to find out what was on her mind. Finally, baffled, I fell silent for longer than seemed comfortable to me, and she began to speak freely.

Pressure and worry were the themes that dominated my talks with Xian Tao; pressure, worry, and a lack of confidence in the ability of the ESL program to get her where she wanted to go--past the TOEFL barrier--as quickly as she could do it on her own. Pressure was a theme, too, in the stories of the twenty other students and teachers interviewed for the next section of this chapter, but no one else spoke of it as so overwhelmingly dominant as did Xian Tao.

\section{INTERVIEWS}

The voices in this section belong to twenty students and teachers spoken to during fifty-three hours of interviews. Some of the interviewees speak several times, 
others, only once or twice. No attempt has been made to present rounded pictures of the individual interviewees; instead, their selected comments have been loosely organized into six categories: Iife in America, classroom differences, English teaching in China, writing in China, language use and translation, and ESL programs. Not much analysis is done: the comments are presented as closely as possible to the way they were given by the students, with grammar corrected and changes made to preserve continuity of thought. The goal is to present a faithful record of the interviewees' comments. 28

The comments have, however, been edited for redundancy; that is, from each interview I have tried to take those parts which reveal another side of Chinese students. The intent here is, once again, to scout out some of the dimensions of the territory, not to plumb the depths. Most of the comments might serve as starting points for further, deeper, more critically analytical inquiry.

\section{Life in America}

"Students who come here are not too upset by the changes they meet," one student suggested, "because, in choosing to become a foreign student they show a readiness to be shaped differently." Finding inadequate the concept

28 While it would also be useful to record and analyze learner speech, that was not the intent here. 
of "boundary theory" used in intercultural communication, which he described as "always drawing a line" between the self and others, he preferred other metaphors: that of the self as egg, perhaps, or as light. A person is more like an egg without a shell than a box with rigid boundaries, he suggested. While the yolk is firm, more resistant to change, the white is quite adaptable.

or a person could be described as being like a light that can go anywhere without changing its essence, obstructed and given limits only by the walls it meets. People do not meet, or collide, as some intercultural theory seems to suggest, solely as minimal units embodying cultural values; there is more adaptability, more freedom from cultural constraint, more unpredictable negotiation involved. 29

However the preceding argument is considered, it must not be taken as representative of the views of all chinese students. I had no sooner said, "Aha! Yes, of course!" to this student than I encountered his opposite (or is it "complement"?) This other student talked of how difficult it is to adapt to life in America for the many students who don't want to be here, but are forced to be by their friends and families.

29 It could also be said that this argument itself confirms some of the perceptions of intercultural communications--the either-or West, and the cyclical, unionof-opposites East--at the same time it is calling for more complexity of analysis. 
Another student said he thought of Chinese students as being divided into two groups, reflecting two different attitudes towards their stay in the U.S.: those who are here to work hard, learn something, and go back to help China modernize, and those who are here to lead a soft life for as long as they can, and whose main goal is to make money. He had little respect for the latter group.

Material Changes. Several of the students' comments about life in America can be loosely grouped together under the heading "material changes." Food is served raw. The air is not thick with the pleasant smells of chinese cooking and charcoal smoke. The school week here is five days, compared to six in China. There is no mid-day rest break in the U.S. People quickly call you by your first name, which is a little embarrassing at first because at home, only your mother does; even your brothers and sisters call you by a title like "older sister," or "younger brother." (Again another voice was raised: "So what? It just means you're getting close faster, and that's good!")

One American commented that time was different: in America you had to be exactly on time; in china it didn't matter as much. Since some intercultural studies state that in China it is important to be early for events, this statement was surprising. There seems to be agreement that 
something is different about time. There also seems to be a need for greater refinement of explanation.

Many students commented on how expensive life in America is. "At home I am rich; here I am poor," said one. "People and schools are poor in China; here schools are comfortable, and have lots of equipment," said another. A third commented, "Cats and dogs are better fed here than people in some other places. You see, here people wouldn't give their pets fat to eat, but in china in the countryside some people still have to survive on fat," commented a third.

one student wanted to make sure I was not misled by the fact that many students are sponsored by relatives or friends in the United States. "It's a big problem," he said. "Students must always think about finances, because even if they have a sponsor, that doesn't mean the sponsor will pay for tuition or living expenses." Yet another student disputed claims that the Chinese government does not give J-1 scholars enough money to live on (Lampton 1986). They get enough for themselves, he claimed, but live frugally in order to save money to help relatives.

Moral Contrasts and Quandaries. Another group of cultural differences could be roughly called "moral contrasts." students spoke of shock at unmarried people living together, at people kissing and caressing in public, at women sunbathing in public places. Another point of 
censure was that American students were lazy, interested only in "fun." Lack of discipline was also mentioned: a class at a Chinese university, viewing a videotape of an American high school classroom, expressed disbelief that anything could be learned amidst such "chaos."

The compromises made to get to the United States and their repercussions once here might fall under the category of moral problems of life in America. One student described the following trouble with a sponsor: long arguments, and threats to cut off funding if a statement of faith was not signed and a commitment made to work for the religious organization back in China for three years after graduation. The student claimed no mention of this was made upon recruitment in china; these conditions were mentioned only on arrival in the United States. Later, however, other students claimed the first student had known of the stipulations all along, but was simply desperate enough to get to the U.S. to be willing to lie. In selfjustification, the first student reportedly said, "At least I am better than the other chinese students before me; while they signed and waited to make the break until the sponsor had financed four years of education, I broke as soon as I arrived." Other students, appalled at this behavior, worried that this student would give all Chinese students a bad name. 
Reluctance to put one's self forward, born perhaps of a wedding of the traditional Confucian value of modesty and the contemporary survival value of obscurity, might also be categorized as a moral problem facing students in America. An American teacher spoke of a man she knew who could not bring himself to send in his transcript in order to qualify for a scholarship; her interpretation was that he felt it would be too boastful, that in China he would rely on someone else to take such an action for him.

Another contrast mentioned, related to morality, was a contrast in the springs of motivation in the two countries. "In the U.S. a waiter or a clerk is nice to a customer because he wants to get a good tip," one student explained. "In china, you can't get a tip, so you have another reason to be nice: you work for the people." 30 Another, perhaps related contrast is the difference one student described between China and the U.S. in the value of struggle and cooperation. The Marxists value struggle, the capitalists, cooperation, he claimed,

30 The same student, a former Red Guard, had more to say about the motivational power of the desire to serve the people encouraged during the Cultural Revolution. If you were tired, he said, you thought of working hard for the people, and you could keep going; if you had a bad thought about stealing something, you would think of Mao's words and stop. In the morning, on waking, you would read Mao's words; at night you would sit around with your group and discuss the day to see if you behaved according to his teachings. If you didn't, you would say, "Today I felt sorry to Chairman Mao for , and so I will correct it tomorrow." 
potentially complicating, if not confounding, intercultural communication theory which makes the contrast of the interdependent, cooperative East vs. an individualistic, competitive West (Brislin 1981:39).

Friendship. Students' comments on the nature of friendships in China and the U.S. could be interpreted as showing both moral and emotional contrasts. Friendship in the United States was characterized by one student as too shallow, meant only for sharing happiness and fun. Friendship in China, he felt, in addition meant lasting obligations to help in times of problems and suffering (his word). He gave as an example (one given by other students and an American visitor to China as well), a friend's obligation to stay with you day and night if you are hospitalized and the nursing staff is inadequate or incompetent.

One American related the contrast in friendship styles to a difference she noticed in the sense of time. In china there was no need to end a conversation before it was over, she said by way of example. If a friend came to talk and the talk went on until dinner, you could eat whatever was around, or go to the college canteen, and keep talking. Immediate objections may arise to such generalizations: that it is possible to do the same thing in the U.S.; that in China the teacher was free of her network of U.S. social obligations and therefore free to 
have such experiences; that traveling across culture also may mean traveling across class, and that the experience of time may be class- as well as culture-related. Nonetheless, many Americans do comment on a feeling of an abundance of time, and many Chinese, conversely, speak of the great rushing whirlwind of the pace of life in America. 31

Related to the question of friendship is the experience of loneliness. Interviewees talked of missing the reassuring presence of crowds of people, of missing the network of a neighborhood-based personal support system. one student said that, of the three separations from her family she had had to endure--during the cultural Revolution, later when she went away to school, and now, in the U.S.--she found life in the U.S. hardest, harder even than the cultural Revolution in which she was threshing wheat in a cold so bitter her sweat froze in sheets that had to be pounded off her back. How could life in the U.S. be worse than that? It was because of the almost unbearable loneliness, she said.

Fear. Fear was another dimension of the American experience talked about by some students. Some fears were

31 How this observation fits with other students' observations that Americans are lazy is not clear, but a study that began from the tension of these observations might yield a welcome sophistication to the currently rather flat--albeit provocative--statements found in intercultural communication. 
discovered here. One student had been told that an American friend had been approached by two men from the F.B.I. who were trying to gather information about people on a list that included at least one chinese student. other fears were brought from China. One scholar said he used to be afraid of the United States as a "war-mongering nation," but that, since being here, he had found Americans to be very friendly. He had been to see "Peace Child," a play in which the children of the world bring a peace that eludes the adults, and was impressed with the American people's desire for peace. He spoke of the foolishness of the hatred between the two peoples.

\section{Classroom and School Life Differences}

Teaching styles. "To be a teacher for one day, you become a father forever," was the way one student translated a well-known Chinese saying, trying to convey to me the respect due teachers, and their responsibility.32

"The way we learn our knowledge is so different from in the U.S., or at least from ESL," one student commented. "It may not be that ESL is not helpful, but a chinese just arriving here is lost, doesn't know what's going on in class." He gave a sketch of a typical class in china. The

32 The same student said her father had "improved" her a lot, taught her a lot, through many means, including physical punishment. He would hit her across the palm with a ruler; she would tell him how many hits she deserved, and count them as she received them. 
teacher comes in; the students stand up and say good morning. The teacher announces the topic he will discuss that day, then writes a brief outline on the board. He then follows the outline point by point, giving examples to make his meaning clear. To be sure students understand, after each example he asks questions of high, middle, and lower level students to make sure everyone has understood. Then he gives another example, and repeats the process.

The contrast of this approach with teaching in the U.S. is bewildering at first, the student said. Students find it hard to take seriously a teacher who dresses in blue jeans, brings a cup of coffee to class, sits on the desk, and starts talking about current $t . v$. shows or water problems he has at home. Though the teacher means to be giving examples of larger points by discussing these topics, the Chinese students don't share U.S. television culture, and water problems in China are handled by the city, not the individual: there are many layers to fathom before arriving at the intended meaning.

Classroom Behavior. When American students start asking questions, the Chinese students' confusion deepens: on the one hand, they feel it is disrespectful to ask questions, and on the other, they don't know how to join in. One typical device they may use--a raised hand, followed by a tentative "May I ask a question?"--tends to rivet what one student called "so much blond-haired, blue- 
eyed attention" on them that the words freeze, unspoken. 33 It is a frustrating experience that compounds the problem and leaves the student feeling stupid, although his ideas are quite clear to him.

other students spoke of the need for teachers to command respect by demonstrating knowledge in the classroom. One student, who was a teacher in China, spoke of the need for teachers to meet student expectations by understanding the purposes students had in taking the class. This was even more important than the need for students to meet teachers' expectations, he felt.

One more point about classroom behavior was brought out during a conflict in an ESL writing class. One of a group of half a dozen Chinese students in the class was particularly weak in listening comprehension; she was often totally lost. Her classmates would try to help her by whispering translations, a solution the teacher found problematic in two ways: it provided a background distraction for the other students, and kept the student herself from having to struggle through to understanding. The teacher spoke to the student outside of class, asking her to sit closer to the front of the room and raise her hand instead, or see her after class, or come to her office. The student replied that she was afraid that the

33 As a solution, this student suggested that ESL could teach students, instead, to signal with their pencils, then plunge right in with an, "It seems to me...." 
teacher would "get mad" if she raised her hand. (Another student said that in China, students were afraid their grades would be lowered if they asked a question the teacher couldn't answer well, so they were reluctant to raise their hands.) The students whispering translations felt caught: they wanted neither to offend the teacher nor to fail to help their classmate.

Ways of Learning. Like Xian Tao, many students emphasized the importance of memorization. One described his method: read an entire passage several times until you understand it well; learn the first sentence; reduce the sentence to a key word that would evoke the rest; learn the next sentence... and so on. Another student spoke with pride of having memorized whole books. It did not matter whether a child understood what he was memorizing as he learned it, I was told; he would understand later, when he was old enough. Several students told me memorization was for young people; old people could use logic and the wisdom of experience.

What to study was also mentioned. Most Chinese students preferred to be scientists, I was told, since they were generally safe from political criticism. It was too dangerous to be a writer or an artist: they were always punished first.

Another question was used to elicit information about cultural knowledge students assumed all Chinese share. 
Three novels were named as being known by everyone, educated or not: The Three Kingdoms, Water Margin, and Journey to the West (or Monkey, as it is often called.) ${ }^{34}$ Cao Xueqin's Dream of the Red Chamber (or story of the stone as it is called in the excellent translation by David Hawkes and John Minford) was named as being well-known among intellectuals. The spring Festival in January or February, the Dragon Boat Festival on the fifth day of the fifth lunar month, and the Moon Cake Festival on the fifteenth day of the eighth lunar month were mentioned as commonly shared cultural events. Two historical periods (the exact dates were not important, the scholar said) were mentioned: the Qin, which unified China, and the Tang, which was known for its strength and its beautiful poetry. organizational Differences, Other students talked about organizational differences in school life. The school year in China is divided into two semesters, from September 1st to a three-week vacation in January or February for spring Festival, and from the end of that vacation to mid-July. Schools run on a six-day week, with Sunday as the day off. October 1st (National Day), January 1st, and May 1st (International Labor Day) are the other holidays observed by school closure. There are local

34 West? the journey is not that of ESL students to the U.S. and Europe, but that of the Monkey King to India in search of Holy Scriptures. Another layer in the noncorrespondence of terms: "East is East and West is West" not spoken here. 
variations in this calendar: the north has shorter summer vacations and longer winter vacations than the south. According to one visiting scholar, Chinese university students typically take more classes--usually six in all-than American students, and consequently do less homework. His speculations about the reasons for this difference suggest the gap in interpretation of the meaning of "education," and provide a refreshing challenge to American perceptions of what is wealth: he thought Chinese students could take more classes because they could afford to; American students were prevented from doing so by the high cost of education that was not adequately supported by the state.

One student pointed out that a college student didn't have to "do anything" in China: when you arrive on campus, she said, a professor hands you a list of all the courses you must take, and you just stay with your classmates. The professors move; you don't. Other students remarked on the difference in exams: they were surprised to see multiple choice tests in college, because in China their final exams were always essay, even in science.

Changes in Education. One scholar spoke of recent changes in education. There is rapid expansion in higher education: in 1983 there were 803 colleges and universities, in 1985, 1017. One new college was being formed every few days. In addition, the emphasis of 
education was shifting. During the Cultural Revolution, "liberal arts" majors accounted for roughly $1 \%$ of the curriculum; now these majors make up 25-30\% of the total. (In China "liberal arts" includes administration and management majors.)

Experiments in college entrance policies are being made as well. For the first time there are commuter day students (those who do not stay in dormitories on the campus). Other students have been accepted under a contract system in which the employer pays some of the fees and the students are contracted to return to work for the employer upon graduation.

A trenchant question about these changes, in particular about opening the curriculum to Western writers and philosophers was raised during the question period of a talk on education in Japan. After hearing that the curriculum used in Japan included Western philosophy and literature, the student stood up to ask, "What I want to know is how you can still form model Japanese--even with all the Western influence in your schools--how Japan seems able to absorb outside influences and yet remain Japanese. It is impossible now in China to form a model Chinese." Later this student talked of the influence of Western ideas, naming Freud and de Beauvoir as examples, in the loss of self-discipline and control in the schools, and in the increase in what she called sexual criminals. After I asked 
her whether she thought the cultural Revolution might also have played a role, she said yes, of course there was more to it than that, you couldn't entirely blame the West: "One cymbal cannot make a sound."

\section{English in China}

Learning English in China "is sometimes more important than Chinese," one student told me with great earnestness, insisting in the face of my protests, "because the whole family is telling the student to learn it so he can go abroad for advanced study and then help them." Another sign of the importance of English is the growth in English departments: at one interviewee's school, for example, the English staff grew from seventeen in 1985 to fifty in 1987. A third sign is the development of "English Corners" in public parks, where people learning English can meet and practice speaking with each other.

Changes in Teaching English. Some of the Chinese and American teachers interviewed discussed changes they have seen over the last decade. Until recently, according to one American who has taught often in China for more than a decade, the field of teaching English was heavily influenced by the Englishman David Crook, who went to China in 1936 and has only recently retired from the ministry of education. The use of his tapes, said this teacher, 
produced millions of Chinese who all spoke the crook idiolect. 35

This same teacher spoke of an accumulation of errors, passed from generation to generation of teachers, especially during the time of the cultural Revolution. This teacher and others, teachers and students alike, spoke of this "Chinglish" as nearing the status of a separate dialect. One chinese teacher suggested the usefulness of a linguistic analysis of Chinglish for helping improve English instruction in China.

A visiting scholar claimed that by now, most English teachers in most colleges have spent at least one year abroad, a fact which, if true, should be a major force for change with an impact on both Chinglish and on methods of teaching English. Others who have taught in Chinese universities dispute the claim, but the point of the potential impact of increased overseas contact remains.

Another scholar spoke of the changes the English department at the technical college where she taught had gone through as they tried to find the most suitable curriculum for their students. At first, students had had two years of "Basic English," then a third year of English geared to their particular majors. When the school tried

35 A similar phenomenon happened during the drive to create a common spoken language, or "putonghua." The language of the influential linguist, Chao Yuen Ren, was chosen as being the best possible balance of southern and northern, and his speech was packaged for replication. 
to substitute a year of "Scientific English" for one of the first two years, students complained that it was too boring and simple-minded, and that the English teachers did not know enough about science to keep from making mistakes; the college therefore returned to its original curriculum. Another change is that the communicative approach is being tried to some extent in china. One teacher had a set of recent college level books produced by the Shanghai Foreign Languages Press that tried to blend the more traditional in-depth analysis of the intensive reading method into a notional-functional syllabus with a communicative goal. This teacher claimed this was the most recent trend in English teaching; another teacher claimed the communicative approach could not work in China, because the level of the teachers' English was too low.

Entrance Levels and Exams. Entrance levels and exams in English were another topic of discussion. Teachers were able to immediately state the number of vocabulary words and the kinds of grammatical structures entering freshmen, and exiting seniors, should know. Entering non-majors should know 700 words from a list provided by the central government; entering English majors should know 1000. By graduation, students are supposed to know 2500-3000 words, although one teacher feels it more realistic to say they know 1500-2000 words. The government also provides a document showing which grammar points are to have been 
studied. Such lists should be useful to American ESL teachers for evaluating the needs of their students.

The entrance exam, characterized as being like the TOEFL, but a little easier, is divided into six parts: structure $(20 \%)$, vocabulary $(20 \%)$, reading comprehension $(20 \%)$, listening comprehension (15\%), cloze test (10\%), and composition (15\%). The composition section is a recent addition, which students are not yet able to handle competently, according to one scholar. They are given a topic, told to write a composition in a given number of parts, and then given a topic sentence for each part. Yet they often write but one or two sentences, or, if they finish, what they write is not well-organized, according to this teacher. The problem, both he and other teachers and students agreed, is that it is difficult to teach writing because the teachers themselves do not know how to write in English.

\section{Students' Knowledge of American Literature.}

Students' rapidly shifting knowledge of American culture would make a good topic for a research project. Only the beginnings of an answer are mentioned here, in the responses of a few interviewees. They had read Mark Twain, John Steinbeck, Jack London, Lincoln, the Declaration of Independence, and churchill. (It could be fairly asked whether including Churchill as an American author is a sign of what they know or what they do not know.), 
Ways of Writing

According to one scholar, students had a good deal of experience writing compositions in Chinese in high school, so much, in fact, (weekly 2000-word, or five page, compostions), that they no longer needed instruction in college. Many students repeated that instruction in writing was appropriate for high school, not college.

When students spoke of kinds of writing they had done in high school, the terms were quite familiar. one said there were three kinds of writing in China: narration, opinion, and explanation. Two others had a longer list: narrative, poetry, process, argument, exposition, description, "read-and-respond," diary, and "political value"--although they wondered if schools still taught this latter form.

Researchers describing the organization of their reports also gave a description that might fit English research papers: state the problem; tell what other people have said about it; tell what you have found, giving examples; repeat the main idea in the conclusion; and finally, in a part called "discussion," compare your conclusion to what others have said.

Whether or not this similarity in nomenclature (in translation) corresponds to a similarity in written texts is another question. However, it seems reasonable to assume that ESL students have experience with these different 
rhetorical patterns, and thus that teaching may need to address the confusion of conflicting definitions, not ignorance.

Despite an apparent similarity in rhetorical forms of writing (with the possible exception of the "political values" writing, although perhaps that corresponds to analysis and/or argument in English), students did have questions and comments about differences in the two styles of writing. One student wanted to know if it was better to write "shorter or longer" in English. In Chinese, he explained, the teacher always urged them to write a short piece, the shorter the better.

Several students commented that English writing seemed simple to them, whereas in china writers sought to be rich, complex, sophisticated, lacing their work with "cheng yu," pithy formulations which bear the authority of commonly accepted knowledge. One student phrased this in terms of an "ivory tower" mentality, in which intellectuals take pride in using words other people cannot understand.

Another student thought that chinese writing tends to depend more on logic and reason, 36 rather than on proof by example. In fiction, according to the same student, this is correlated with extensive development of psychological

36 An interesting reversal of the views held by some in the contrastive rhetoric debate. See Erbaugh in the section on cognition in the "Review of the Literature" (language contrasts). 
detail and little attention to physical detail; therefore, Tolstoy is appreciated, Dickens loathed, she said.)

In non-fiction this student felt this dependence on logic and reason led to the form "one detail plus one detail plus one detail leads to a conclusion," in contrast to the English pattern, "generalization leads to supporting details." This tendency to "put the conclusion first" she evaluated as a sign of American aggressiveness, in contrast to the Chinese values of reserve and modesty exemplified in the conclusion coming after the proof.

Another scholar explained the way she had been taught to develop a conclusion. The teacher would have students read an article, covering the concluding paragraph. students were then to guess the conclusion. The expectation was that, if they had read carefully, they would be able to predict the author's conclusion.

Several students agreed that what they needed to learn about writing in English was not how to get ideas they repeatedly emphasized that they had plenty. What they needed to learn, they said, was how to arrange their ideas, and how to manipulate such "mechanics" as conjunctions.

Language Use and Translation

While English may be the first non-Chinese language many ESL students learn, many of them have had considerable experience dealing with other languages before they come to 
that task, as the experience of one scholar illustrates. Born in the countryside, he first learned the dialect of his native village. When he won a scholarship to attend high school in the provincial capital, he found himself with students from throughout the province, a region of one hundred dialects. The diversity was multiplied when he went to Beijing for university training. In the classroom he could understand what was said, but not be understood when he spoke--a situation not dissimilar to many ESL students' experience of the language class in the U.S. There was one more layer to the scholar's experience with language before he started his study of English: for a short while, during the 1950's, he studied Russian as his first "foreign" language.

Another level of language experience is the distinction several students made between the language of the intellectuals 37 in China and the language of the workers and the peasants who make up $80 \%$ of the population. One difference mentioned was the intellectuals' use of "cheng $y u, "$ or what are in English called Chinese proverbs. Chinese Lives: An oral History of Contemporary China (Zhang and sang) was recommended by one student as an

37 "Intellectuals," as used in China, is broader than its equivalent in English. It may include all high school graduates and even be roughly equivalent to "white collar workers," although that is another term that cannot translate directly. 
introduction to the "real language," the variety of real languages, of the chinese people.

The difficulty of translation across culture was discussed with regard to both words and symbols. one experienced translator's grappling with the word "alienation" illustrates the slipperiness of direct translation of words. The first association that came to his mind--"illegal alien"--while potentially a link to the meaning through its implication of distance, also set up obstacles to understanding through its implication of official exclusion. A further issue is whether or not alienation is a concept that makes sense in a chinese context, or is, because of the societal relationships it presupposes, limited to the west or to those Chinese who may be officially labeled as corrupted by Western influences.

Symbols cause more problems for translation. One student told me, for example, that the name of a new restaurant, "House of Louie," was a pun which in Cantonese meant "House of Thunder." The gold phoenixes and dragons decorating its walls likewise represented thunder, because "everyone knows" that when the dragon and phoenix meet, there is thunder. "Why would you want thunder?" I asked, thinking of cataclysms and dark, stormy nights. "Thunder is supposed to be lucky," the student replied. "It chases away evil." 
Another student found herself lost in interpreting the meaning of Poe's "The Black cat," because she had no idea a black cat symbolized bad luck. She stressed the need for teachers to help students with interpreting cultural symbol systems.

\section{ESL Programs}

While most students said they could see ESI programs were intended to be helpful, most also had criticisms of the programs they knew.38 The strongest cry came from a student who complained, "Some ESL teachers make me feel stupid. I can't learn from someone who treats me like that."

Most other students made much more limited comments. one student asked for more help organizing ideas in English writing, more use of models in writing. Most of the rest of the comments touched on the TOEFL. "ESL is supposed to help with the TOEFL, but it offers us baby stuff," said one. Two others complained that while they got $A^{\prime} S$ in ESL classes, their TOEFL scores improved but little. Another said the reverse was also true: it was possible to get low grades in ESL and "pass" the TOEFL. Others said that "regular classes" were easier than either the TOEFL or ESL: that they were able to get $A^{\prime} s$ and $B^{\prime} s$ in their major, but not able to pass ESL. This led one student to comment that ESL

38 For examples of ways in which the students thought the programs were helpful, see the section on the second student questionnaire. 
prevented students from making the most rapid progress possible. The best way to learn English, he said, was by floundering through "regular" classes.

The comments by students and scholars in this chapter may be taken as the start of a multi-dimensional answer to the question, "Who are these Chinese students?" They are people under external and internal pressure, many of them intent on doing as much as possible in as short a time as possible. And they are various. Some welcome the changes life in America brings; some endure it; some both welcome and endure. They face obvious changes in food, housing, and standards of wealth. They face conflicting ethical standards: Should you or should you not--even how to phrase it is problematic--take credit for what you do/ put yourself forward/ admit your abilities/ boast?

Some face moral dilemmas as well: Is it better to lie and thereby put yourself in a position to help your entire family financially, or be honest and watch them suffer? What responsibility do you have towards other people? What is the meaning of love, of marriage, of relationships given conflicting Chinese and Aemrican models?

In school, these students face more conflicts. At one of the times in their lives they feel under the most pressure to learn as quickly as possible, thy are faced with a switch in approaches to knowledge. Memorization and 
silent acceptance of the teacher's authority are replaced, or at least overlaid, by challenges to critical thinking and group discussion. Should their attitude towards learning be one of acceptance or challenge? Should they keep silent or speak at the risk of being misunderstood and appearing foolish?

Who are these students? Adults with rich, complex lives who are engaged in ESL for a brief episode in their lives as they hurry toward their goals. 


\section{CHAPTER V}

\section{QUESTIONNAIRE RESULTS}

Leung Wai Ping and Li Xian Tao were at the same time typical and atypical of other chinese students in the ESL program at their university. This chapter will give information that can help put their stories in perspective. The chapter begins with a brief statistical overview of Chinese students at that university, and some comparison of those figures with national statistics. The next sections analyze the responses of fourteen students to two questionnaires, and the final section reports on a questionnaire for ESL teachers.

CHINESE STUDENTS AT A UNIVERSITY IN THE NORTHWEST

In the fall of 1987, when Wai Ping and Xian Tao first enrolled in ESL, they were two of one hundred chinese students in the city, two of sixty-eight chinese students enrolled at the university, two of 18 Chinese students enrolled in ESL (Xu 1988; ISS 1988; ESI 1988). Like enrollment of Chinese students nationwide, enrollment at that university had jumped dramatically; after a one-time bulge of 20 in the fall of 1980, it went from 8 students in 
the fall of 1981 to 35 in the spring of 1983 , to $67-72^{39}$ in the spring of 1988 .

At the university wai Ping and Xian Tao attended, there were perhaps fewer government-sponsored scholars in proportion to privately-funded scholars than was true as a national average. A "perhaps" must be added because the national statistics are from 1983, the university statistics from 1988. While in 1983 the national figures showed that $37 \%$ of the students held F-I visas and $63 \%$ held J-I's the figures for the university were almost exactly reversed: roughly $63 \% \mathrm{~F}-1^{\prime} \mathrm{s}$ (48 students) and $37 \% \mathrm{~J}-I^{\prime} \mathrm{s}$ (28 students) (Lampton 1986:32; ISS 1988).

The statistics for gender also vary from the national averages: there were more Chinese women at this university than the national figures would have predicted. In 1983 there were 18 women and 17 men there, while nationally only 23\% of the Chinese students were women (Lampton:46). In 1988, however, there were 24 women and 43 men; the proportion of women declined from a little more than half to roughly 35\% (Institutional Research 1988). It is tempting to ask why the numbers of men increased so sharply (or, conversely, why the genders were more balanced earlier), and whether the proportion of women at this university reflects

39 The status of some of these students, those not enrolled in the current term, is unclear. They may be working for a term; they may be writing a thesis; they may be deciding to drop out. Tallies for 1988 vary slightly depending on which groups were included in the count. 
the higher proportion of $\mathrm{F}-1$ visa holders. It is possible, because the sample is so small, that it reflects nothing more than the strength of a few families. But these questions are beyond the scope of this present study. Roughly $78 \%$ of the Chinese students had enrolled during the period 1986-1988: 23 in 1986, 23 in 1987, and 14 in the first half of 1988. Ten students were still enrolled from 1985, three from 1984, and one from 1982 (ISS).

In 1988 , twenty-two of the Chinese students were undergraduates, while forty-five were graduates, of whom 28 were working for a master's degree, 12 for a Ph.D. (Institutional Research). The largest undergraduate major was computer science ( 7 students); the largest graduate major, electrical and computer engineering (10 students). Their mean GPA's in 1988 were 2.90 for undergraduates (range: $1: 58-4.0$ ), 3.50 for graduates (range: $2.0-4.0$ ) (Institutional Research). While the cumulative GPA for graduate and undergraduates has risen from 3.05 in 1983 to 3.29 in 1988 , there are two reasons to be wary of making generalizations based on this information: the sample is too small, and the proportion of graduates to undergraduates was unavailable for 1988 at the time of this study. The apparent rise in GPA could make an interesting future study, however.

statistics were not available on age, TOEFL scores, 
place of origin, work experience, or educational background.

\section{FIRST QUESTIONNAIRE}

Fourteen students, all of whom had had at least one term's experience of ESL at that university, responded to a five-page questionnaire on their language background, work experience, education (in English and in writing in Chinese), and experience in ESL in the United States. These categories will also be the major divisions of this section. Eight of the students were men, six were women. Eight held F-l visas, $5 \mathrm{~J}-1$ 's, and one, an F-2 (spouse of an F-1 visa holder?). Six were from Beijing. One was from Inner Mongolia. The six others who responded to this question were all from south of the Yangtze: from Guangzhou, Fuzhou, Shanghai, Jiang Su, Guangxi, and Yunnan. 40 The weather and terrain to which they were accustomed before the United States, then, varied from the humid, tropical south to the dry, wind-swept north, from mountain to desert to rich river valleys.

40 Since the sample size is far too small for numerical statements to achieve statistical significance, the numbers given throughout this section should be understood accordingly: they are used for showing the range found in an arbitrarily limited section of the Chinese student population at a specific place at a specific time, and are not generalizable, though they may raise questions for larger studies. 
Languages

Their languages reflected their geographic diversity. Four said their first language was Mandarin (or "Putong hua," common speech, as it is called in China); six claimed some other "dialect" (four did not respond). 41 Eight currently speak Mandarin at home; eleven speak it at work. (Language of instruction was not asked, but would make an interesting study-) All understand Mandarin, most understand at least one other dialect, and many know several dialects, some as many as four or five others.

As for foreign languages, three had studied Japanese, two French, one German, and one Mongolian.

\section{Work Experience}

Their work experience ranged from none (three of the fourteen; another two were left blank) to sixteen years. Five of the remaining nine had been teachers, four at universities (in physics, pharmacology, Japanese, and Chinese as a second Language), and one at a technical school. The sixth was a veterinarian, the seventh, a research assistant. The eighth had had three consecutive jobs: electrical supply worker, insurance clerk,

41 It is important for understanding these students' language experiences to know that what are commonly called "dialects" in China range from mutually intelligible dialects to what are commonly called languages in other parts of the world. John Francis points out that the question, "Do you speak Chinese?" has its Western language equivalent in "Do you speak romance?" (1984:39). 
accountant. The last student 1 isted farm, radio factory, steel plant, and hotel. (Although only one student listed farmwork under work experience, in conversation almost every student spoke of having done it; such a discrepancy illustrates the limitation of relying on questionnaire results.)

\section{Education}

All students but one said they had had some higher education, ranging from two to seven years. The length of time of their primary and secondary educaton varied as well: some had had 10 years, some 12. Although the dates of education are sketchy, at least three started primary school in the last half of the 1950's. Five others gave dates in the $1960^{\prime} \mathrm{s}$, and the rest were unclear or not given.

Before coming to the U.S., students had studied English from one to twelve years; the average was five. Seven had studied for four years or less; seven had studied for five years or more. One started at age 10, four between 12 and 14, three from 17-20, and six from 23-30.

Students reported learning English from a variety of sources: parents (2), radio (4), a tutor (1), television school (2), night school (2), part-time school (1), conversation (3), and reading "China Daily" (1), as well as 
in primary school (2), middle school (5), high school (3), university (10), and graduate school (1).42

Ten different English texts were named. New Concept English was mentioned four times, Xu Guo Zhang's series three times, and college English twice. The other texts, each named once, were English (Beijing Foreign Language Institute), English 900, Essential English, English for Today, Business English, Understanding, and Modern American English.

Nine of the fourteen said they had received no special training to prepare them for study in the U.S. Two had had "a little" TOEFL training, one had listened to a tape of English 900, and one had gone to an English Training Center.

The fourteen students had had twelve different majors in China: two each in mechanical engineering and physics, and one each in geology, pharmacology, medicine, veterinary science, foreign trade, international accounting, management, Japanese, Chinese language and literature, and English language and literature. Eight reported that advanced students in their majors were required to read articles or books in English. Those majors were physics, foreign trade, medicine, pharmacology, and veterinary

42 The figures given leave much room for interpretation, and should be used only to provoke clarification and further questions. 
sciences. One student in mechanical engineering said yes, another, no.

In reporting on the way they learned English in China, students were asked to rank the amount of class time or study time given to various English-learning activities. They ranked reading and translation highest, writing and conversation lowest. Pronunciation and listening received more evenly distributed marks, with listening slightly lower.

On a question about use of class time, 12 of the 14 students said most class time was given to teacher lecture. Small group work and work with a partner were at the other end of the scale, as were teacher-directed oral exercises. Individual written exercises were ranked in the middle.

Experience with English outside the classroom ranged from three students who had none to two students who had done translating and interpreting for businesses and other organizations.

Seven students reported liking to write in English, four said they didn't, and one said "sometimes."

Making sentences from vocabulary words led the list of the kinds of writing the students had done in English, followed by making sentences based on grammar points, and answering questions. Only two said they had written compositions in English. The results from this section seem questionable, however, in that only four reported having 
done dictation, and five, fill-in-the-blank exercises, while both are forms reported to be popular in China (Terdal $1988)$.

Although most students had not written compositions in English, all fourteen said they had written them in Chinese in middle school, and twelve had written them at the university as well. Thirteen had written term papers at the university, six, in high school. The terms "composition" and "term paper" were left purposefully undefined. The point was to discover whether students, on hearing these terms, would feel they had any prior experience with them. The next step would be to find out similarities and differences of the two genre in the two cultures.

Most students wrote letters in high school and college. Most kept a diary in high school. Nine wrote reactions to readings in high school, and nine wrote scientific reports at the university. Three had written something that was published (one in a student newspaper, another in scientific journals). While several (six in high school, four in college) had written poetry, only one in high school and two in college had written fiction. Eight said they liked writing in Chinese, two said they didn't, and two said "sometimes."

When asked how they had learned to write in Chinese, students most frequently named two approaches. One was visiting a place (e.g. a factory or museum) and then 
writing about it; the other was making an outline and then writing. Next in order of frequency were following an outline given by the teacher and imitating examples. Writing two drafts and individual discussion with a teacher ranked last.

only one student said all compositions were corrected, though three said they were all graded. Four said "some," and four others said "most" were corrected; there were three students each for "some" and "most" for grading. Corrections were fairly evenly distributed among grammar, vocabulary, organization, and ideas; one student added, "How to support the thing you discuss."

When asked to choose sentences to describe differences they had noted between Chinese and English writing, six chose the following: "In Chinese you must lead your reader through your whole composition to your conclusion; in English you start with the conclusion." Two chose a response which said English was simple, while Chinese was rich, complex, "feng fu." Three chose neither response, instead offering the following ideas: "No topic sentence in Chinese!"; "Chinese adjectives are very rich, whereas English verbs are more vivid"; and "Chinese is rich, complex, but less vocabulary than English. A Chinese word can form very many words; knowed 1,000 words can read newspaper, but knowed 1000 English words can't read anything." 
Experience in ESL

All the students had expected to study English when they came to the United states, although one added, "Not so much!" The students surveyed had had from one to five terms experience in ESL at that university; three had also had experience in other college ESL programs, and three in test preparation centers.

In rating the usefulness of various aspects of the university's ESL program, writing was ranked first, grammar and reading next, followed by speech, listening, TOEFL, and cultural orientation.

At the end of the questionnaire, students had a chance to respond freely to three questions about the program: What do you like about the program? What don't you like? What suggestions do you have for improvement? Four of the twelve responses to the question, "What do you like?" related to teachers and teaching. "The teachers are warm and friendly," wrote one student. "Their corrections are clear and timely and careful. Teachers' English is clear, standard, easy to understand." Another student spoke of wantng to learn about the American way of teaching, and a fourth said ESL was good preparation for entering a college here.

Five responses dealt with specific skill areas students found helpful. Writing was mentioned by three students; reading, speech, listening, grammar, and technical 
English were mentioned once each. Cultural orientation was also mentioned once.

Compared to twelve statements of what they liked, students had six comments about what they did not like: ESL was too expensive; there was "no concern" for the TOEFL; one student did not like grammar. 43

Two comments seemed rooted in cross-cultural

contrasts. One student wrote that classmates had hardly any communication with each other, adding that this was the same in other "non-English" classes at the university. The second comment pertained to the style of teaching reading. "We always do reading first and then teacher explain for us. I'd like teacher explain some vocabulary and main ideas first."

While there was no consensus, two of the suggestions for improvement paralleled the criticisms. Students wanted less expense and more TOEFL preparation. Other suggestions concerned teaching methods. "No working with partners," was one. "Too much homework," was another. One student asked for more introduction of background knowledge, more explanation of language points and vocabulary, and more analysis of student writing.

43 Questions can be raised about which grammar, at which level, for students with what backgrounds. While a study focused on grammar could yield interesting results, it is enough for the purposes of this study to point out that generalizations must not be made too easily. 
Several suggestions were about content. In addition to more TOEFL preparation, there was a request for more listening and more chances to speak in smaller speech classes. More preparation for specific majors was suggested. There was an ambiguous comment about "much many Iibrary class and computer class." Were there too many now or too few? Unclear. Finally, there was a suggestion for a text that would teach grammar and word use through composition. Table IV gives selected results of the first questionnaire. 
TABLE IV

FIRST QUESTIONNAIRE: SELECTED RESULTS

Gender:

Visa status:

Home province:
8 men, 6 women

8 F-1's, 5 J-1's, 1 F-2

6 Beijing

1 Inner Mongolia

6 South of the Yangtze:

Jiangsu

Fuzhou

Guangzhou

Guangxi

Yunnan

First languages: 4 Mandarin

6 Another dialect (but all understood Mandarin)

Work experience: Range of length

3 - none

1 - 16 years

Variety

5 teachers (4 at universities, in physics, pharmacology, Japanese, and Chinese as a second Language); 1 at a technical school)

1 veterinarian

1 research assistant

1 electrical supply worker, insurance clerk, accountant

1 farm, radio factory, steel plant, hotel

Education:

pre-university/10-12 years

university (13 students)/2-7 years

majors:

mechanical engineering

physics

geology

pharmacology

medicine

veterinary science

foreign trade

international accounting

management 
TABLE IV

FIRST QUESTIONNAIRE: SELECTED RESULTS

(Continued)

\section{Japanese \\ Chinese language and literature \\ English language and literature}

English language training before coming to the U.S.:

range $=1-2$ years

average $=5$ years

skills most often taught: reading and translation

skills least often taught: writing and conversation

writing experience in English:

most frequent--making sentences from vocabulary words

least frequent--compositions (only two students) 


\section{SECOND QUESTIONNAIRE}

Part way through interviewing and administering the first questionnaire, a second questionnaire was developed to elicit more information about the students' purposes in taking ESL classes, their expectations of it, and their evaluations of their own skills. A brief questionnaire was developed to address these questions.

Seven students responded. Five had been in ESL one term (present or past), one had been in two terms, another, three terms. Five were currently in ESL. After ESL, they all intended to continue their studies. Two also intended to work, one in pharmacology, the other in U.S.-China trade. They were asked to rate themselves in five skills areas as beginners, or as having $1-2,3-4$, or more than 5 years of experience. Grammar was the only area where students felt they had considerable experience: four students said they had had 5 years or more experience, one said 3-4. The two others said 1-2. Reading came next: two said 5 or more, two said 3-4, and three said 1-2. Only one had more than 5 years experience writing (and even s/he rated it the weakest of his/her skills). Another said 3-4 years; five said $1-2$ years. One person claimed more than 5 years experience speaking, one claimed 3-4, three said 1-2, and two ranked themselves as beginners. In listening, two said 5 or more years, three said 1-2, and, again, the same two ranked themselves as beginners. 
The purpose ranked first by students for being in ESL was to improve their English before starting their major; five out of the seven ranked this first. Two others ranked help with the TOEFL first, and one person also ranked getting the necessary credits for immigration as first. (They were allowed to give equal ranks to as many reasons as they wished.) Finding out about U.S. university expectations before beginning their majors was ranked second by four people, and third by another. TOEFL practice was ranked first by two, second by another, and fourth by a third.

As for expectations of what would be most useful to them, three each thought writing and listening would be, and two thought speech. only one thought grammar would be. They had heard a variety of complaints and praise for ESL. This question elicited some new comments, and some that overlapped with the answers given on the first questionnaire about what they personally had liked and disliked. As in the first questionnaire, there were complaints about ESL's not being useful for the TOEFL. That is why "so many students (Chinese) transfer to the education center to study," wrote one student. "They can concentrate on the preparation of the TOEFL."

Also overlapping with answers to the first questionnaire were complaints about expense and lack of communication among classmates. This latter point was 
elaborated a bit more this time, however, and attributed to the impermanent structure of the classes, cultural differences, and the teachers' "design of teaching."

A final complaint was that grammar teaching was "very elementary. Teacher's understanding of grammar is no better than some students'."

Teachers were also praised. "Wonderful teachers," wrote one student, "but they are too busy, both in the class and after class, to spend more time with students." Another student wrote that she needed the help of the teachers, did not have the ability to study on her own.

Another student wrote that ESL was a good place to improve speech and writing, and to learn about U.S. culture. Learning about study in the U.S.--how to use the library, how to find the main idea--was also mentioned as an advantage of ESL.

The last question asked students to describe in their own words their purpose for taking ESL. Passing the TOEFL was mentioned by three of the seven students. Two students, scientists in China, spoke of English as necessary for international communication about "the newest information." Two students spoke of being forced to take ESL, only to find out later it was helpful for their studies. Improving writing, listening, and speaking were mentioned by two students as their reasons for taking ESL. one student mentioned wanting time to adjust to the U.S. 
before beginning his major. Two wrote of ESL as being useful for immigration requirements, one because "you can be admitted to study in ESL without passing the TOEFL," and the other in order to take some easy credits to round out his schedule. One teacher of English in China wrote that he wanted to observe how the subject was being taught in this country, learn techniques, and compare those with the way he had been teaching before.

\section{QUESTIONNAIRE FOR ESL TEACHERS}

A questionnaire was developed for ESL teachers that closely paralleled the second questionnaire for students. The intent was to check for congruence or disparity between teachers' perceptions of their chinese students and the students' reports about themselves. Once again, the sample size was far too small (seven students and ten teachers) to achieve statistical significance, so the goal was not generalizability, but rather to see whether the results suggest the usefulness of a larger study of a similar kind. The results of the survey will be discussed question by question. The first question asked teachers to rate separately each of nine reasons given in answer to the question, "Why do Chinese students take ESL?" The choice that received the most ratings of 1 (most important) was "They are told they have to be in ESL because their TOEFL scores aren't 
scores aren't high enough for their majors." While this answer received five l's out of ten teacher responses, it received no I's from the students.

On the other hand, the answer that received the most I's (five) from students, which was "I want to improve my English before I begin my major," received only three I's out of ten from the teachers. The teachers also tended to rate learning about U.S. university expectations lower than the students did.

In response to the question, "What do you think Chinese students expect to find most useful?" teachers rated grammar, speech and listening highest. Students, on the other hand, gave writing and listening equally high ratings, followed by speech. Only one student rated grammar as a 1 . If this contrast holds true for a larger sample size, it suggests a conflict over what is perceived as useful that could negatively influence learning and teaching.

Teachers and students generally shared perceptions about Chinese students' strengths and weaknesses in specific skills: they were perceived as strongest in grammar, followed by reading, and weakest in speech and listening. There was a slight discrepancy in writing: teachers thought students had a little more experience than the students thought they had. Five of the seven students claimed 1-2 years experience; while four of the teachers said 1-2, three said $3-4$. 
Teachers and students both thought that after ESL, students would go on to study their majors, mainly in engineering, computers, or the sciences. While the teachers thought most would be graduate students, more of the students said they would be undergraduates.

When asked about complaints and/or praise students had for ESL, teachers and students agreed on one point: Chinese students want more help with TOEFL preparation. The second most frequent response given by teachers (five of the ten gave some variation on this point), but not mentioned at all by the students, was that Chinese students didn't like work that appeared to be "fun," not serious. Teachers thought the students preferred a more direct, formal, straightforward approach that was teacher, not small group, based, and in which "the best method" was taught with great clarity. On the other hand, one teacher reported that, while the foregoing is what students said, she felt that in fact they had often also shown her they appreciated the informal structure of her classes.

While students had other criticisms (especially cost, but also that the grammar was too elementary, that the "wonderful" teachers too busy to be as helpful as they could be, and that some teachers were lazy), they also had much more praise for the program than the teachers said they would. (See the appropriate section of the report on the "Second student Questionnaire.") only two of the ten 
teachers surveyed suggested points students might praise, and each of them did so very briefly, one almost as an aside as she was discussing complaints at length. Both of these teachers thought the chinese students liked the grammar classes; one mentioned especially the fourth level grammar class, which is largely "TOEFL grammar." It seems possible that teachers have too negative an idea of the way these students see them.

Teachers and students largely agree about the purposes of ESL: to prepare students to function adequately in university courses, including helping them pass the first hurdle, the TOEFL. Many teachers, however, also mentioned cultual awareness and integration as purposes, while no student did.

The last item on the survey was an invitation for teachers to make any additional comments they wanted to. The most consistent response, one included by five of the seven who responded to this question, was some variation on the theme that chinese students were diligent, hard-working, well-motivated, scholarly, bright, the "cream of the [Chinese] crop." Two teachers nuanced such comments by mentioning the wide variety they had seen, the difficulty of generalizing. A third teacher commented that this quality led "nearly all [to] take on more than they can handle and push themsleves unmercifully to complete it all with top grades." 
Two teachers said they felt students came with unrealistic expectations of the language-learning process, and so were frustrated by what they perceived as their slow pace of improvement. This frustration was compounded, according to one teacher's report, by the students' feeling pressure from friends at home who nagged them about "still" being in ESL.

Two other teachers commented on students' having clear expectations of what they needed for learning that made them more likely than other students to want to reshape the program according to their perception of their needs, rather than just accept what they found.

A writing teacher said students had told her they did not like to "come right out" at the start of a composition and tell the reader what they were going to say. They preferred to write "around" the topic and let it gradually unfold to the reader. The idea of topic sentences seemed strange.

Two reading teachers commented on the very slow pace of Chinese students' reading, combined with their insistence on word-for-word translation. A speech teacher commented that they did not take speech seriously, except for formal, structured speech-making. A few worked to improve their speech, she said, but she thought most just "suffered through." [This same teacher perceived newly arrived students as being confused, almost disoriented (no 
pun intended, presumably). She described one student at this stage as "like a zombie." She suggested forming a support group for first year students.]

Another teacher had an amusing story to tell about a student's attempt to negotiate cultural differences:

The funniest misunderstanding I have had with a Chinese student was when I ran into a young man in the library whom I had taught a few terms previously. I had known him as well as one knows any student--not at all intimately--and I was therefore very surprised when he gave me a big hug! It seemed he had over-learned the casual greeting behaviors of Americans--students don't usually hug their teachers!

The first two questionnaires set the experiences of Wai Ping and Xian Tao into a larger context. Like the majority of other Chinese students at their university, they had attended a university in China, had worked in China before coming here, and were here on $F-1$ visas. Like half the students there they came from south of the Yangtze; and like most other students, they knew more than one Chinese dialect. That they were both women was not typical: twothirds of the chinese students at their university were men. The third questionnaire made possible a comparison of ESL students' and teachers' perceptions. They disagreed over the reason Chinese students take ESL, and over the ESL classes students found most helpful. While teachers said students took ESL because their TOEFI score was not high enough to let them in to "regular" classes, more students said they took ESL to improve their English before beginning 
their majors. And while teachers expected students to find grammar, speech, and listening classes most helpful, students said writing and listening were most helpful.

Teachers and students agreed on the students strengths and weaknesses: they were strongest in grammar, weakest in speech and listening. They also agreed that students wanted more help on the TOEFL.

The students gave more praise to the ESL program and its teachers than the teachers expected.

Much could be done to make this comparison clearer and stronger: for example, the sample size could be increased, the questions could be defined more pointedly, and an attempt could be made to account for possible cultural influences in the way questions were answered. The information gathered by these questionnnaires should therefore be looked upon as preliminary, a useful starting point leading to deeper questioning. 
"A DAY ON THE GRAND CANAL WITH THE EMPEROR OF CHINA OR SURFACE IS ILLUSION BUT SO IS DEPTH"

In the movie that bears the same name as the title of this chapter, writer David Hockney muses on issues of perspective in 17 th century Chinese and Italian art while he compares two scrolls depicting imperial visits to the Grand Canal. The first has multiple, intersecting viewpoints that change as the viewer unrolls and re-rolls successive portions of a 72-foot scroll. The viewer is assumed to be mobile, changing positions; the painters take him over walls and across rivers and back again, giving equal importance, equal care and attention to the smallest detail of each of the thousands of separate characters and objects that make up the painting. Each is unique, vibrating life. Characters do not lose their richness with distance; it is assumed that when the viewer changes his perspective what now is distant will become close, what now close, distant. Life does not increase or diminish in relation to a fixed viewing point; life is rich and abundant from all perspectives. There is no privileged position. Infinity is everywhere, as Hockney puts it. 
Hockney then unrolis the second scroll, which depicts another imperial visit to the Grand Canal roughly 70 years later. He attributes the differences in the scrolls to the influence of the missionaries who arrived in China in the intervening years. The characters have lost their individualized personality; they often turn their backs to the viewer; the verve of non-converging lines is lost; the emperor looms larger than life while other figures are diminished. Infinity becomes a vanishing point, out of reach for the viewer.

This study is a modest attempt to imitate the first scroll: the richness of life drawn from multiple angles, or rather, intimations of what some of the perspectives are from which the richness could be drawn in future, deeper, studies.

What conclusions can be drawn from such a kaleidoscopic study? First, conclusions will be given in the form of answers to the guiding questions framed in the introduction. What background in English and writing do Chinese students bring with them to ESL classes? How do they describe their experiences in ESL? How do their ESL teachers describe and explain their chinese students? How did the writing of two chinese students change over the course of 6 months? Following that discussion, a look at the implications for future studies will provide a measure for the usefulness of descriptive studies in ESI. 
The findings of this study do not lead to neat generalizations in answer to the questions posed. They lead, instead, to the realization that generalizations are inadequate to cover the range of experience of ESL students. That is useful knowledge. Answers given in this conclusion, then, will be meant not as points of closure but as points of departure for teachers, as attempts to open up a range of possibilities, to provide questions that the individual teacher in the individual classroom can use to discover something about particular students.

What then, can be said about these students' academic backgrounds? Age is a key consideration. Students born up to roughly 1970 will have had some experience of the closing, purging, and reorganizing of schools during the Cultural Revolution. Those born in 1950 or earlier will have lived through two other major shifts: the period of Russian influence, and the period of schooling that was part study, part labor.

In many cases 44 students responded to these shifts by taking charge of their own education, on the assumption that there was no one other than themselves to rely on. Given such experience, it should be no surprise if some

44 One student interviewed, for example, spoke of learning English from the Voice of America, clandestine Bible study classes, and by reciting aloud in the halls of an empty school building. Another talked of using the time of the Cultural Revolution to teach herself by voraciously reading Chinese literature. Another used the time to learn painting and calligraphy. 
students are reluctant to accept without question the form of education in which they currently find themselves.

Age also affects the kind of English instruction students bring to ESI study. The oldest students may have begun their training with instructors of Russian hastily retooled to teach English. While most current students will have approached English largely through memorization of vocabulary and grammar rules, and painstaking, sentenceby-sentence analysis of texts ("intensive reading"), perhaps with some early training in audio-lingual pattern drill, younger students may have had experience with foreign teachers and a more interactive approach. In writing, they may have had experience in outlining and in basing their writing on interaction with the world outside the classroom, but they are unlikely to have had experience with a process approach.

students may consider training in writing to be appropriate for high school, not college. They may not want help with the development of ideas, since they feel confident they know what to say and simply need help learning how to say it in good English. They may consider the process approach to writing to be a waste of time, preferring models instead. Good writing, in their terms, may come close to what would be considered plagiarism by American standards: extensive quoting from authorities instead of original thoughts. 
Their response to ESL varies from, "It's a waste of time and money" (read: "It doesn't drill you on TOEFL preparation") to a conspiratorial, "You know, I've talked to $\mathrm{x}$ (another chinese student) and we really like this thinking approach--you can just say whatever you like." Given the intense pressure spoken of by almost all students interviewed, it is no wonder that they feel forced to look for the most efficient route to their goal: passing the TOEFL in order to get on with "regular" classes.

The teachers and students in this study both saw that Chinese students wanted more TOEFL practice in the program. They differed in understanding which of the skills presently taught the students found most valuable; the teachers thought grammar, speech, and listening, but the students said writing and listening. There was a difference, too, in their overall evaluations of the program. The students were more positive than the teachers expected them to be.

Two sets of implications can be drawn from this study: ideas for future studies, and ideas of weaknesses to be avoided in future studies. These will be dealt with in turn.

Virtually every comment of every student could be a starting place for further inquiry, suggesting the richness of descriptive study for generating research ideas. Even a partial listing will suggest the potential wealth. 
Such samples of learner speech as were recorded, coupled with learner references to mistaken rules and interviewees' comments about the existence of a body of errors passed from generation to generation of teachers in China as "Chinglish," suggest the usefulness of further descriptive research based on analysis of tapescripts of learner speech. A catalogue of errors could be correlated to proficiency level, length of instruction, and kind of instruction. An attempt could be made to distinguish phonologically based errors from those rooted in grammar. Cataloguing learners' explanations for their errors might lead to insight into both the developmental stages of language acquisition and the patterns that create "Chinglish," or indeed, whether there is a body of patterns appropriately to be described by that name.

A second line of inquiry is suggested by the student who pled for more instruction in cultural references so she could understand such symbols as Poe's black cat, and by the students who claimed they read passages ten times, looking up all the words, but still did not understand the meaning. A study could be done in which chinese students would do a series of close readings of texts. After the first reading, students could be required to summarize the meaning and make a list of impediments to their understanding. Successive readings could show the development of understandings. A map or catalogue of cultural points needing explication 
could thus be developed. Included in this study would be the connotations of words, a problem suggested by Qiu (1983) .

The astonishing comment that Muslims do not eat pork because their ancestor was a pig could lead to a fruitful study of the way Chinese students perceive classmates from other countries. What do they know of these other students' history and culture, and what assumptions do they make about their character, motivations, and behavior?

The record of particular incidents of conflicting cultural assumptions, for example when Wai Ping appeared for an interview dressed in pyjamas, could provide a list of direct teaching points or points teachers could use more indirectly to help their students understand cultural differences as the occasions arose. The concept and uses of time could be part of such a study. Another part, or separate study in itself, could be the interpretation of silence, as suggested in two incidents in this study: first, when the teacher mis-interpreted a silence meaning disagreement as a silence showing lack of understanding; and secondly, when the teacher interpreted silence as a vacuum needing to be filled with questions, a sign of the student's needing help to articulate what was on her mind, when what the student really needed was a longer period of silence preceding a quite articulate discussion of a complex topic. 
More purely ethnographic studies, which might or might not be the approach taken in the studies suggested in the preceding paragraphs, would also help ESI teachers' understanding of their students. How does the world look to these students? What perceptions and expectations do they have of America? What are the cultural, historical, and inter-personal frames through which they experience their lives and studies here? To what extent and in what way do they see themselves as a group here? What are the sub-groups, and what are the ways membership is defined and maintained?

The list of possibilities for future study seems inexhaustible. Perhaps the above ideas are enough to suggest the wealth, as well as the usefulness of descriptive study for ESL research.

The limits of this study stem from that same richness. Nothing is examined in depth. Most statements remain on the level of assumption, incipient hypotheses to be tested rather than coherent chunks of information to be added to a growing body of knowledge, or judgments adding to the evidence accumulating for this or that argument or theory.

But those limits are limits of the genre. Within the genre, this study could have gone into greater depth had it pursued a more narrowly focused topic. Another possible change for a future study is in the manner of recruiting 
case study students. Perhaps long-term case studies could grow more naturally, with less stress and freer flow of information, out of a first round of short interviews, rather than out of a general announcement calling for a sixmonth commitment. This seems a possible improvement because the shorter interviews did feel less stressful; however, it is also true that most of those interviewed for shorter periods of time had been living in the U.S. longer, and were directly or indirectly familiar with the interviewer, so the relevant factor is not clear.

The conclusion of this study is, finally, an accumulation of questions: hypotheses to be tested, students to be understood not through formulaic prior knowledge, but through interaction. It aspires not to be a closing, but rather, in the words clifford Geertz uses to describe one of the aims of anthropology, "an enlargement of the universe of human discourse" (1973). It is a goal appropriate, as well, for the field of teaching language across cultures. 


\section{CHAPTER VII}

\section{EPILOGUE}

A year has passed since the last interview in this study. Wai Ping is still at the education center, studying for the TOEFL. She has moved twice since the end of our interviews, first to work au pair for an elderly woman who is now in a retirement home, and then to her own apartment downtown. She works part-time in a chinese restaurant, and rarely has the chance to speak English. Her goal is still to begin her major in business as soon as possible.

Last summer, Xian Tao came close enough to getting the TOEFL score necessary for graduate work that her department waived the requirement and let her begin her studies in electrical and computer engineering that fall, 1988 .

The student who asked the first question in this study, "Why can't we work with beautiful language?" moved to the east coast to be near an aunt. He is now attending college and working there, and has been joined by his wife and one son. Another son is still in China, studying hard to enter "a famous American university." His last letter was in very formal, very beautiful English. 
SOURCES CONSULTED

General

Bennett, Milton. 1985. Introductory lecture to a graduate course in intercultural communication, Portland state University.

Brislin, Richard W. 1981. Cultural Encounters: Face-toFace Interaction. New York: Pergamon Press.

Butterfield, Fox. 1988. "China Plans to Let Fewerstudents Go Abroad, Especially to the U.S.," The New York Times, March 24, lff.

Center For English as a Second Language, Portland State University. 1988. Departmental statistics.

Chinatown Resources Development Center. (No date given). "California Cultural Awareness Resource Guide. Culture -specific Training Materials: Chinese Cultures." San Francisco: Chinatown Resources Development Center.

Dillard, Annie. 1984. Encounters With Chinese Writers. Middletown, Connecticut: Wesleyan University Press.

Fairbank, John K., Edwin O. Reischauer, Albert M. Craig. 1965. East Asia: The Modern Transformation, Boston: Houghton Mifflin Company.

Hall, Edward T. 1959. The Silent Lanquage. Greenwich, Connecticut: Fawcett Publications.

- 1977. Beyond Culture. Garden City, New York: Anchor Books.

Hua, Gu. 1985. Pagoda Ridge. Beijing: Panda Books.

Hunter, Jane. 1984. The Gospel of Gentility: American Women Missionaries in Turn-of-the-Century China. New Haven: Yale University Press.

International student Services, Portland State University. 1988 . 
International student Services, Portland State University. 1988.

Kingston, Maxine Hong. 1975. Woman Warrior. New York: vintage.

Lampton, David M., Joyce Madancy, and Kristin M. Williams, (Comittee for Scholarly Communication with the Peoples' Republic of China). 1986. A Relationship Restored: Trends in U.S. China Educational Exchanges, 1978-84. Washington, D.C.: National Academy Press.

Lee, Douglas. 1984. Talk given for the oregon Committee for the Humanities/World Affairs Council/Northwest China Council China series.

Liu, Zongren. 1984. Two Years in the Melting Pot. San Francisco: China Books and Periodicals.

office of Institutional Research and Planning, Portland State University. 1988.

Rushdie, Salman. 1988. The Satanic Verses. New York: Viking.

Said, Edward w. 1978. orientalism. New York: Vintage Books.

Samovar, Larry A., and Richard E. Porter. 1982. Intercultural Communication: A Reader. Belmont, Ca.: Wadsworth Publishing Company.

Sellin, Eric. 1988. "Obsession with the white Page, the Inability to Communicate, and Surface Aesthetics in the Development of Contemporary Maghrebian Fiction: The 'Mal de la Page Blanche' in Khatibi, Fares, and Meddeb." International Journal of Middle Eastern Studies. 20:165-173.

$\mathrm{Xu}$, Han. August 12, 1987. A talk given by Ambassador Xu to the World Affairs Council of oregon.

Zhang, Xianliang. 1985. Mimosa. Beijing: Panda Books.

Zhang, Xinxin and Sang Ye. 1987. Chinese Lives: An Oral History of Contemporary China. New York: Pantheon.

Zikopoulos, Marianthi. 1987. Open Doors. New York: The Institute for International Education. 
Education and Teaching

Barlow, Tani, and Donald M. Lowe. 1985. Chinese Reflections: Americans Teaching in the People's Republic. New York: Praeger.

Chen, Theodore Hsi-en. 1981. Chinese Education Since 1949: Academic and Revolutionary Models. New York: Pergamon Press.

Grabe, William, and Denise Mahon. 1983. "Teacher Training in China: Problems and Perspectives." On TESOL '82: Pacific Perspectives on Lanquage Learning and Teaching. Mark A. Clarke and Jean Handscombe. Washington, D.C.: TESOL.

Hayhoe, Ruth. 1984. "Chinese, European and American Scholarly Values in Interaction." Occasional Papers, London Association of Comparative Educationists.

- (no date given). "China's Higher Curricular Reform in Historical Perspective." (Paper distributed in a class on Chinese education taught at Portland State University by Cai Yuyu, 1988.)

Kaplan, Frederic M., Julian M. Sobin and Stephen Andors. 1979. Encyclopedia of China Today. London: Macmillan.

Price, R.F. 1979. Education in Modern China. London: Routledge and Kegan Paul.

Robinson, Jean C. 1986. "Decentralization, Money, and Power: The Case of People-run Schools in China." Comparative Education Review. 30 (1): Feb. 1986.

Tang, Li-xing. 1983. TEFL in China: Methods and Techniques. Shanghai: Shanghai Foreign Language Education Press.

Terdal, Marjorie. 1988. "In-service Training for Nonnative ESL Teachers." Paper presented at the national TESOL convention in Chicago.

Tinberg, Howard B. 1986. "Language and Estrangement: Lessons from the People's Republic of China." English Journal. 75:7. p. 46-50.

Turner-Gottschang, Karen, with Linda A. Reed. 1987. China Bound: A Guide to Academic Life and Work in the PRC. Washington, D.C.: National Academy Press. 
Unger, Jonathan. 1982. Education Under Mao. New York: Columbia University Press.

Van Naerssen, M., N.E. Huang, and E. Yarnall. 1984. "How is a Chinese student Like a Thermos Bottle?" ED 249 818 .

$\mathrm{Xu}$, George Q. 1987. "Teaching English to Chinese Students: A Bibliography." ED 286368 .

zhuang, Jia-ying. April 1984. "English Teaching in China's Colleges." CATESOL paper. ED 245565.

\section{Language}

Bloom, Alfred. 1981. The Linguistic Shaping of Thought: A study of the Impact of Language on Thinking in China and the West. Hillsdale, N.J.: Lawrence Erlbaum.

Chao, Yuen Ren. 1968. A Grammar of Spoken CHinese. Berkeley: University of California Press.

1976. Aspects of Chinese Sociolinguistics. Stanford: Stanford University Press.

DeFrancis, John. 1984. The Chinese Language: Fact and Fantasy. Honolulu: University of Hawaii Press.

Domino, George. 1985. "Cross Cultural Differences as Reflected in Stories Given by American and Chinese Children." Paper for the Rocky Mountain Psychological Association. ED 258872 .

Erbaugh, Mary. 1988. "The Chinese Language and Its Effect on Cognition: A Debate over Chopsticks Versus Forks." Draft copy.

Feng, Chen-yu. 1981. Teaching Advanced English Composition to chinese college students. Unpublished M.A. Thesis, California State University at Fresno.

Houghton, Diane, and Michael Hoey. 1983. "Linguistics and Written Discourse: Contrastive Rhetorics." in Robert B. Kaplan, ed. Annual Review of Applied Linguistics, 1982. Rowley, Mass.: Newbury House.

Kaplan, Robert. 1968. "Contrastive Grammar: Teaching Composition to the Chinese Student." Journal of English as a Second Language. $3: 1$. p. 1-14. 
- 1980. "Cultural Thought Patterns in InterCultural Education." in Kenneth Croft, ed. Readings on English as a Second Language. Cambridge, Mass.: winthrop Publishers.

Lehmann, Winfred P., ed. 1975. Language and Linguistics in the People's Republic of China. Austin and London: University of Texas Press.

Lu, Min-zhan. 1987. "From Silence to words: Writing as Struggle." College English. 49:4, April. p. 437-448.

McKay, Sandra Lee. 1986. "Topic Development and Written Discourse Accent." CATESOL paper. ED 272031.

Mohan, Bernard A. and Winnie Au-Yeung Lo. 1985. "Academic Writing and Chinese Students: Transfer and Developmental Factors." TESOL Quarterly. 19:3. p. 515-534.

Pease, Jonathan. 1988. Personal communication. Department of Foreign Languages, Portland state University.

Qiu, Xiu Bai. 1983. "Cross-Cultural Differences and the Teaching of English as a Foreign Language." ORTESOL Journal. Vol. 4. p. 54-60.

Taborek, Elizabeth, and Eleanor Adamowski. 1984. "To Seal Up one's Mouth Three Times: Understanding the Educa tion and Linguistic Differences That Confront Chinese Students in ESL Writing Classes." TESL Talk. 15:3. p. $88-95$.

Tsao, Feng-fu. 1983. "Linguistics and Written Discourse in Particular Languages: Contrastive Studies: English and Chinese (Mandarin)." in Robert Kaplan, ed. Annual Review of Applied Linguistics. Rowley, Mass.: Newbury House.

Sun, Amelia, Mimi Chan, and Helen Kwok. 1970. "Brokenly with Their English Tongue...the Writing Programme in the Contemporary English Course, University of Hong Kong." English Language Teaching. 25:1, October. p. $79-89$.

Yau, Margaret Siu-Siu. June 1983. Syntactic Development in the Writing of ESL STudents. M.A. Thesis, University of British Columbia. 
Methodology

Agar, Michael H. 1980. The Professional Stranger: An Informal Introduction to Ethnography. New York: Academic Press.

- 1986. Speaking of Ethnography. Beverly Hills: Sage Publications.

Allwright, Richard. 1987. "Understanding Classroom Language Learning: A Case Study Approach." Presentation at Tri-TESOL (seattle), Oct. 1987.

Christison, Mary Ann and Karl J. Krahnke. 1986. "Student Perceptions of Academic Language Study." TESOL Quarterly. 20:1. p. 61-81.

Crano, William D. 1981. "Triangulation and cross Cultural Research." in Marilyn B. Brewer and Barry E. Collins (eds.). Scientific Inquiry and the social sciences. San Francisco: Jossey-Bass Publishers.

Frolich, Maria. 1976. "Case Studies of Second Language Learners." M.A. thesis, University of Toronto. ED 201182 .

Geertz, clifford. 1973. The Interpretation of cultures. New York: Basic Books.

Hymes, Dell H. and others. February 5, 1981. "Ethnographic Monitoring of Children's Acquisition of Reading/ Language Arts Skills in and out of the Classroom." Final Report to the National Institute of Education. ED 208096.

Kidder, Louise H. 1981. "Qualitative Research and QuasiExperimental Frameworks." in Marilyn B. Brewer and Barry E. Collins, eds. Scientific Inquiry and the Social Sciences. San Francisco: Jossey-Bass Publishers. p. 226-256.

Klaus, Carl H. 1982. "Research on Writing Courses: A Cautionary Essay," Freshman English News, 11:1, 1-13.

Miles, Matthew B. 1983. "Qualitative Data as an Attractive Nuisance." in John Van Maanen, ed. Qualitative Methodology. Beverly Hills: Sage.

Myers, Miles. 1985. The Teacher-Researcher: How to study Writing in the Classroom. Urbana, Illinois: ERIC/NCTE. 
Pratt, Mary Louise. 1986. "Fieldwork in Common Places." in James Clifford and George E. Marcus, eds. Writing Culture: The poetics and Politics of Ethnography. Berkeley: University of California Press. p. 27-50.

Rosansky, E. 1976. "Methods and Morphemes in Second Language Acquisition Research." Language Learning. $26: 409-425$.

Rubin, Joan. 1975. "What the Good Language Learner Can Teach Us," TESOL Quarterly, 1975:9, 41-51.

Sanday, Peggy Reeves. 1983. "The Ethnographic Paradigm(s)." in John Van Maanen, ed. Qualitative Methodology. Beverly Hills: Sage.

Schumann, John H. 1983. "Art and Science in Second Language Acquisition Research," Language Learning, 35:5, 4975 .

1986. "Locative and Directional Expressions in Basilang Speech." Lanquage Learning. 36:3. p. 27794 .

Smith, John K. 1983. "Quantitative Versus Qualitative Research: An Attempt to clarify the Issue," Educational Researcher, March, 6-13.

Spindler, George, ed. 1982. Doing the Ethnography of Schooling: Educational Anthropology in Action. New York: Holt, Rinehart and Winston.

Spradley, James P. 1979. The Ethnographic Interview. New York: Holt, Rinehart and winston.

1980. Participant Observation. New York: Holt, Rinehart and winston.

Stevick, Earl. 1981. "Learning a Foreign Language: The Natural Ways." On TESOL 1981. Washington, D.C.: TESOL. 1-10.

Whittemore, Robert. 1988. Personal communication about an undergraduate research paper by Michael Walker on contrasts in the perceptions of ESL students and teachers on the purpose of an ESL program. Lewis and clark college, Portland, Oregon. 
Ethnography of Schooling: Educational Anthropology in Action. New York: Holt, Rinehart and winston.

Wolcott, Harry F. 1983. "Ethnographic Research in Education." Draft copy.

1981. "Confessions of a "Trained" Observer." in Thomas S. Popkewitz and B. Robert Tabachnick, eds. The Study of Schooling, Filed Based Methodologies in Educational Research and Evaluation. New York: Praeger.

Zamel, Vivian. 1983. "In Search of the Key: Research and Practice in Composition." On TESOL 1983. Washington, D.C.: TESOL. 195-207.

Zamel, Vivian. 1983. "The Composing Processes of Advanced ESL Students: Six Case Studies." TESOL Quarterly $17: 2$. p. 165-187.

Zukav, Gary. 1979. The Dancing Wu Li Masters. Toronto: Bantam. 


\section{APPENDIX A}

CONTRASTING MODELS OF CHINESE EDUCATION SINCE 1949

Taken from Theodore Hsi-en Chen's chinese Education Since 1949: Academic and Revolutionary Models, published in 1981 by Pergamon Press, New York. p. 222. 


\section{Characteristics of Contrasting Models}

\section{Revolutionary Model (1966-76)}

Nationa! goals

Desired product

Schools

Curriculum

Methods

Learning process

Leadership

Ideological framework
Primary emphasis on revolution and Communism, with attention to production and development.

The zealous revolutionary; the unswerving ideologue and activist. Redness more crucial than expertness. Indigenous experts, baref oot professionals.

Merging of formal, informal, nonformal education. Open-door schools, work-study schools. No clear-cut demarcation between elementary, secondary, higher education. Schools for the masses.

Unity and continuity of experience inside and outside the schools. Action as important as knowledge from books (or more so). Politicalideological education the core curriculum. Knowledge and skills as needed for production and politics. Practical education for present needs.

The whole society educates. Learning takes place on the farm, in the factory, the street, and the parade grounds. Participation in production and political work is a major method of learning.

Ad hoc learning to meet practical needs of production and politics. Promotion based on political and production record.

The Communist Party, the workerpeasant-soldier teachers and administrators of schools. Intellectuals downgraded.

Maoism. Literal acceptance of the quotes, instructions, directives, etc. Rigid adherence to Party lines, narrowly conceived.

\section{Academic Model (since 1976)}

Primary emphasis on developrnent and modernization, with attention to politics and ideology.

Trained personnel with skills and technical competence. Trained experts and scholars committed to the proletarian cause arid ideology.

School the center of educational system, existing primarily for full-time study. The educational ladder, with coordinated and articulated schools on ascending levels. Key schools and universities for intellectual elite.

Distinction between school studies and extracurricular activities. Basic studies, theoretical know!edge, on graded levels. Prerequisites for advanced studies. Education to meet present and future needs.

The classroom, the library, the laboratory are the places where learning is centered. The study of books is essential. Examinations are an important aid to learning.

Systematic learning of orgarized subject matter. Sorne knowledge and skills must be learned as foundation for further study or in preparation for future needs. Academic criteria for promotion.

Active role of professionals teachers, educators - under Party leadership.

Liberal concept of the Thought of Mao. His teachings interpreted to meet current conditions. Emancipation of mind from hardened dogmas. 
APPENDIX B

QUESTIONNAIRES 


\section{CHINESE STUDENTS, ENGLISH WRITING: A QUESTIONNAIRE}

This questionnaire is designed to help ESL teachers understand their chinese students better, so they can improve their teaching. It should take you 15-20 minutes to complete. For most of the answers, you can make a check mark or circle your choice; for some you will need to write "yes" or "no"; for a few you will need to write a few words or dates. If there are other comments you would like to make, please feel free to do so.

If there are some questions you don't know the answer to or don't want to answer, just draw a line through them. If you have any questions, I will be glad to answer them. You can call me any time at 230-1087, or leave a message for me on campus at the ESL office, $319 \mathrm{SH}$. I hope the time you spend on this will be useful to all of us involved in learning and teaching English. Thank you for participating.

If you would like a copy of the results of the questionnaire, please leave a note for me in SH 319 or call me at 2301087. Please do not put your name on this questionnaire. 
A. General Information

1. Where are you from in china (city and province)?

2. Gender: Female Male

3. Is your visa: $\mathrm{F}-1$

4. What Chinese languages (dialects) do you speak or understand?

a. At home: speak understand

b. At work or school: speak understand

c. Which language (dialect) did you learn first?

5. What foreign languages have you studied?

6. Education: dates and levels. Please give the approximate dates for any of the following kinds of education that your have had.

a. Primary school

b. Middle school (junior middle school)

c. High school (senior middle school)

d. University (4 year 3 year 2 year

e. Study: for an M.A. for a doctorate

f. Vocational or technical school (please say what kind)

g. Night school

h. Part-time school

i. T.V. school

j. Radio classes

k. Self-taught (self study)

1. Other (please explain)

7. Work experience: please list the work you have done and the dates, for examples, middle school English teacher, 1983-1085.

B. English Education in China

1. How long did you study English in China?

Do you have an idea how many words you know?

$100-500$ $500-2000$ 2000-5000 more than 5000 
2. How old were you when you started studying English?

3. How did you learn English in China? (If you can, please say how many hours each week you studied English.)

a. Primary school

b. Middle school (junior middle school)

c. High school (senior middle school)

d. University (4 year 3 year 2 year

e. Graduate school

f. Vocational or technical school

g. Night school

h. Part-time school

i. T.V. school

j. Radio classes

k. Self-taught

1. Other (please explain)

4. How did you first learn English?

5. Can you remember the name of the last text you used? a. New Concept English

b. College English

c. Other (please give the name if you can)

6. Did you go through a special training program to prepare you for studying in the United States?
a. Conversation
b. TOEFL preparation
c. Technical English
d. Other 
7. What amount of your class time or study time was given to these different skills? Circle 5 for a lot, 1 for very little.

$\begin{array}{lllllll}\text { a. Reading } & 5 & 4 & 3 & 2 & 1 & 0 \\ \text { b. Grammar } & 5 & 4 & 3 & 2 & 1 & 0 \\ \text { c. Conversation } & 5 & 4 & 3 & 2 & 1 & 0 \\ \text { d. Writing } & 5 & 4 & 3 & 2 & 1 & 0 \\ \text { e. Listening } & 5 & 4 & 3 & 2 & 1 & 0 \\ \text { f. Pronunciation } & 5 & 4 & 3 & 2 & 1 & 0 \\ \text { g. Translation } & 5 & 4 & 3 & 2 & 1 & 0\end{array}$

8. Did you ever write in English? Please check the kind of writing you did.

a. Dictation

b. Fill-in-the blank exercises

c. Copying from the text

d. Writing sentences for vocabulary words

e. Writing sentences for grammar points

f. Answering questions

g. Informal letters

h. Business letters/reports

i. Summarizing

j. Compositions

$\mathrm{k}$. Letters

1. Stories

m. Poems

n. Scientific reports

o. Term papers

Other:

9. Do you like to write in English?

10. Did you ever use English outside of class? Please explain.

11. If you studied at a university, please answer questions a-g about your university study.

a. What was your major?

b. Were advanced students in your major required to read articles (or books) in English?

c. Did you write compositions in your English classes? 
d. What amount of your in class time was given to the following activities? Circle 5 for a lot, 1 for very little.

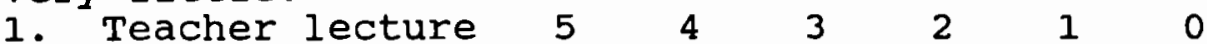

2. Teacher-directed $\begin{array}{lllllll}\text { oral exercises } & 5 & 4 & 3 & 2 & 1 & 0\end{array}$

3. Individual written exercises

4. Work with a partner

$\begin{array}{llllll}5 & 4 & 3 & 2 & 1 & 0\end{array}$

5. Small group

6. Other (please

5

4

$\begin{array}{llllll}5 & 4 & 3 & 2 & 1 & 0\end{array}$
explain) 54 3

e. Did you have homework in English? If you did, how many hours of English homework did you have each week?

f. What was the name of the last text you used (if you can remember)?

g. Were you an average_, above average_, or below average student in most of your English classes?

c. Writing Background in Chinese

1. Do you like to write in Chinese?

2. Please check the kinds of writing you have done in Chinese.

In middle school:

a. Letters

b. Diary (journal)

c. Poems

d. Compositions

e. Term papers

f. Scientific reports

g. Business letters or reports

h. Publications (what kind/)

i. Fiction (stories)

j. Reactions to readings 
At the university:

a. Letters

b. Diary (journal)

c. Poems

d. Compositions

e. Term papers

f. Scientific reports

g. Business letters or reports

h. Publications (what kind/)

i. Fiction (stories)

j. Reactions to readings

other:

3. Which of these methods did you use to learn writing? circle 5 for a lot, 1 for a little.

In middle school:

a. We went out to look

at something (an

exhibition, or a

factory, for example),

then wrote about it

at home, any what

we wanted.

5

b. We read several

examples in out text

then imitated their

$\begin{array}{lllllll}\text { arrangement. } & 5 & 4 & 3 & 2 & 1 & 0\end{array}$

c. We followed an outline

the teacher gave us. 5

d. We discussed our work

with a classmate.

e. We made an outline

first, then wrote.

f. We wrote one draft,

the teacher corrected

it, and then we wrote

a second draft.

5

$\begin{array}{llllll}5 & 4 & 3 & 2 & 1 & 0\end{array}$

$\begin{array}{llllll}5 & 4 & 3 & 2 & 1 & 0\end{array}$

g. We discussed our work individually with our teacher.

$\begin{array}{llllll}5 & 4 & 3 & 2 & 1 & 0\end{array}$

h. other

At the university: Please list the letters $(a-h$, from the section you just finished) that describe how you wrote at the university. 
4. Were all some most of your compositions corrected?

Were all some most of your compositions graded?

5. What kinds of corrections were made?

a. In middle school:

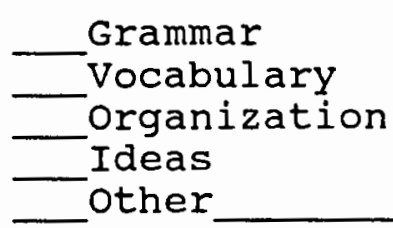

b. At the university:

Grammar

Vocabulary

organization

Ideas

other

6. Were you an average_, above average_, or below average student in most of your writing?

7. If you have noticed differences between English and Chinese writing, how would you describe those differences?

a. English is simple, Chinese is rich, complex ("feng fu") .

b. In chinese you must lead your reader through your whole composition to your conclusion; in English you start with the conclusion.

c. Other

D. English Education in the United States

1. Have you studied English in the United States?

a. How long did you study before coming to PSU?

b. How long have you studied (did you study) English here?

c. Are you still studying ESL?

2. Did you expect to study English when you came to the U.S.? 
3. How have you studied English in the U.S.?

a. English language institute

How long?

b. ESL program

at PCC (how long)?

at PSU (how long)?

c. Test preparation institute

How long?

4. If you know your TOEFL or Michigan score, please put a check next to the right letter below.

TOEFL
a. Less than 400
b. 400-450
c. $451-500$
d. 501-525
e. 626-550
f. 551-600
g. More than 600

Michigan
a. Less than 40
b. 40-50
c. 51-60
d. 61-70
e. 71-80
f. $81-90$
g. More than 90

5. Please rate the following parts of an ESL program. circle 5 for very useful, 0 for not useful or a waste of time.

I have_have not_had experience in an ESL program.

I have_have not program. had experience in PSU's ESL

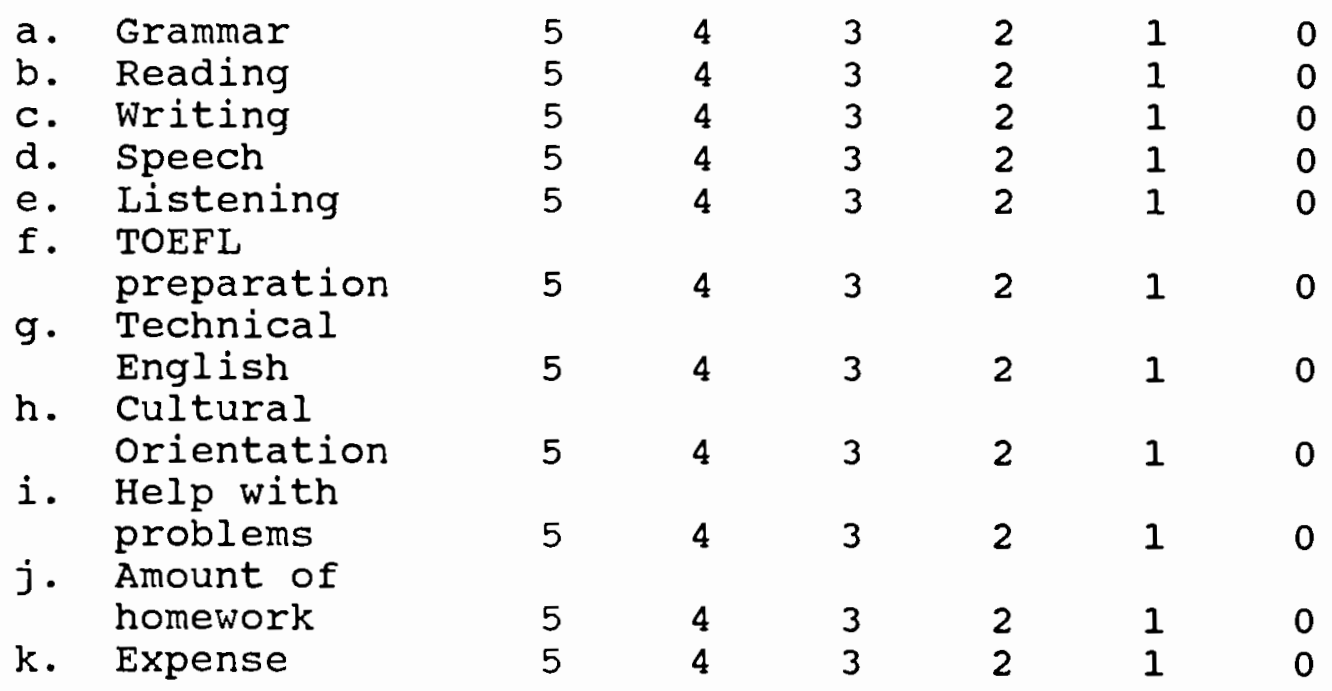


6. What did you like about ESL?

7. What didn't you like about ESL?

8. What suggestions do you have for changes in ESL? 


\section{QUESTIONNAIRE ABOUT THE ESL PROGRAM}

1. Why are you in ESL? Please rank the following reasons in order of their importance to you. Put 1 beside the most important reason, 2 beside the next, etc.

I want to improve my English before I begin my major.

I want to learn about U.S. university expectations before I begin my major.

I want help for the TOEFL.

I was told I had to be in ESL because my TOEFL score isn't high enough for my major.

I want a way to meet friends.

I want to learn about life in the United States.

I need credits in order to keep my visa status.

My husband or wife is a student here, and I need to do something. other (please explain):

2. How did you hear about ESL?

From an advisor.

From friends who have been in the program.

From friends who have heard about the program.

I read about it.

other (please explain):

3. What do you expect to find most useful? Please rate each of these, on a scale from 1 (most useful) to 10 (least useful).

Grammar (vocabulary and patterns)

Reading

Writing

Speech

Listening

4. What complaints and/or praise have you heard about he ESL program? Please be as specific as possible, and use the back of this sheet if you need more space. 
5. In your own words, please explain your purpose in taking ESL classes. Please be as specific as you can about what you want to learn. (Please use the back if you need more space.)

6. Please rank yourself in the following areas, as beg. (beginner), 1-2 (1-2 years of experience), 3-4 (3-4 years of experience), or $\underline{5}$ (more than 5 years of experience).

Grammar

Reading

Writing

speaking

Listening

7. What will you do after ESL?

Return to China.

_ study my major: __ undergraduate __ graduate in:

business

- engineering computer science science (which field?) other (what?)

Find work.

other (what?)

8. Are you in the ESL program at PSU right now? yes _ no

How many terms have you been in ESL at PSU?

Which levels have you been in? $1 \begin{array}{lllll} & 2 & 3 & 4\end{array}$

THANK YOU VERY MUCH FOR HELPING!! If you have any questions, please feel free to call me, Diane Fox, at 230-1087. You can leave the competed questionnaire for in SH 319. 
Hello!

Just when you thought you were safe--here comes another graduate student with another survey for her thesis. Sorry - . but I really would appreciate your help on this.

If you can help, please don't spend much time on answering--first responses are good. You can leave them in my box when you're done. (If you check off your name on the sheet there, I'll know who not to harass!) I'll be in the office Tuesday and again Thursday, and would love to get them then if possible, but anytime is great.

\section{THANKS !!!}

P.S. My study is on Chinese students learning English. If you have any questions about it, I'd be glad to answer--just give me a call at 230-1087. 


\section{QUESTIONNAIRE ABOUT CHINESE STUDENTS IN THE ESL PROGRAM}

Please answer the following questions about the chinese students you have had in ESL. Feel free to amend the questions in any way you see fit.

1. Why do Chinese students take ESL? Please rank the following reasons in order of their importance. Put 1 beside the most important reason, 2 beside the next, etc. (If you think several of the reasons have the same weight, give them the same number.)

They want to improve their English before beginning their majors.

They want to learn about U.S. university expectations before they begin their majors. They want help for the TOEFL.

They are told they have to be in ESL because their TOEFL scores aren't high enough for their majors. They want a way to meet friends.

They want to learn about life in the United States.

They need credits in order to keep their visa status. Their spouses are students, and need to do something. other (please explain):

2. What do you think chinese students expect to find most useful? Please rate each of these, on a scale from 1 (most useful) to (10 least useful).

Grammar (vocabulary and patterns)

Reading

Writing

Speech

Listening

3. What complaints and/or praise do you think chinese students have about the ESL program? Please be as specific as possible, and use the back of this sheet if you need more space. 
4. Please rank an imaginary average of your Chinese students in the following areas, as beg. (beginner), $1-2$ (1-2 years of experience), $3-4$ ( $3-4$ years of experience), or $\underline{5}$ (more than 5 years of experience.

Grammar

Reading

Writing

Speaking

Listening

5. What do you think most chinese students do after ESL?

Return to China.

study a major:

undergraduate

graduate

in:

business

engineering

computer science

science (which field?)

other (what?)

Find work.

- Other (what?)

6. In your own words, please explain the purpose of ESL classes. (Please use the back if necessary.)

7. Anything else? If you have additional comments about your work with Chinese students, they could be very helpful. (For example: strengths or weaknesses you have notice, misunderstandings you have had, insights you have gained.)

THANK YOU VERY MUCH FOR HELPING!! 